UNIVERSIDADE DE SÃO PAULO

ESCOLA DE ENFERMAGEM DE RIBEIRÃO PRETO

LUANA SELES ALVES

ÁREAS DE RISCO DE MORTES POR TUBERCULOSE EM LONDRINA/PARANÁ: UMA ABORDAGEM GEOEPIDEMIOLÓGICA

Ribeirão Preto 


\title{
ÁREAS DE RISCO DE MORTES POR TUBERCULOSE EM LONDRINA/PARANÁ: UMA ABORDAGEM GEOEPIDEMIOLÓGICA
}

\author{
Dissertação apresentada à Escola de \\ Enfermagem de Ribeirão Preto da \\ Universidade de São Paulo para obtenção \\ do título de Mestre em Ciências. Programa \\ de Pós-graduação Enfermagem em Saúde \\ Pública
}

Linha de pesquisa: Processo Saúde-doença e epidemiologia Orientador: Prof. Dr. Ricardo Alexandre Arcêncio

Ribeirão Preto 
AUTORIZO A REPRODUÇÃO E DIVULGAÇÃO TOTAL OU PARCIAL DESTE

TRABALHO, POR QUALQUER MEIO CONVENCIONAL OU ELETRÔNICO, PARA FINS DE ESTUDO E PESQUISA, DESDE QUE CITADA A FONTE

\section{FICHA CATALOGRÁFICA}

Serviço de Documentação Enfermagem

Escola de Enfermagem de Ribeirão Preto da Universidade de São Paulo

Alves, Luana Seles

Áreas de risco de mortes por tuberculose em Londrina/Paraná: uma abordagem geoepidemiológica. Ribeirão Preto-SP, 2018.

121p.: il.; $30 \mathrm{~cm}$

Dissertação apresentada à Escola de Enfermagem de Ribeirão Preto/USP.

Orientador: Ricardo Alexandre Arcêncio

1. Tuberculose. 2. Mortalidade. 3. Análise espacial. 4. Vigilância em Saúde Pública 
ALVES, Luana Seles

Áreas de risco de mortes por tuberculose em Londrina/Paraná: uma abordagem geoepidemiológica

Dissertação apresentada à Escola de Enfermagem de Ribeirão Preto da Universidade de São Paulo para obtenção do título Mestre em Ciências, Programa de Pós-graduação Enfermagem em Saúde Pública.

Aprovado em ......./ ....../ .........

Banca Examinadora

Prof. Dr. Instituição:

Julgamento: Assinatura

Prof. Dr. Instituição:

Julgamento: Assinatura

Prof. Dr. Instituição:

Julgamento: Assinatura 


\section{Dedicatória}

A Deus, por ter me dado a vida, por me iluminar e me dar força para seguir a minha caminhada.

À minha mãe Márcia Seles, minha melhor amiga, meu exemplo de vida, pelo amor infinito e estímulo em todos os momentos da minha vida. Ao meu pai Cláudio Alves, meu porto seguro e amor incondicional. Ao meu irmão Luis Philipe por sempre me acompanhar em toda essa caminhada e pelos sinceros consethos.

Ao meu noivo Luiz Fermando Bento Batista por estar sempre ao meu lado e também pelo companheirismo, respeito e incentivo. Às minhas avós Neire Magesto Vieira Seles e Esmênia Silva Alves (in memorian) pelos valiosos ensinamentos da vida. 


\section{Agradecimentos}

À Deus pelo dom da vida, da sabedoria nas minhas escolhas e pela coragem para lutar pelo que desejo em minha vida.

À minha mãe Márcia Seles, a quem devo minha vida e a pessoa que sou. Obrigada por ter sido meu grande exemplo de determinação, coragem e amor incondicional. Ao meu pai Cláudio Alves, por ter me mostrado a cada dia que o dom $D \mathcal{D}$ vida é o maior presente de Deus.

Ao meu irmão Luis Philipe, pelo amor e carinho que nos une, pelo apoio e torcida. Ao meu noivo Luiz Fermando Bento Batista que sempre me apoiou e incentivou para a realização dos meus ideais.

À todas as minhas tias em especial a Tia Sivalda, Tia Valquiria, Tia Mari, Tia Karina, Tia Lenice e Tia Cris por sempre me ampararem quando foi preciso e por todo incentivo que sempre me deram A todos os meus tios, em especial ao meu padrinho tio Adilson e ao Tio Clóvis por serem tão presentes em minha vida e por todo carinho.

A todos os meus primos, em especial a minha prima e irmã Alessandra, e às minhas pequenas $e$ amadas primas Lillian, Vivian, e Lucia por serem minhas joias raras.

Às minhas grandes e velhas amigas Bi, Jé, Carol e Annie, que mesmo distantes nunca foram ausentes, e por serem os grandes presentes que a vida me deu.

A Daya e Alesson por sempre me incentivarem a buscar meus sonhos e por estarem sempre presentes nos momentos mais importantes dessa jornada. A minha amiga Glaucia pela paciência de sempre me escutar e me ajudar sempre que foi preciso.

A minha amiga e grande parceira em toda essa caminhada Thaís, obrigada por todo o carinho.

Aे Concy, mulher forte e batalhadora, pois ela foi quem me inspirou a seguir esse caminho como pesquisadora sempre me estimulando e incentivando a aprender cada vez mais. Á Clara Souza por toda generosidade e solidariedade para me auxiliar em tudo que foi necessário durante toda a trajetória até aqui. Ao Antônio Ramos, por ser tão atencioso, amigo e sempre trazer a paz, principalmente nos momentos de turbulência. 
Ao Marcos Arcoverde, por compartilhar comigo toda sua sabedoria e propiciar momentos de grande aprendizagem.

À Josy e Iza, por todos os momentos descontraídos e também de amparo e apoio durante as etapas desse trabalho.

Ao Luiz Henrique Arroyo, pela disponibilidade de dividir comigo momentos de discussões e reflexões importante para execução desse projeto.

À Dani, Aylana, Ana Angélica e Marcela por sempre me tranquilizarem e confiarem em mim. Aos queridos alunos de Iniciação Científica, Yan, Laleska, Lud, Bianca, Geovanna, Jr,

Camila, Alícia, e Ana Carolina por me oportunizarem momentos de muito aprendizado. Ao meu orientador Prof. Dr. Ricardo Alexandre Arcêncio, por toda disponibilidade, incentivo e dedicação às nossas discussões e contribuições a este trabalho.

Ao Prof, Dr. Pedro Fredemir Palha, pelos ensinamentos e contribuições que me proporcionou desde o segundo ano de graduação e por ter sido um exímio tutor no Programa de Educação Tutorial e Supervisor no meu último estágio da graduação.

A todos os membros do Grupo de Estudo Epidemiológico-Operacional em Tuberculose (GEOTB) e do Grupo de Altos Estudos de Avaliação de processos e práticas da Atenção Primária à Saúde e Enfermagem (GAAPS) pelo acolhimento e todo aprendizado. À Escola de Enfermagem de Ribeirão Preto da Universidade de São Paulo, de modo especial ao Programa de Pós-graduação Enfermagem em Saúde Pública, por tonar possível a realização do curso de mestrado. E a todos os funcionários, por sempre me auxiliarem com muito zelo nos momentos de precisão.

À Secretaria Municipal de Saúde de Londrina pela autorização e incentivo da pesquisa. À Coordenação de Aperfeiçoamento Pessoal de Nïvel Superior (Capes) pela concessão da bolsa de mestrado.

A todos, que na ocasião deixo de citar e que contribuíram direta ou indiretamente para realização desse trabalho. 


\section{Vida}

Já perdoei erros quase imperdoáveis,

tentei substituir pessoas insubstituíveis

e esquecer pessoas inesquecíveis.

Já fiz coisas por impulso,

já me decepcionei com pessoas

que eu nunca pensei que iriam me decepcionar,

mas também já decepcionei alguém.

Já abracei pra proteger,

já dei risada quando não podia,

fiz amigos eternos,

e amigos que eu nunca mais vi.

Amei e fui amado,

mas também já fui rejeitado,

fui amado e não amei.

Já gritei e pulei de tanta felicidade,

já vivi de amor e fiz juras eternas,

e quebrei a cara muitas vezes!

Já chorei ouvindo música e vendo fotos,

já liguei só para escutar uma voz,

me apaixonei por um sorriso,

já pensei que fosse morrer de tanta saudade

e tive medo de perder alguém especial (e acabei perdendo).

Mas vivi!

E ainda vivo!

Não passo pela vida.

E você também não deveria passar!

Bom mesmo é ir à luta com determinação, abraçar a vida com paixão,

perder com classe

e vencer com ousadia,

porque o mundo pertence a quem se atreve

$e$ a vida é muito para ser insignificante.

Viva!!

(Augusto Branco) 


\section{RESUMO}

ALVES, L.S. Áreas de risco de mortes por tuberculose em Londrina/Paraná: uma abordagem geoepidemiológica. 2018. 121f. Dissertação (Mestrado) - Escola de Enfermagem de Ribeirão Preto, Universidade de São Paulo, Ribeirão Preto, 2018.

Introdução: A tuberculose (TB) é uma doença milenar que permanece como um grave problema de saúde pública, faz parte do ranking mundial das dez principais causas de morte no mundo. Objetivo: Identificar aglomerados espaciais de risco de mortes por tuberculose em Londrina/PR. Métodos: Trata-se de um estudo ecológico cujas unidades foram setores censitários urbanos de Londrina/PR definidos pelo Censo Demográfico de 2010, do Instituto Brasileiro de Geografia e Estatística (IBGE). A população do estudo foi composta dos casos de óbito por TB como causam básica e associada, registrados no Sistema de Informações sobre Mortalidade (SIM) no período de 2008 a 2015. A análise exploratória das variáveis sociodemográficas e clínico-epidemiológicas do SIM ocorreu por meio da estatística descritiva dos parâmetros quantitativos, sendo calculadas as frequências absolutas e relativas para as variáveis no software Statistica versão 12.0. O georreferenciamento dos endereços foi processado no software TerraView versão 4.2.2. Posteriormente, realizou-se a análise de área calculando-se as taxas brutas e bayesianas empíricas globais anuais de mortalidade. A dependência espacial da mortalidade por TB foi verificada pelo Índice de Moran Global $(I)$. Utilizou-se a ferramenta Incremental Spatial Autocorrelation (ISA) para definir o raio de influência do estimador de intensidade Kernel, tais análises foram realizadas no software ArcGIS versão 10.5. Para detecção dos aglomerados espaciais foi aplicada a técnica Estatística de Varredura Espacial Tradicional e na versão Isotônica, a qual traz como novidade a visualização gradativa do Risco Relativo Espacial (RRE) no interior do aglomerado através dos Steps in Risk Function, utilizou-se o software SaTScan ${ }^{\mathrm{TM}}$ versão 9.4. Em todos os testes estatísticos foi fixado o nível de significância em 5\% ( $\mathrm{p}<0,05)$. Resultados: Identificou-se 61 óbitos por TB, destes $40(65,6 \%)$ eram causa básica e $21(34,4 \%)$ causa associada. Observou-se que 27 casos $(44,3 \%)$ apresentavam idade entre 40 e 59 anos; $49(80,3 \%)$ eram homens, $39(63,9 \%)$ da cor branca, $20(32,8 \%)$ com ensino médio, $32(52,4 \%)$ apresentaram forma clínica pulmonar e $54(88,5 \%)$ ocorreram em ambiente hospitalar. As maiores taxas bayesianas foram identificadas nos bairros, Alpes (2,5 por 100.000 hab./ano), Vila Recreio (2,6 por 100.000 hab./ano)e Aeroporto (2,7 por 100.000 hab./ano). A dependência espacial demonstrou-se baixa e positiva $(I=0,014 \mathrm{e}$ $\mathrm{p}=0,004)$, porém com alto $z$-score $(2,83)$ nos aglomerados. O estimador de intensidade Kernel identificou as regiões Norte, Centro e Leste como sendo áreas quentes para a mortalidade por TB, assim como na Estatística de Varredura Espacial Tradicional e Isotônica. A versão tradicional identificou um aglomerado espacial de risco para $10 \%$ da população exposta com $\mathrm{RRE}=4,9$ (IC $95 \%$ 2,6-9,4), para 30\% RRE=3,2 (IC $95 \%$ 2,1$5,7)$ e para $50 \% \mathrm{RRE}=3,2$ ( $\left.\mathrm{IC}_{95 \%} 2,1-5,7\right)$, na versão Isotônica encontrou-se para $10 \%$ da população expostas com $\mathrm{RRE}=2,8\left(\mathrm{IC} \mathrm{I}_{95}\right.$ 1,5-5,1), para 30\% RRE=2,7 (IC $95 \%$ 1,6- 4,4) e para 50\% RRE=2,2 (IC $95 \%$ 1,4-3,9). Conclusão: A identificação do gradiente do RRE nas populações expostas, certamente, servirá como um indutor de mudanças em termos da melhoria do acesso aos serviços de saúde no intuito de promover ambientes saudáveis

Palavras-chave: Tuberculose. Mortalidade. Óbito. Análise espacial. Vigilância em saúde Pública. 


\begin{abstract}
ALVES, L.S. Areas of risk of tuberculosis deaths in Londrina/Paraná: a geoepidemiological approach. 2018. 121f. Dissertation (Master's degree) - College of Nursing at Ribeirão Preto, University of São Paulo, Ribeirão Preto, 2018.
\end{abstract}

Background: Tuberculosis (TB) is a millenial disease that remains a serious public health problem and is one of the world's top ten causes of death. Aim: Identify spatial clusters of risk for occurrence of tuberculosis mortality in Londrina/PR. Methods: This is an ecological study whose units of analysis were urban census sectors of Londrina/PR defined by the Demographic Census of 2010, of the Brazilian Institute of Geography and Statistics. The study's population was composed by deaths due to TB as a basic and associated cause, registered in the Mortality Information System (MIS) from 2008 to 2015. The exploratory analysis of the sociodemographic and clinical-epidemiological variables of the MIS occurred by means of the descriptive statistics of the quantitative parameters and calculated the absolute and relative frequencies for all the variables, using the Statistica (version 12.0) software. The geo-referencing technique of the cases was performed using the Terraview (version4.2.2) software. Subsequently, was calculate the TB mortality rate, it was smoothed by Empirical Bayes Method. Autocorrelation of TB mortality was analyzed by Moran Global Index (I). The Incremental Spatial Autocorrelation (ISA) tool was used to define the radius of influence of the Kernel estimator, such analyzes were performed in ArcGIS software version 10.5. For the detection of the spatial clusters we used the Standard Spatial Scan Statistics (SS) and Isotonic version (ISSS), which provides, as a novelty, the gradual visualization of the Spatial Relative Risk (SRR) inside the cluster through the Steps in Risk Function, these techniques were applied in SaTScan ${ }^{\text {TM }}$ software version 9.4. It was defined level of significance at $5 \%$ as statistically significant $(\mathrm{p}<0.05)$ for all statistical tests. Results: We identified 61 deaths due to TB, of which 40 (65.6\%) were per basic cause and $21(34.4 \%)$ were associated causes. It was observed that 27 cases (44.3\%) were aged between 40 and 59 years; 49 (80.3\%) male, 39 (63.9\%) white, 20 (32.8\%) high school students, $32(52.4 \%)$ had a pulmonary clinical form and 54 (88.5\%) occurred in a hospital. The highest Bayesian rates were identified in the neighborhoods, Alpes (2.5 per 100,000 inhabitants/year), Vila Recreio (2.6 per 100,000 inhabitants/year) and Aeroporto (2.7 per 100,000 inhabitants/year). Spatial autocorrelation was low and positive $(\mathrm{I}=0.014$ and $\mathrm{p}=0.004)$, but with a high $\mathrm{z}$-score (2.83) in the clusters. The Kernel estimator identified the North, Center and East regions as hotspot areas for TB mortality, as well as in the Standard and Isotonic Space Scan Statistics. For the SS, spatial risk clusters were identified for $10 \%$ of the exposed population with $\mathrm{SRR}=4.9$ (95\%CI 2.6-9.4), for 30\% SRR=3.2 (95\%CI 2.1-5.7) and for $50 \% \mathrm{SRR}=3.2(95 \% \mathrm{CI} 2.1-5.7)$, while for the ISSS spatial risk clusters were identified for $10 \%$ of the exposed population with $\mathrm{SRR}=2.8$ (95\%CI 1.5-5.1), for 30\% SRR=2.7 (95\%CI 1.6-4.4) and for 50\% SRR=2.2 (95\%CI 1.4-3.9). Conclusion: Identifying the RRE gradient in exposed populations, will certainly serve as an inducer of changes in terms of improving access to health services in order to promote healthy environments.

Keywords: Tuberculosis. Mortality. Death. Spatial analysis. Public Health Surveillance. 


\section{RESUMEN}

ALVES, L.S. Análisis espacial de la mortalidad por tuberculosis en Londrina/Paraná. 2018. 121f. Disertación (Maestría) - Escola de Enfermagem de Ribeirão Preto, Universidade de São Paulo, Ribeirão Preto, 2018.

Introducción: La Tuberculosis (TBC) es una enfermedad milenaria que sigue siendo un grave problema de salud pública, forma parte del ranking mundial de las diez principales causas de muerte en el mundo. Objetivo: Identificar aglomerados espaciales de riesgo para la mortalidad por tuberculosis en Londrina / PR. Métodos: Estudio ecológico cuyas unidades fueron fracciones censales urbanas de Londrina/PR. La población del estudio fue conformada por muertes por TBC como causa básica y asociada, registrados en el Sistema de Información sobre Mortalidad (SIM) entre el período de 2008 a 2015. El análisis exploratorio de las variables sociodemográficas y clínico-epidemiológicas del SIM fue realizado por medio de estadística descriptiva, siendo calculadas las frecuencias absolutas y relativas para las variables en el software Statistica versión 12.0. La georreferenciación de direcciones fue procesada en el software TerraView versión 4.2.2. Para el análisis del área fueron calculadas las tasas brutas y bayesianas empíricas globales. La dependencia espacial de la mortalidad por TBC fue verificada por el Índice de Moran Global (I). Se utilizó la herramienta Incremental Spatial Autocorrelation (ISA) para definir el radio de influencia del estimador Kernel, tales análisis se realizaron en el software ArcGIS versión 10.5. Para la detección de los aglomerados espaciales se aplicó la Análisis Espacial de Barredura Tradicional e Isotónica, la cual tiene como novedad la visualización gradual del Riesgo Relativo Espacial (RRE). En el interior del aglomerado a través de los Steps in Risk Function, se utilizó el software SaTScan TM versión 9.4. En todas las pruebas estadísticas se estableció el nivel de significancia de un 5\% (p <0,05). Resultados: Se identificaron 61 muertes por TBC, de estos $40(65,6 \%)$ fueron de causa básica y 21 $(34,4 \%)$ de causa asociada. Se observó que 27 casos $(44,3 \%)$ presentaban edad entre 40 y 59 años; (49,3\%) eran hombres, $39(63,9 \%)$ de raza blanca, 20 (32,8\%) de enseñanza media, $32(52,4 \%)$ presentaron la enfermedad de forma clínica pulmonar y $54(88,5 \%)$ de las muertes ocurrieron en un hospital. Las mayores tasas bayesianas fueron en los barrios, Alpes (2,5 por 100.000 hab./ano), Vila Recreio (2,6 por 100.000 hab./ano) y Aeropuerto (2,7 por 100.000 hab./ano). La dependencia espacial se mostró baja y positiva $(\mathrm{I}=0,014$ y $\mathrm{p}=0,004)$ e con alto $\mathrm{z}$-score $(2,83)$ en los aglomerados. El estimador Kernel identificó las regiones Norte, Centro y Oeste como zonas de exposición para la mortalidad por TBC, así como en el Análisis Espacial de Barredura Tradicional e Isotónica. La versión tradicional, identificó un aglomerado espacial de riesgo para el 10\% de la población expuesta con RRE = 4,9 (IC95\% 2,6-9,4), 30\% RRE $=3,2(\mathrm{IC} 95 \%$ 2,1-5, Y para el 50\% RRE = 3,2 (IC95\% 2,1-5,7), en la versión Isotónica se encontró para el 10\% de la población expuesta con RRE $=2,8$ (IC95\% 1,5-5, 1), al $30 \%$ RRE $=2,7($ IC95\% 1,6-4,4) y al 50\% RRE $=2,2$ (IC95\% 1,4-3,9).Conclusiones: La identificación del gradiente del RRE en las poblaciones expuestas, podrá inducir cambios, en términos de la mejora del acceso a los servicios de salud con el fin de promover ambientes saludables.

Palabras claves: Tuberculosis. Mortalidad. Muerte. Análisis Espacial. Vigilancia en Salud Pública 


\section{LISTA DE FIGURAS}

Figura 1- Etapas do processo de Mapeamento Sistemático segundo Petersen e

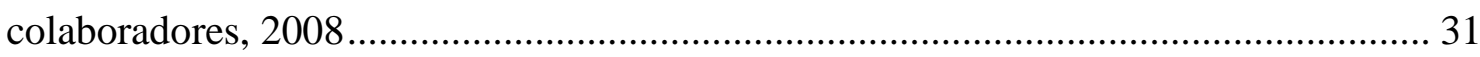

Figura 2- Diagrama do processo de seleção dos artigos (2007- 2017)......................... 35

Figura 3- Técnicas de análise espacial utilizadas em estudos sobre mortalidade por Tuberculose, segundo o Mapeamento Sistemático (2007-2017) ................................. 38

Figura 4- Unidades de análise utilizadas em estudos sobre mortalidade por Tuberculose, segundo o Mapeamento Sistemático da Literatura (2007-2017) .............. 39

Figura 5- Países que utilizaram técnicas de análise espacial para a mortalidade por Tuberculose, segundo o Mapeamento Sistemático da Literatura (2007-2017) .............. 40

Figura 6- Categorização das principais contribuições dos estudos de análise espacial sobre a mortalidade por Tuberculose, segundo o Mapeamento Sistemático da Literatura (2007-2017)

Figura 7- Determinantes da Tuberculose no Brasil, segundo Maciel e Reis-Santos (2015) 48

Figura 8- Modelo teórico da importância da análise espacial para Vigilância da Saúde sob a ótica da mortalidade por Tuberculose (2018) 53

Figura 9- Localização geográfica do município de Londrina/Paraná, Brasil (2018) .... 58

Figura 10- Setores censitários do município de Londrina/Paraná, Brasil (2018).......... 60

Figura 11- Síntese esquemática dos procedimentos metodológicos para análise dos dados da investigação

Figura 12- Casos de óbito por tuberculose georreferenciados sobrepostos aos setores censitários. Londrina/Paraná, Brasil (2008 - 2015)

Figura 13- Mapa das taxas de mortalidade* por tuberculose, segundo os setores censitários Londrina/Paraná, Brasil (2008-2015) 80

Figura 14- Teste da pseudo-significância estatística das taxas suavizadas de mortalidade por TB, Londrina/Paraná, Brasil (2008-2015) 81

Figura 15- Mapa da distribuição da densidade dos óbitos por tuberculose. Londrina/Paraná, Brasil (2008-2015)

Figura 16- Aglomerados espaciais de alto e baixo risco para a mortalidade por TB através da Estatística de Varredura Espacial Tradicional. Londrina/Paraná, Brasil (20082015)

Figura 17- Aglomerados espaciais dos óbitos por tuberculose através da Estatística de Varredura Espacial Isotônica segundo os "Steps in risk function", Londrina/Paraná, Brasil (2008-2015). 86 


\section{LISTA DE QUADROS}

Quadro 1-Componentes da questão de pesquisa ......................................................... 32

Quadro 2- Estrutura da estratégia de busca, segundo descritores ................................ 33

Quadro 3- Critérios de inclusão e exclusão para seleção dos papers ............................ 34

Quadro 4- Descrição dos estudos incluídos no mapeamento sistemático (2007-2017) 36

Quadro 5- Modelos Assistenciais e Vigilância da Saúde (2000) ................................. 50

Quadro 6- Formas clínicas consideradas no estudo, segundo a Classificação

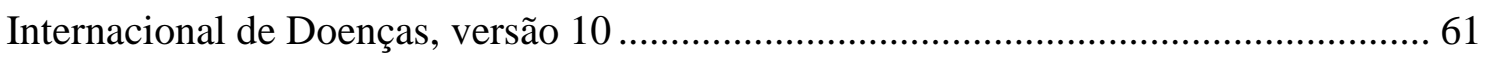

Quadro 7- Variáveis selecionadas para a pesquisa conforme dados disponíveis na

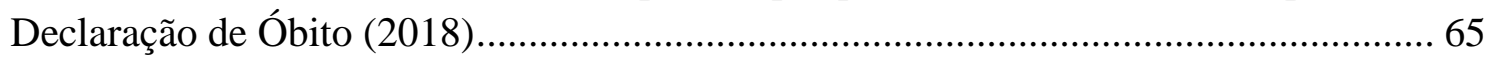




\section{LISTA DE TABELAS}

Tabela 1- Características Sociodemográficas das pessoas que morreram de tuberculose em Londrina/Paraná, Brasil (2008 a 2015)

Tabela 2- Características Clínico- Epidemiológicas das pessoas que morreram de tuberculose em Londrina/Paraná, Brasil (2008 a 2015) ................................................ 77

Tabela 3- Aglomerados espaciais de risco das mortes por TB segundo Steps in risk function. Londrina/Paraná, Brasil (2008-2015) ......................................................... 87

Tabela 4- Comparação entre a Estatística de Varredura Espacial Tradicional e a Isotônica. Londrina/Paraná, Brazil (2008-2015) .......................................................... 88 


\section{LISTA DE GRÁFICOS}

Gráfico 1- Autocorrelação Espacial por distância dos casos de óbito por TB, Londrina/Paraná, Brasil (2008-2015) 


\section{LISTA DE ABREVIATURAS}

Aids

APS

BCG

BRICS

CID

DO

DOTS

ESF

HIV

I

IDHM

ISA

LLR

MDR

MS

MSL

OMS

PACS

PNCT

PRISMA

PSF

RRE

RSL

SIM

SUS

TB

UBS

UPA

$U T M$

VS

WGS 84
Acquired Immunodeficiency Syndrome

Atenção Primária a Saúde

Bacilo de Calmette-Guérin

Brasil, Rússia, Índia, China e África do Sul

Classificação Internacional de Doenças

Declarações de Óbito

Directly Observed Treatment Short-course

Estratégia Saúde da Família

Vírus da Imunodeficiência Humana

Índice de Moran

Índice de Desenvolvimento Humano Municipal

Incremental Sptaial Autocorrelation

Log Likelihood Ratio

Tuberculose multidrogarresistente

Ministério da Saúde

Mapeamento Sistemático da Literatura

Organização Mundial de Saúde

Programa dos Agentes Comunitários de Saúde

Plano Nacional de Controle da Tuberculose

Preferred Reporting Items for Systematic Reviews and Meta-

Analyses

Programa Saúde da Família

Risco Relativo Espacial

Revisões Sistemáticas de Literatura

Sistema de Informação sobre Mortalidade

Sistema de Único de Saúde

Tuberculose

Unidades Básicas de Saúde

Unidades de Pronto Atendimento

Universal Transversa de Mercator (UTM)

Vigilância da Saúde

World Geodetic System 1984(WGS/84) 


\section{Sumário}

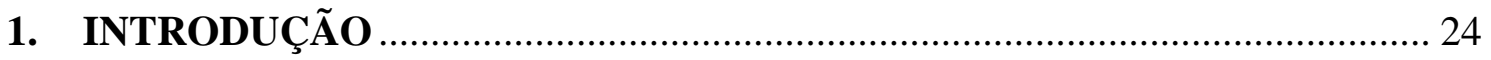

2. MAPEAMENTO SISTEMÁTICO DA LITERATURA …................................ 29

2.1. Definição da questão de pesquisa do MSL ...................................................... 31

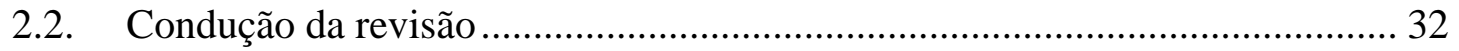

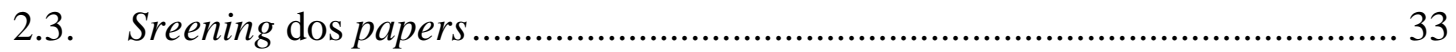

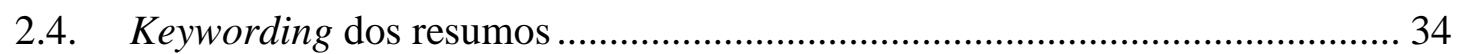

2.5. Processo de extração dos dados e mapeamento ................................................ 34

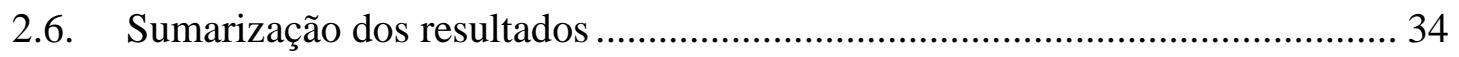

2.7. Análise dos resultados do MSL e Lacuna do conhecimento ........................... 41

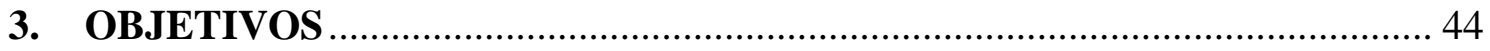

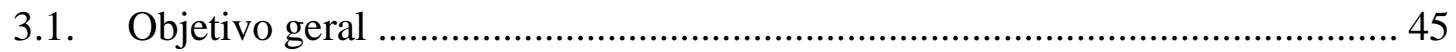

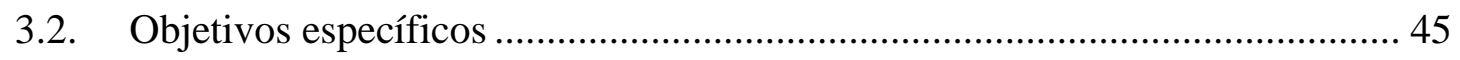

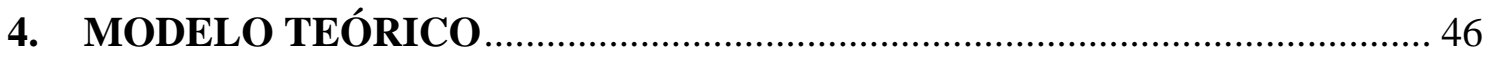

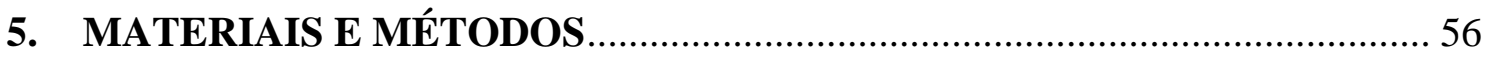

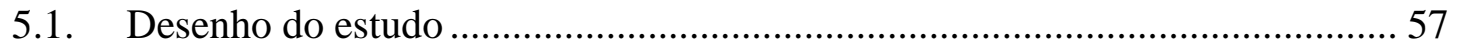

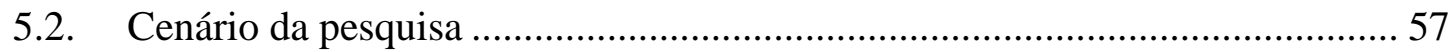

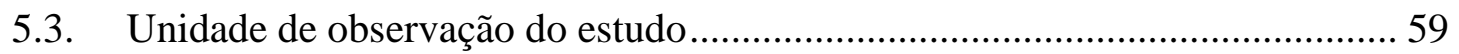

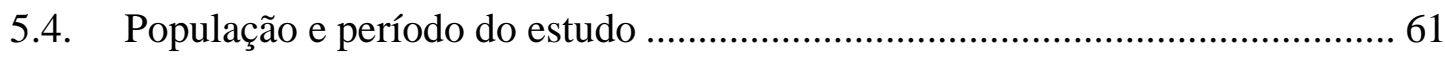

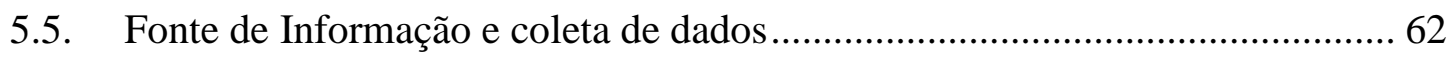

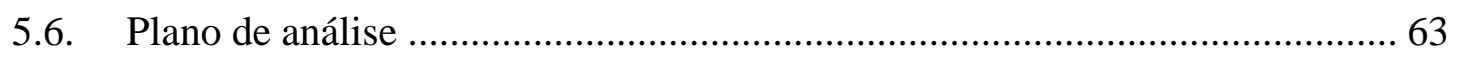

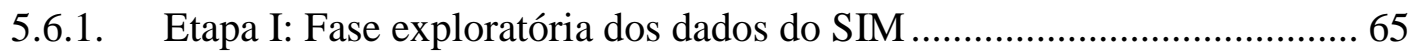

5.6.2. Etapa II: Georreferenciamento dos endereços........................................ 65

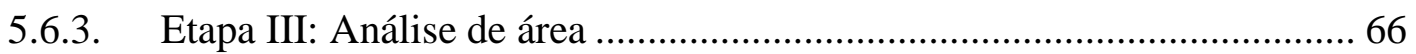

5.6.3.1. Taxa bruta da mortalidade por TB segundo os setores censitários ........ 66

5.6.3.2. Suavização das taxas de mortalidade: Método Bayesiano Empírico Global 67

5.6.3.3. Autocorrelação espacial: Índice de Moran Global............................... 67

5.6.4. Análise de densidade de pontos: Estimador de Intensidade Kernel .......... 68

5.6.5. Análise de detecção de glomerados espaciais: Estatística de Varredura.. 70

5.6.5.1. Descrição da análise de formação de aglomerados através da Estatística de Varredura Espacial Tradicional ..................................................................... 70 
5.6.5.2. Descrição da análise de formação de aglomerados através da Estatística de Varredura Espacial Isotônica............................................................................ 72

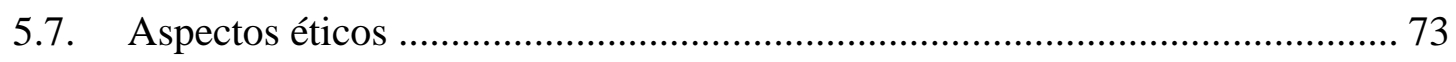

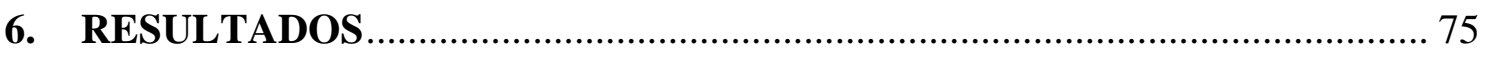

6.1. Análise exploratória dos dados do SIM …….................................................... 76

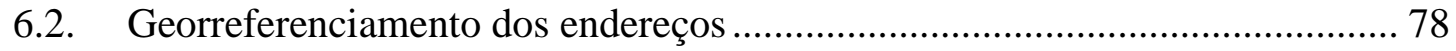

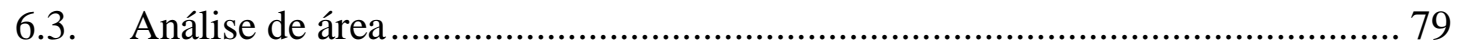

6.4. Análise de densidade de pontos: Estimador de Intensidade Kernel ................ 81

6.5. Análise de detecção de aglomerados espaciais: Estatística de Varredura ........ 83

7. DISCUSSÃ

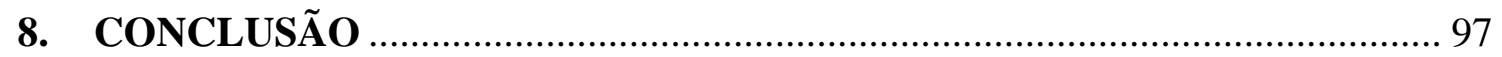

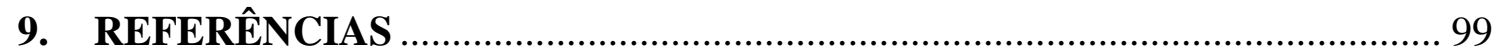

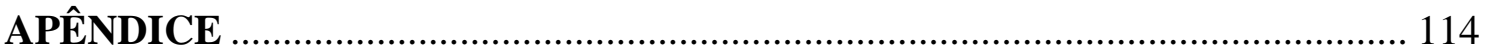

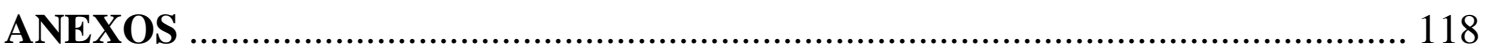


"Nós podemos mudar o mundo e torná-lo um lugar melhor. Está em suas mãos fazer a diferença" (Nelson Mandela) 
Meu ingresso na Escola de Enfermagem de Ribeirão Preto da Universidade de São Paulo (EERP/USP) ocorreu no ano de 2011, a escolha pela enfermagem como profissão ocorreu devido ao meu interesse em melhorar a assistência e o cuidado em saúde, principalmente da população desassistida e até mesmo em situação de rua.

No ano de 2012, durante o segundo ano de graduação, quando cursava a disciplina "Integralidade do Cuidado em Saúde II" tive a oportunidade de realizar visitas domiciliares aos doentes de tuberculose (TB) através do Tratamento Diretamente Observado (TDO), o que me fez refletir sobre a complexidade da TB e as suas implicações no individuo acometido. Nas discussões com os docentes da disciplina e profissionais de campo de estágio, sobretudo com o Prof. Dr. Ricardo Alexandre Arcêncio, surgiu minha motivação em estudar a temática TB, a qual pode se iniciar com o convite do Prof. Ricardo para participar de seu grupo de pesquisa.

Da participação no grupo de pesquisa originou-se a minha primeira iniciação científica, intitulada: "Tratamento das famílias com tuberculose latente e a produção do cuidado nos serviços de saúde”, projeto este financiado pelo Programa Institucional de Bolsas de Iniciação Científica do Centro Nacional de Desenvolvimento Científico e Tecnológico (PIBIC/CNPq-Processo nº 152248/2012-9).

Neste período todo meu estudo estava voltado na compreensão da dinâmica familiar perante o processo saúde-doença da TB, o que me proporcionou uma compreensão de que o contexto socioeconômico era um dos determinantes para o adoecimento por TB. Desta forma, no decorrer desse projeto de iniciação científica, percebi a complexidade dos estudos de TB e que esta doença ocorria com maior frequência em determinadas localidades e de forma desigual.

Ao término da minha primeira iniciação científica tive a oportunidade de um estágio sanduíche na Escola Superior de Enfermagem de Coimbra (EsenfC) através da bolsa de Mobilidade Estudantil Mérito Acadêmico da USP. Nesta instituição de ensino, realizei visitas técnicas nos serviços de saúde do município, e, ao me deparar com a população acometida pela TB observei que as características se assemelhavam com as encontradas no Brasil.

Ao final do intercâmbio e retorno às atividades com o grupo de pesquisa fui inserida em uma nova etapa de estudos em que o grupo estava se debruçando, o estudo da TB na perspectiva das análises espaciais no cenário nacional.

Sob a liderança do professor Ricardo iniciou-se um estudo multicêntrico intitulado: "A mortalidade por tuberculose e sua relação com as iniquidades sociais: um 
estudo multicêntrico" e financiado pela Fundação de Amparo e Apoio à Pesquisa do Estado de São Paulo (FAPESP- Processo no 17586-3/2015).

Este projeto multicêntrico está sendo desenvolvido em cinco metrópoles do país sendo elas: Manaus/AM, São Luís /MA, Natal/RN, Curitiba/PR e Cuiabá/MT; e em três municípios prioritários para o controle da tuberculose sendo: Ribeirão Preto/SP, Londrina/PR e Foz do Iguaçu.

Por conseguinte, minha segunda iniciação científica estava vinculada a este projeto e tinha o objetivo de investigar as internações por tuberculose em Natal/RN, sendo assim obteve-se como título do estudo: "Análise espacial das internações por tuberculose em NATAL/RN através do estimador de intensidade Kernel”, o qual foi financiando também pela FAPESP (Processo $n^{\circ}$ 2014/09124-7) e vinculava-se ao Projeto Universal CNPQ (PRocesso nº473963/2013-2) intitulado, “Iniquidades sociais e as internações evitáveis por tuberculose em dois municípios brasileiros: uma abordagem geoespacial"

A participação nesse projeto possibilitou incremento significativo na minha formação e me permitiu o conhecimento de um novo horizonte nas pesquisas de enfermagem, pois a análise espacial não é um método comumente citada na graduação e no que se refere especificamente à enfermagem.

Além disso, as técnicas de análise espacial me proporcionaram grande aprendizado quanto a construção e manipulação de banco de dados e os mais distintos softwares. Foi com esse projeto que consegui elaborar trabalhos a serem apresentados em eventos nacionais e internacionais, dentre eles destaca-se a $47^{\mathrm{a}}$ The Union Conference on Lung Health, realizada em 2016 na cidade de Liverpool, United Kingdom.

Os achados dessa pesquisa mostraram que as regiões com maior densidade de internações eram as regiões com maior vulnerabilidade social, a partir do exposto me surgiram alguns questionamentos, como: Se o tratamento da tuberculose é realizado diariamente nas casas dos doentes por que ocorrem complicações da doença que o levam a internação e até mesmo ao óbito? Como o espaço em que elas residem influenciam tão incisivamente na saúde? Quais ferramentas as equipes de saúde podem utilizar para auxiliar no controle da disseminação da tuberculose?

Nesse contexto, tive a curiosidade em conhecer alguma região do Brasil marcada pelas desigualdades sociais, e foi então que participei do projeto Rondon, que consiste na realização de atividades de promoção à saúde com um foco amplo nos direitos 
humanos e cidadania, oportunizando aos universitários de todo o Brasil experiências relevantes para uma formação acadêmica que considera as desigualdades no país, preparando-os no enfrentamento das mais diversas realidades.

Foi no Projeto Rondon que consegui entender as grandes dificuldades para realização de atividades de promoção à saúde em regiões com poucos recursos para executar ações e cuidados em saúde. Nesse projeto de extensão que foi realizado na cidade de Ananás/TO, identifiquei diversas barreiras para a assistência aos doentes de $\mathrm{TB}$, principalmente no que diz respeito as barreiras de acesso aos serviços e equipes de saúde.

Foi durante as atividades de busca de sintomáticos respiratórios e visitas domiciliares àquela população, que consegui entender a relevância do território de residência como unidade de análise às pesquisas em saúde para auxiliar no diagnóstico situacional em saúde, e desta forma, auxiliar no combate de diversas doenças, não apenas a TB, como também a hanseníase, leishmaniose, chagas, entre outras tantas doenças negligenciadas.

Esses fatores pelos quais me deparei nesse projeto de extensão, somado às atividades do grupo de pesquisa me instigaram na construção desse projeto de mestrado, o qual tem como objeto de estudo o óbito por TB, um evento marcado pelas vulnerabilidades sociais e atrelado as iniquidades em saúde.

Além disso, esse projeto de mestrado demonstrou que é importante investir nos estudos de análise espacial na temática da mortalidade, e para isso, torna-se essencial o uso de novas ferramentas espaciais que sejam sensíveis para as análises em unidades de agregação menores e populações pequenas, principalmente para a TB, já que as políticas nacionais e mundiais reforçam a importância dos estudos locais para o controle da transmissão da doença.

Ademais, a presente pesquisa retoma a relevância da reorganização do atual modelo assistencial de saúde pautada nos conceitos da Vigilância em Saúde para melhor atender as demandas da população.

Portanto, esperasse que essa pesquisa seja utilizada pelas equipes de saúde de Londrina, cenário do estudo, com a finalidade de auxiliar as ações de promoção à saúde nas regiões prioritárias, e que dessa forma, contribua para a redução da mortalidade por tuberculose. 
A estrutura dessa dissertação de mestrado está composta pela introdução, mapeamento sistemático da literatura, objetivos, modelo teórico, materiais e métodos, resultados, discussão e conclusão. 


\section{INTTRODUÇÃ̃O}

"Por vezes sentimos que aquilo que fazemos não é senão uma gota de água no mar. Mas o mar seria menor se the faltasse uma gota.".

(Madre Teresa de Calcutá) 
A tuberculose (TB) é uma doença milenar que permanece como um grave problema de saúde pública, faz parte do ranking mundial das dez principais causas de morte e assume desde 2016 a liderança entre as doenças infecciosas que mais matam no mundo (WHO, 2017).

Mesmo com diagnóstico simples, tratamento gratuito e a vacina Bacilo de Calmette-Guérin (BCG) disponível para prevenção das formas mais graves da doença, ainda permanece como um desafio para as políticas públicas de saúde e continua sendo um problema mundial de saúde. (HEAD, et al., 2016; BRASIL, 2014; PILLER, 2012).

Um fato histórico que deve ser assinalado é que, após a descoberta dos tuberculostáticos nos anos de 1940, a Organização Mundial de Saúde (OMS) considerou a TB como um problema controlado, porém, em meados de 1980, com o aparecimento do HIV/Aids a TB ressurgiu em um novo contexto epidemiológico e, no ano de 1993, foi decretada como emergência global (LOPES; VIEIRA; LANA, 2015); isso nos países desenvolvidos; no Brasil ela não foi e ou é um problema emergente e tampouco reemergente, ela sempre figurou entre as principais doenças de saúde pública, o que o Ruffino-Netto (2002) classificou como calamidade negligenciada ou descalabro consentido.

É válido resgatar que a pandemia sofrida pelos países desenvolvidos quanto ao recrudescimento da tuberculose fez com que a OMS lançasse a estratégia DOTS (Directly Observed Treatment Short-course), incorporada em 1998 ao Plano Nacional de Controle da Tuberculose (PNCT) (FIGUEIREDO, et al.; 2009).

Tal estratégia constitui-se de diretrizes de trabalho com vistas à incorporação das ações pelos sistemas de serviços de saúde, definindo responsabilidades quanto às especialidades e à Atenção Primária à Saúde (APS) e adoção de novas medidas sanitárias para a quebra da cadeia transmissão com vistas à descentralização e horizontalização das ações de vigilância, prevenção e controle da TB, para o âmbito da APS (BRASIL, 2012).

Dando continuidade às ações de combate à essa doença, em 2006 foi divulgada a estratégia Stop TB, com vistas a fortalecer a estratégia DOTS, cujas metas eram reduzir em $50 \%$ os coeficientes de prevalência e mortalidade por TB em relação ao ano de 1990, até 2015 (Stop TB, 2006).

Destaca-se que o ano de 2015 se iniciou com uma conquista, pois houve o alcance da meta de redução de 50\% da prevalência e dos óbitos por TB desde 1990, ano em que foi considerada uma emergência global (WHO, 2016). 
Em seguida, a OMS reestabeleceu a classificação dos países prioritários para controle da TB, levando em consideração três características epidemiológicas: 1) carga da tuberculose, 2) tuberculose multidrogarresistente (MDR) e 3) coinfecção TB/HIV. Desta forma, existem três listas, cada uma contendo 30 países (WHO, 2016). O Brasil faz parte de duas delas, a primeira referente à carga da doença e a segunda diz respeito à coinfecção TB/HIV. Somado a isso, o país ainda compõe um bloco de países denominados como BRICS (Brasil, Rússia, Índia, China e África do Sul), os quais representam cerca de 50\% dos casos mundiais de tuberculose (WHO, 2016).

Estima-se que em 2016 tenham ocorrido 10,4 milhões de casos novos de TB no mundo, e 1,3 milhão de mortes pela doença, dados alarmantes, tendo em vista que o diagnóstico e tratamento da doença são conhecidos e disponíveis gratuitamente à população (WHO, 2017).

Em 2016, o Brasil apresentou incidência de 42 casos por 100.000 habitantes e mortalidade de 2,6 para cada 100.000 habitantes e uma taxa de sucesso de tratamento de $71 \%$ entre os pacientes seguidos em 2014, resultados aquém das recomendações da Organização Mundial de Saúde (OMS) (BRASIL, 2017).

Após o alcance da meta até o ano de 2015, e a reclassificação dos países prioritários para controle da TB, a OMS ingressou na luta contra a TB pós-2015 com o lançamento de uma nova e mais rigorosa meta, denominada Estratégia End TB, que se sustenta em três pilares que consistem na prevenção e cuidado integrado e centrado no paciente; políticas arrojadas e sistema de apoio, e ainda, intensificação da pesquisa e inovação (MIGLIORI; SOTGIU, 2015).

A Estratégia End $T B$ prevê também a redução dos óbitos em $95 \%$ até 2035, considerando a situação epidemiológica de 2015 e ainda eliminação da doença até 2050 ( $<1$ caso por 100.000 habitantes), o que representa um grande desafio aos países em desenvolvimento, principalmente para um país com grandes dimensões territoriais como o Brasil, o qual ocupa cerca de 20,8\% da área total da América e 47,3\% da América do Sul (BRASIL, 2017; LONNROTH; RAVIGLIONE, 2016).

Assim, a OMS tem buscado todas as medidas para aliviar o sofrimento humano decorrente da TB, fazendo vítimas fatais notadamente em áreas mais vulneráveis e pobres. Segundo dados da OMS (2017), apesar da disponibilidade das tecnologias de diagnóstico e tratamento, há questões de logística e infraestrutura que impedem que essas tecnologias cheguem de forma praticamente universal e equitativa a todas as populações. Assim, o óbito ganha expressão importante na presente dissertação, haja 
vista que ele é uma resultante de fatores de ordem social, antropológica, cultural e dos serviços de saúde; a morte por TB se traduz em faltas de oportunidades e do não acesso ou acessibilidade aos serviços de saúde, um problema de equidade, o que deve ser investigado criteriosamente.

Um trabalho muito interessante de Ribeiro (2015) traz reflexões sobre a equidade e a justiça social na saúde, a justiça social estaria vinculada à noção de igualdade na distribuição dos recursos/ bens na saúde, o que ficaria a encargo das diferentes instituições que compõem o Estado. Para o autor, a justiça valoriza a igualdade em determinado espaço, todavia as pessoas são tão diferentes em diversos aspectos de suas vidas, nas condições econômicas, nas biológicas, nos ideais e nos planos de vida, assim, como se deve igualar para que haja justiça?

Essa é uma questão que se coloca nas mortes por TB: como se oportunizar condições e qualidade de vida, para prevenção dessas mortes? A resposta disto é bastante complexa e esbarra no cultural, político e ideológico (que não é objeto da presente tese), todavia, do ponto de vista jurídico-legal, como reza o artigo $6^{\circ}$ da Constituição de 1988, é responsabilidade do Estado oferecer condições para o desenvolvimento social e humano de sua população e protegê-la em situação de fraqueza e ou vulnerabilidade. Está amparada nesse artigo uma série de dispositivos que assegure à população todo o básico necessário para a sua existência digna (PESSOA, 2011).

Ainda retomando o trabalho de Ribeiro (2015), e tornando mais palpável a diferença entre equidade e justiça, a igualdade seria uma imagem-objetivo, o que se pretende alcançar com a justiça - quais são os concernidos e o que igualar para propósitos de justiça, ao ponto de que a equidade está relacionada às estratégias de políticas públicas que visam superar a desigualdade entre aqueles que alcançaram e os que não alcançaram a igualdade pretendida.

Desse modo, a igualdade não é senão o patamar que se pretende alcançar, sendo as ações de equidade uma medida adotada no sentido de alcançar esse objetivo. Ribeiro (2015) é muito coerente no sentido de estabelecer níveis de equidade, classificando-a em duas dimensões: a da equidade horizontal, de tratar pessoas iguais de modo equivalente, e a da equidade vertical, de tratamento diferenciado àquelas que por sua essência são diferentes, buscando-se assim a justiça.

Desse modo, para o estudo é importante ter clareza acerca das concepções de justiça e equidade que estão circunscritas a presente tese. E sob estas definições é que se 
presente analisar as mortes por tuberculose, que por sua essência se traduzem como fragilidade por parte do Estado em contemplar tais dimensões de igualdade e oportunidades.

Uma questão igualmente complexa é perceber as diferenças que há no Brasil em termos das mortes por $\mathrm{TB}$, havendo áreas mais em risco do que outras da ocorrência desse evento, o que é bastante preocupante. O Brasil é um país por essência de grandes dimensões territoriais, quase que um continente, o que implica grandes diferenças entre as suas regiões, não somente do ponto de vista cultural, da língua e dos seus ambientes (seis biomas), mas também diferenças em termos de oportunidades quanto a recursos de saúde e desenvolvimento; o pais assina uma lista entre aqueles com maior desigualdade social, perdendo para países como Serra Leoa, Lesoto e Namibe (THE WORLD BANK, 2017)

Assim, o lançamento da estratégia End TB é um desafio grande para o país, haja vista que nem todas as suas subunidades conseguirão satisfazer às metas dessa estratégia (ALBUQUERQUE et al., 2009), o que obriga aproximações desses locais no sentido de evidenciar a situação epidemiológica da TB e seus indicadores em termos de evolução da doença.

Em se tratando de mortes por tuberculose e sendo este evento intrinsecamente relacionado aos ambientes e ou espaço onde as populações vulneráveis habitam, tornase relevante buscar metodologias que sejam sensíveis e ou possam evidenciar a dinâmica e ou impacto desse evento.

Dessa forma, inicialmente buscou-se por meio do Mapeamento Sistemático da Literatura (MSL) uma abordagem exploratória no sentido de trazer estudos que se propuseram investigar as mortes por TB no espaço e, ainda, observar qual o tipo de ferramenta ou técnica de análise espacial tem sido usada evidenciando a dinâmica da doença em dadas comunidades e tendências em termos do cumprimento da estratégia End TB, e, como um exercício acadêmico, também evidenciar as lacunas de conhecimento e sustentar a originalidade do estudo. 


\section{MAPEAMENTO SISTEMÁTICO DA LITERATURA}

"O saber a gente aprende com os mestres e os livros. A sabedoria, se aprende é com a vidae com os humildes" (Cora Coralina) 
A análise espacial é considerada como importante instrumento de avaliação de doenças, pois ajuda a evidenciar a subnotificação de agravos e obter taxas fidedignas por meio do mapeamento dos casos. Estas técnicas contribuem para o avanço na gestão pública e no fortalecimento das ações da vigilância da saúde (HINO et al., 2013; SALES et al.; 2010).

Vários estudos estão sendo realizados em diversos cenários como África, China e Brasil (SANTO-NETO et al., 2015, SARTORIUS et al., 2013; MUSENGE, VOUNATSOU, KAHN, .,2011), e Portugal (NUNES, 2007) referentes à epidemiologia da TB e aos sistemas de informação geográfica.

Para melhor compreender sobre os atuais estudos de análise espacial no âmbito da mortalidade por TB, realizou-se o Mapeamento Sistemático da Literatura (MSL).

Define-se MSL como um método que elabora um esquema de classificação e estrutura em um campo de interesse, tendo como resultado a apresentação do Estado da arte referente a uma temática (PETERSEN et al., 2008). Desta forma, pode ser caracterizado como uma revisão de estudos primários numa área específica que busca identificar quais evidências estão disponíveis nessa área (KITCHENHAM, 2007).

O termo "Sistemático" refere-se aos conceitos das Práticas Baseadas em Evidências, procedimentos que visam eliminar vieses na localização, seleção e extração dos conteúdos das referências (PROENÇA-JÚNIOR; SILVA, 2016).

Kitchenham (2007), contrastou as diferentes características do processo de revisão sistemática da literatura e estudos de MSL. Existem diferenças em relação às questões de pesquisa, processo de busca, requisitos de estratégia de pesquisa, avaliação de qualidade e resultados.

As questões de pesquisa nos estudos de MSL são gerais, pois visam descobrir tendências de pesquisa (por exemplo, tendências de publicação ao longo do tempo, tópicos abordados na literatura). Por outro lado, as revisões sistemáticas visam a agregação de evidências e, portanto, um objetivo muito específico deve ser formulado (por exemplo, se uma intervenção tem utilidade prática na indústria).

Ressalta-se que tanto o MSL, quanto as Revisões Sistemáticas de Literatura (RSL) constituem-se como importantes métodos de síntese de evidência, os quais seguem processos rigorosos, objetivos, transparentes e passíveis de auditagem/auditoria, que visam minimizar o viés de seleção dos pesquisadores (KITCHENHAM, 2007; CRUZ-BENITO, 2016). 
Por se tratar de análises rigorosas, cabe ressaltar que a engenharia de software vem avançando para construção de ferramentas que auxiliam durante todo o processo de automatização, colaborando para otimização das etapas de análise para a construção das RSLs e MSLs.

Para este estudo foi utilizado como ferramenta computacional o software Start (State of the Art through Systematic Review), o qual proporciona mais qualidade e confiabilidade na aplicação das técnicas exigidas para seleção de estudos (HERNANDES et. al, 2012).

É importante frisar a relevância da realização do MSL, levando-se em conta que a partir dos resultados foi possível conhecer mais sobre a aplicação das técnicas de análise espacial no contexto da mortalidade por TB, uma doença milenar que ainda atinge negativamente a sociedade a nível mundial.

Para esta pesquisa, utilizaram-se como referência as diretrizes de Petersen et al 2008 para as etapas do Mapeamento Sistemático da Literatura (Figura 1)

Figura 1- Etapas do processo de Mapeamento Sistemático segundo Petersen e colaboradores, 2008

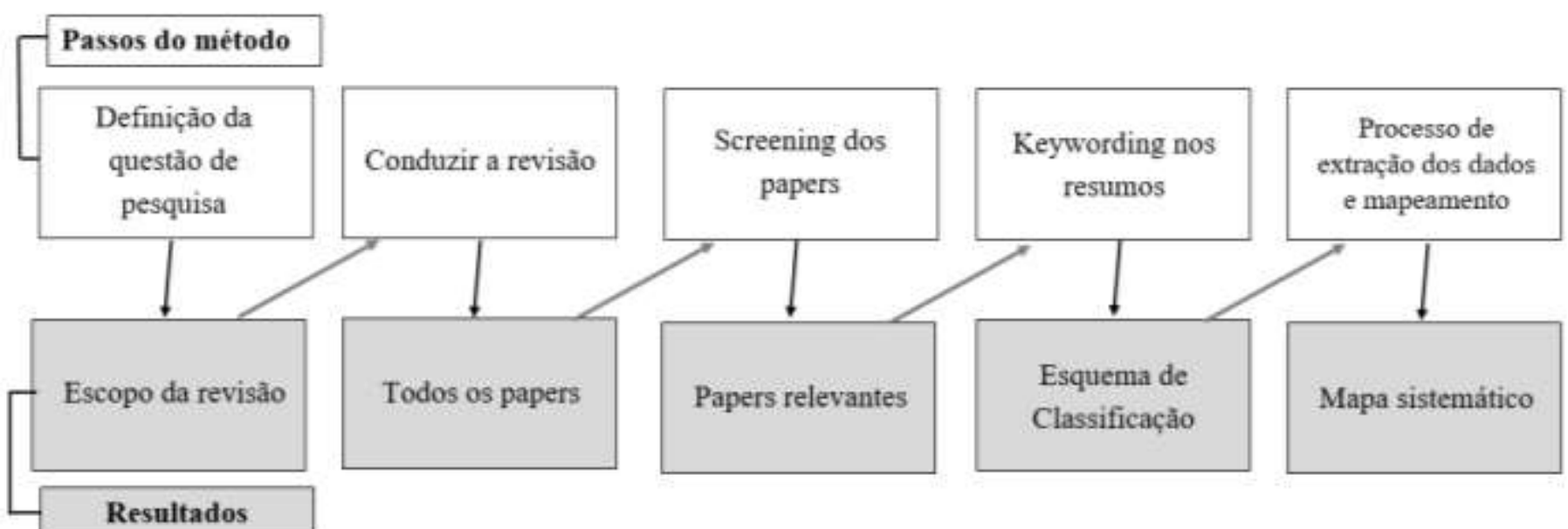

Fonte: Adaptado Petersen e colaboradores (2008)

\subsection{Definição da questão de pesquisa do MSL}

Obteve-se como objetivo do MSL a identificação das principais técnicas de análise espacial utilizadas no contexto da mortalidade por tuberculose no cenário mundial. Sendo assim, a elaboração da questão de pesquisa baseou-se na estratégia do acrômio PICO, cujo significado consiste em Problema, Intervenção; Controle (ou comparação); Outcomes (desfecho de interesse) (GALVÃO; PEREIRA, 2014). 
O Quadro 1 apresenta os componentes estabelecidos para a formulação da pesquisa científica.

Quadro 1-Componentes da questão de pesquisa

\begin{tabular}{|c|c|c|}
\hline Descrição & Acrônimo & Componentes da pesquisa \\
\hline População & P & Casos de tuberculose \\
\hline Intervenção & I & $\begin{array}{c}\text { Utilização das técnicas de análise } \\
\text { espacial para vigilância em saúde }\end{array}$ \\
\hline Comparação & $\mathbf{C}$ & $\begin{array}{c}\text { Não se aplica, pois se trata de uma } \\
\text { revisão de caracterização }\end{array}$ \\
\hline $\begin{array}{c}\text { Outcomes } \\
\text { (Desfecho) }\end{array}$ & O & Óbito/Morte \\
\hline
\end{tabular}

Fonte: próprio autor

A partir da definição dos componentes formulou-se a seguinte questão de pesquisa:

Quais as principais técnicas de análise espacial utilizadas no contexto da mortalidade por tuberculose?

Para melhor descrição dos estudos encontrados elaboraram-se ainda as questões secundárias (Qs):

Qs1- Como se encontram os estudos de mortalidade por TB de acordo com autor, ano e periódico de publicação, objetivos e resultados da análise espacial?

Qs2-Quais são as técnicas de análise espacial mais utilizadas sobre a mortalidade por TB?

Qs3-Quais são as unidades de análise usadas com maior frequência para as análises espaciais sobre a mortalidade por TB?

Qs4-Quais países tem empregado com maior frequência a abordagem espacial para a mortalidade por TB?

Qs5-Quais as principais contribuições das técnicas de análise espacial para a vigilância da saúde?

\subsection{Condução da revisão}

Primeiramente, foram selecionadas as seguintes bases de dados: Biblioteca Virtual em Saúde- BVS (http://bvsalud.org/); PubMed (ncbi.nlm.nih.gov/pubmed); Scopus (scopus.com/periódico.capes.gov.br); EMBASE (http://www.embase.com) CINAHL (http://web.a-ebscohost-com.ez67.periodicos.capes.gov.br/). 
As bases de dados eletrônicas utilizadas foram as disponibilizadas pela Coordenação de Aperfeiçoamento de Pessoal de Nível Superior (CAPES), acessadas por meio dos serviços de conteúdo (Proxy) da Universidade de São Paulo - Campus Ribeirão Preto.

Em seguida, realizou-se a consulta ao Medical Subject Heading (MeSH) e aos Descritores em Ciências da Saúde- DECS (decs.bvs.br), para seleção dos descritores: "Tuberculose/Tuberculosis"; "Análise espacial/Spatial Analysis/ Análisis Espacial”; "Mortalidade/ Mortality/ Mortalidad" e seus sinônimos, combinadas com os operadores boolianos apropriados (OR e AND), conforme demonstra o Quadro 2.

Adotaram-se como critérios de elegibilidade: artigos disponíveis na íntegra, publicados no período de 2007 a 2017, nos idiomas português, inglês e espanhol. Foram excluídas dissertações, teses e notas editorais e também artigos com repetição nas bases de dados.

Quadro 2- Estrutura da estratégia de busca, segundo descritores

\begin{tabular}{|c|c|c|}
\hline Descrição & Acrônimo & Decs/ Mesh \\
\hline População & $\mathrm{P}$ & Tuberculose OR sinônimos \\
\hline & & AND \\
\hline Intervenção & $\mathrm{I}$ & Análise espacial OR sinônimos \\
\hline & & AND \\
\hline $\begin{array}{c}\text { Outcomes } \\
\text { (Desfecho) }\end{array}$ & $\mathrm{O}$ & Mortalidade OR sinônimos \\
\hline
\end{tabular}

Fonte: próprio autor

Nas bases de dados, as exportações dos artigos foram feitas nas extensões Medline, Ris e Bibtex e em seguida os dados foram importados para o software StArt (State of the Art through Systematic Review) versão 2.3.4.2 (ZAMBONI, 2010), o qual serviu como apoio na identificação dos artigos duplicados, excluídos, incluídos e demais processos do MSL.

A estratégia de busca foi realizada respeitando as peculiaridades de cada base de dados (Apêndice A).

\subsection{Sreening dos papers}

Após a elaboração do banco de dados com os papers encontrados, foram aplicados os critérios de inclusão e exclusão, conforme Quadro 3: 
Quadro 3- Critérios de inclusão e exclusão para seleção dos papers

\begin{tabular}{|l|l|}
\hline \multicolumn{1}{|c|}{ Critérios de Inclusão } & \multicolumn{1}{|c|}{ Critérios de Exclusão } \\
\hline - Responder aos objetivos desta pesquisa; & - Não responder aos objetivos dessa \\
- Artigos publicados com texto na íntegra; & pesquisa; \\
- Publicado no período de 2007 a 2017; & - Publicação de resumo; \\
- Estar nos idiomas português, inglês ou & - Publicado fora do período de 2007 a \\
espanhol; & 2017; \\
- Abordar técnicas espaciais; & - Estar fora dos idiomas português, inglês \\
- Pesquisa realizada com seres humanos. & ou espanhol; \\
& - Não abordar técnicas espaciais; \\
& - Pesquisa realizada com animais. \\
\hline
\end{tabular}

Fonte: próprio autor

\subsection{Keywording dos resumos}

Nesta etapa, foram selecionados artigos que apresentaram informações no título, resumo e palavras-chave relacionadas à questão de pesquisa principal. Para cada estudo que foi incluído ou excluído foi selecionado pelo menos um critério (Inclusão ou Exclusão).

\subsection{Processo de extração dos dados e mapeamento}

Nessa etapa foi feita leitura na íntegra dos estudos selecionados, realizando-se uma análise mais minuciosa de cada um, a fim de identificar e extrair dados de acordo com os critérios de inclusão e exclusão, bem como obter as respostas para as questões secundárias anteriormente formuladas.

\subsection{Sumarização dos resultados}

A partir das strings(explicar no rodapé) de busca e fontes definidas de acordo com o protocolo descrito, foram encontrados 455 estudos não duplicados: 73 foram identificados na base de dados Pubmed, 315 na BVS, 42 na EMBASE e 18 na CINAHL.

Após aplicação dos critérios de elegibilidade, permaneceram 25 estudos, dos quais, ao término da leitura na integra e aplicação dos critérios de inclusão e exclusão, obtiveram-se 11 estudos para extração dos dados.

A Figura 2 apresenta o diagrama do Preferred Reporting Items for Systematic Reviews and Meta-Analyses (PRISMA) (MOHER et al, 2010), que ilustra a dinâmica do processo de identificação e seleção dos artigos para análise. 
Figura 2- Diagrama do processo de seleção dos artigos (2007- 2017)

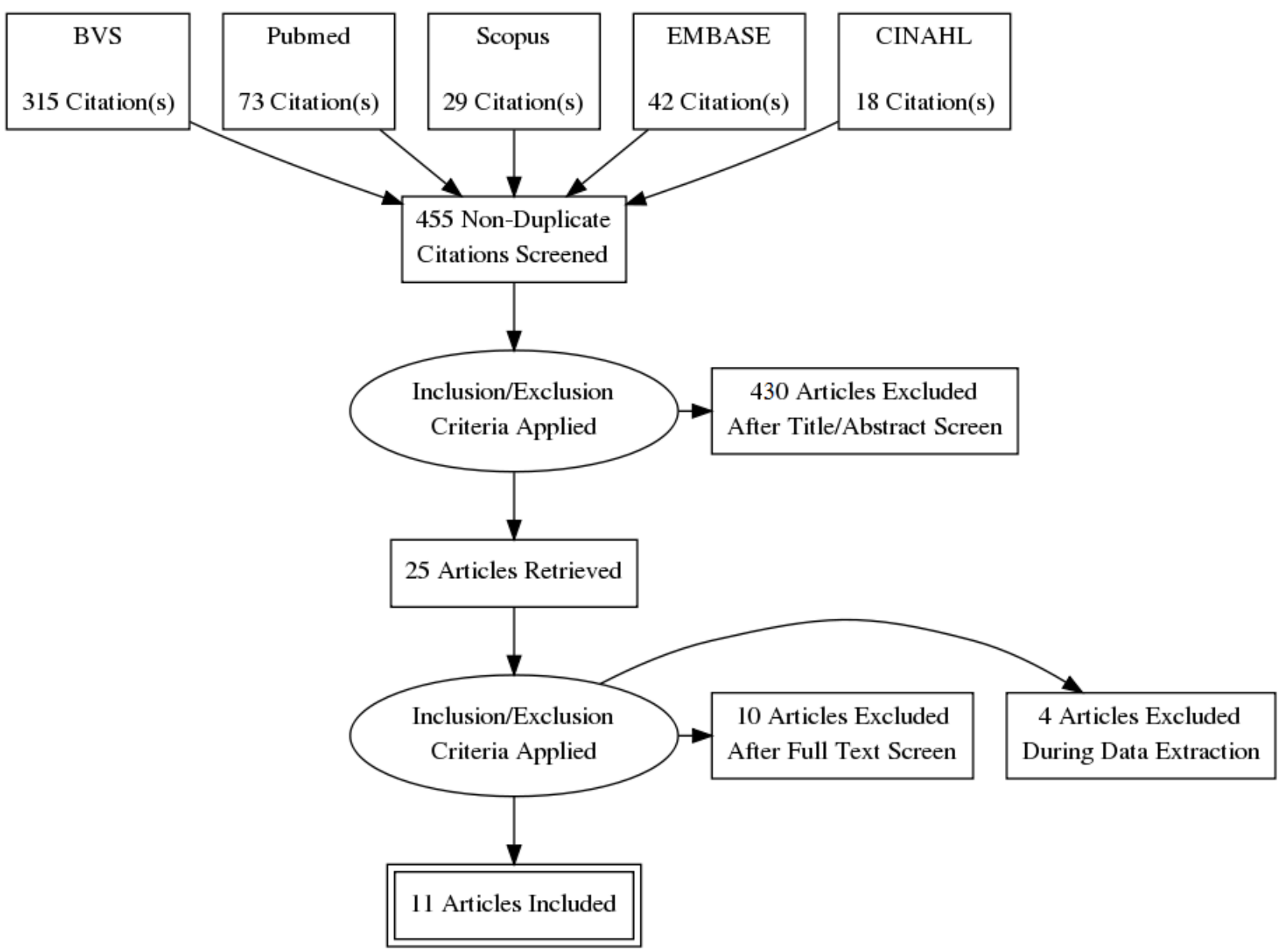

Fonte: Adaptado do diagrama da recomendação PRISMA (2015)

Ressalta-se que, durante o processo do MSL, encontram-se algumas variáveis que podem determinar viés nos resultados (KITCHENHAM, 2007), como pode ocorrer durante a elaboração do protocolo de busca, mesmo que tenha havido uma ampla discussão com especialistas na temática. Além disso, nesse MSL não foi possível utilizar uma equipe com múltiplos revisores. Estes acontecimentos podem impactar nos resultados encontrados.

Após a seleção dos estudos a serem incluídos no MSL, no intuito de responder à questão secundária "Qs1-Como se encontram os estudos de mortalidade por TB de acordo o com autor, ano e periódico de publicação, objetivos e resultados da análise espacial?" foi elaborado um quadro (Quadro 4) com a sumarização dos mesmos, contendo um código de identificação (ID), os autores, título, ano e periódico de publicação, bem como os objetivos e principais resultados do estudo. 
Quadro 4- Descrição dos estudos incluídos no mapeamento sistemático (2007-2017)

\begin{tabular}{|c|c|c|c|c|c|}
\hline ID & $\begin{array}{c}\text { Autor e Ano } \\
\text { de Publicação }\end{array}$ & Título & Periódico & Objetivos & $\begin{array}{l}\text { Principais } \\
\text { resultados }\end{array}$ \\
\hline E01 & $\begin{array}{c}\text { YAMAMURA } \\
\text { et al., } 2017\end{array}$ & $\begin{array}{l}\text { Areas with evidence of } \\
\text { equity and their } \\
\text { progress on mortality } \\
\text { from tuberculosis in an } \\
\text { endemic municipality } \\
\text { of southeast Brazil }\end{array}$ & $\begin{array}{l}\text { Infectious } \\
\text { Diseases of } \\
\text { Poverty }\end{array}$ & $\begin{array}{c}\text { Identificar áreas } \\
\text { geográficas que } \\
\text { mostraram } \\
\text { progressos em } \\
\text { termos de } \\
\text { equidade (de } \\
\text { renda, } \\
\text { escolaridade e } \\
\text { ocupação urbana) } \\
\text { e testar seu efeito } \\
\text { na mortalidade por } \\
\text { TB em um } \\
\text { município do } \\
\text { sudeste do Brasil. }\end{array}$ & $\begin{array}{l}\text { Identificou-se } \\
\text { associação } \\
\text { negativa entre } \\
\text { equidade social e } \\
\text { óbitos por TB. }\end{array}$ \\
\hline E02 & $\begin{array}{c}\text { BERRA et al., } \\
2017\end{array}$ & $\begin{array}{c}\text { Spatial risk of } \\
\text { tuberculosis mortality } \\
\text { and social } \\
\text { vulnerability in } \\
\text { Northeast Brazil }\end{array}$ & $\begin{array}{l}\text { Revista da } \\
\text { Sociedade } \\
\text { Brasileira de } \\
\text { Medicina } \\
\text { Tropical }\end{array}$ & $\begin{array}{c}\text { Analisar o risco } \\
\text { espacial da } \\
\text { mortalidade por } \\
\text { tuberculose e } \\
\text { verificar } \\
\text { associações em } \\
\text { áreas de alto risco } \\
\text { com } \\
\text { vulnerabilidade } \\
\text { social. }\end{array}$ & $\begin{array}{c}\text { Este estudo } \\
\text { comprovou que } \\
\text { as áreas com alto } \\
\text { risco para } \\
\text { mortalidade por } \\
\text { TB estão } \\
\text { associadas com e } \\
\text { a vulnerabilidade } \\
\text { social. }\end{array}$ \\
\hline E03 & $\begin{array}{l}\text { LIMA et al., } \\
\quad 2016\end{array}$ & $\begin{array}{l}\text { Mortality related to } \\
\text { tuberculosis- } \\
\text { HIV/AIDS co- } \\
\text { infection in Brazil, } \\
\text { 2000-2011: } \\
\text { epidemiological } \\
\text { patterns and time } \\
\text { trends. }\end{array}$ & $\begin{array}{c}\text { Cadernos de } \\
\text { saude publica }\end{array}$ & $\begin{array}{c}\text { Analisar os } \\
\text { padrões } \\
\text { epidemiológicos e } \\
\text { as tendências } \\
\text { temporais da } \\
\text { mortalidade } \\
\text { relacionada à } \\
\text { coinfecção TB- } \\
\text { HIV / AIDS no } \\
\text { Brasil, de } 2000 \text { a } \\
2011 . \\
\end{array}$ & $\begin{array}{l}\text { As regiões Sul e } \\
\text { Sudeste } \\
\text { apresentaram as } \\
\text { maiores taxas de } \\
\text { mortalidade } \\
\text { relacionado à co- } \\
\text { infecção TB- } \\
\text { HIV/AIDS }\end{array}$ \\
\hline E04 & $\begin{array}{l}\text { SANTOS- } \\
\text { NETO et al., } \\
2015\end{array}$ & $\begin{array}{c}\text { Pulmonary } \\
\text { tuberculosis in Sao } \\
\text { Luis, State of } \\
\text { Maranhão, Brazil: } \\
\text { space and space-time } \\
\text { risk clusters for death } \\
\text { (2008-2012). }\end{array}$ & $\begin{array}{l}\text { Revista da } \\
\text { Sociedade } \\
\text { Brasileira de } \\
\text { Medicina } \\
\text { Tropical }\end{array}$ & $\begin{array}{c}\text { Identificar } \\
\text { aglomerados de } \\
\text { risco espaço- } \\
\text { temporal para a } \\
\text { ocorrência de } \\
\text { óbitos em uma } \\
\text { cidade prioritária } \\
\text { para controle de } \\
\text { TB no Nordeste do } \\
\text { Brasil. }\end{array}$ & $\begin{array}{l}\text { Identificou } \\
\text { aglomerados de } \\
\text { risco para a } \\
\text { mortalidade por } \\
\text { TB. }\end{array}$ \\
\hline
\end{tabular}




\begin{tabular}{|c|c|c|c|c|c|}
\hline ID & $\begin{array}{c}\text { Autor e Ano } \\
\text { de Publicação }\end{array}$ & Título & Periódico & Objetivos & $\begin{array}{l}\text { Principais } \\
\text { resultados }\end{array}$ \\
\hline E05 & $\begin{array}{l}\text { SANTOS- } \\
\text { NETO et al., } \\
2014\end{array}$ & $\begin{array}{l}\text { Spatial analysis of } \\
\text { deaths from } \\
\text { pulmonary } \\
\text { tuberculosis in the city } \\
\text { of Sao Luis, Brazil. }\end{array}$ & $\begin{array}{c}\text { Jornal } \\
\text { Brasileiro de } \\
\text { Pneumologia }\end{array}$ & $\begin{array}{c}\text { Caracterizar } \\
\text { mortes por } \\
\text { tuberculose } \\
\text { pulmonar, de } \\
\text { acordo com } \\
\text { variáveis } \\
\text { sociodemográficas } \\
\text { e operacionais, na } \\
\text { cidade de São } \\
\text { Luís, Brasil, e } \\
\text { descrever sua } \\
\text { distribuição } \\
\text { espacial. }\end{array}$ & $\begin{array}{c}\text { Identificou que a } \\
\text { distribuição da } \\
\text { mortalidade por } \\
\text { TB é } \\
\text { heterogênea. }\end{array}$ \\
\hline E06 & $\begin{array}{l}\text { CHAN TC et } \\
\text { al., } 2014\end{array}$ & $\begin{array}{l}\text { Geographic disparity } \\
\text { in chronic obstructive } \\
\text { pulmonary disease } \\
\text { (COPD) mortality } \\
\text { rates among the } \\
\text { Taiwan population. }\end{array}$ & PloS one & $\begin{array}{c}\text { Análise dos } \\
\text { aglomerados } \\
\text { espaço-temporais } \\
\text { de } \\
\text { Mortalidade } \\
\text { relacionada à } \\
\text { DPOC e explorar } \\
\text { suas correlações } \\
\text { com } \\
\text { fatores de risco } \\
\text { específicos locais. }\end{array}$ & $\begin{array}{c}\text { Identificou } \\
\text { aglomerados } \\
\text { espaciais para } \\
\text { ocorrência do } \\
\text { óbito por TB, } \\
\text { identificou que a } \\
\text { maioria da } \\
\text { população com } \\
\text { TB era do sexo } \\
\text { masculino. }\end{array}$ \\
\hline E07 & $\begin{array}{l}\text { SARTORIUS } \\
\text { B et al., } 2013\end{array}$ & $\begin{array}{l}\text { Dying in their prime: } \\
\text { determinants and } \\
\text { space-time risk of } \\
\text { adult mortality in } \\
\text { rural South Africa }\end{array}$ & $\begin{array}{c}\text { Geospatial } \\
\text { health }\end{array}$ & $\begin{array}{l}\text { Investigar a } \\
\text { dinâmica, as } \\
\text { tendências, a } \\
\text { causalidade e as } \\
\text { implicações da } \\
\text { mortalidade na } \\
\text { África do Sul. }\end{array}$ & $\begin{array}{c}\text { Apontou que a } \\
\text { mortalidade por } \\
\text { TB possui grande } \\
\text { peso para a } \\
\text { formação de } \\
\text { aglomerados de } \\
\text { risco para } \\
\text { mortalidade por } \\
\text { doenças } \\
\text { infecciosas. }\end{array}$ \\
\hline E08 & $\begin{array}{l}\text { MUSENGE E } \\
\text { et al., } 2013\end{array}$ & $\begin{array}{l}\text { The contribution of } \\
\text { spatial analysis to } \\
\text { understanding HIV/TB } \\
\text { mortality in } \\
\text { children: a structural } \\
\text { equation modelling } \\
\text { approach. }\end{array}$ & $\begin{array}{c}\text { Global health } \\
\text { action }\end{array}$ & $\begin{array}{c}\text { O principal } \\
\text { objetivo era } \\
\text { investigar } \\
\text { determinantes da } \\
\text { mortalidade por } \\
\text { HIV/TB em } \\
\text { crianças e sua } \\
\text { distribuição } \\
\text { espacial } \\
\text { num subdistrito } \\
\text { rural. } \\
\end{array}$ & $\begin{array}{l}\text { Os modelos } \\
\text { espaciais } \\
\text { revelaram que as } \\
\text { áreas que tiveram } \\
\text { maior } \\
\text { mortalidade por } \\
\text { HIV / TB foram } \\
\text { aquelas sem } \\
\text { nenhum tipo de } \\
\text { serviço de saúde. }\end{array}$ \\
\hline E09 & $\begin{array}{c}\text { YANG et al., } \\
2013\end{array}$ & $\begin{array}{c}\text { Epidemiology of } \\
\text { pulmonary } \\
\text { tuberculosis in } \\
\text { Wenchuan earthquake } \\
\text { stricken area: } \\
\text { population-based } \\
\text { study. }\end{array}$ & $\begin{array}{l}\text { Journal of } \\
\text { Evidence- } \\
\text { Based } \\
\text { Medicine }\end{array}$ & $\begin{array}{c}\text { Para explorar a } \\
\text { distribuição } \\
\text { espaço-temporal e } \\
\text { os fatores } \\
\text { associados da TB } \\
\text { pulmonar em } \\
\text { Wenchuan. }\end{array}$ & $\begin{array}{l}\text { Detectou } \\
\text { aglomerados de } \\
\text { risco espaciais } \\
\text { em cinco } \\
\text { distritos. } \\
\text { Continua... }\end{array}$ \\
\hline
\end{tabular}




\begin{tabular}{|c|c|c|c|c|c|}
\hline ID & $\begin{array}{c}\text { Autor e Ano } \\
\text { de Publicação }\end{array}$ & Título & Periódico & Objetivos & $\begin{array}{l}\text { Principais } \\
\text { resultados }\end{array}$ \\
\hline E10 & $\begin{array}{l}\text { YAMAMURA } \\
\text { et al., } 2015\end{array}$ & $\begin{array}{l}\text { Epidemiological } \\
\text { characteristics of cases } \\
\text { of death from } \\
\text { tuberculosis and } \\
\text { vulnerable territories }\end{array}$ & $\begin{array}{c}\text { Revista } \\
\text { Latino- } \\
\text { americana de } \\
\text { Enfermagem }\end{array}$ & $\begin{array}{c}\text { Analisar a } \\
\text { distribuição } \\
\text { espacial dos } \\
\text { casos de óbito } \\
\text { por tuberculose } \\
\text { nos territórios } \\
\text { de Ribeirão } \\
\text { Preto, SP. }\end{array}$ & $\begin{array}{l}\text { A distribuição } \\
\text { dos óbitos não } \\
\text { ocorreu de forma } \\
\text { aleatória no } \\
\text { espaço. }\end{array}$ \\
\hline E11 & $\begin{array}{l}\text { MUSENGE et } \\
\text { al., } 2011\end{array}$ & $\begin{array}{c}\text { Space-time } \\
\text { confounding adjusted } \\
\text { determinants of child } \\
\text { HIV/TB mortality for } \\
\text { large zero-inflated data } \\
\text { in rural South Africa }\end{array}$ & $\begin{array}{c}\text { Spat. Spatio- } \\
\text { temporal } \\
\text { Epidemiology }\end{array}$ & $\begin{array}{c}\text { Compreender } \\
\text { geograficamente } \\
\text { os } \\
\text { fatores de risco } \\
\text { para mortalidade } \\
\text { por HIV / TB } \\
\text { infantil } \\
\text { na África do Sul } \\
\text { rural. }\end{array}$ & $\begin{array}{l}\text { A TB está entre } \\
\text { os fatores de } \\
\text { risco para a } \\
\text { mortalidade } \\
\text { infantil nas áreas } \\
\text { rurais da África. }\end{array}$ \\
\hline
\end{tabular}

Fonte: próprio autor

Posteriormente, foi elaborado o gráfico correspondente à questão secundária “Qs2-Quais são as técnicas de análise espacial mais utilizadas sobre a mortalidade por $T B$ ? Segundo os estudos incluídos nesse MSL, as técnicas de análise espacial mais usadas foram as Regressões espaciais (40\%), seguido do Estimador de intensidade Kernel (30\%) e Estatística de Varredura (20\%).

Figura 3- Técnicas de análise espacial utilizadas em estudos sobre mortalidade por Tuberculose, segundo o Mapeamento Sistemático (2007-2017)

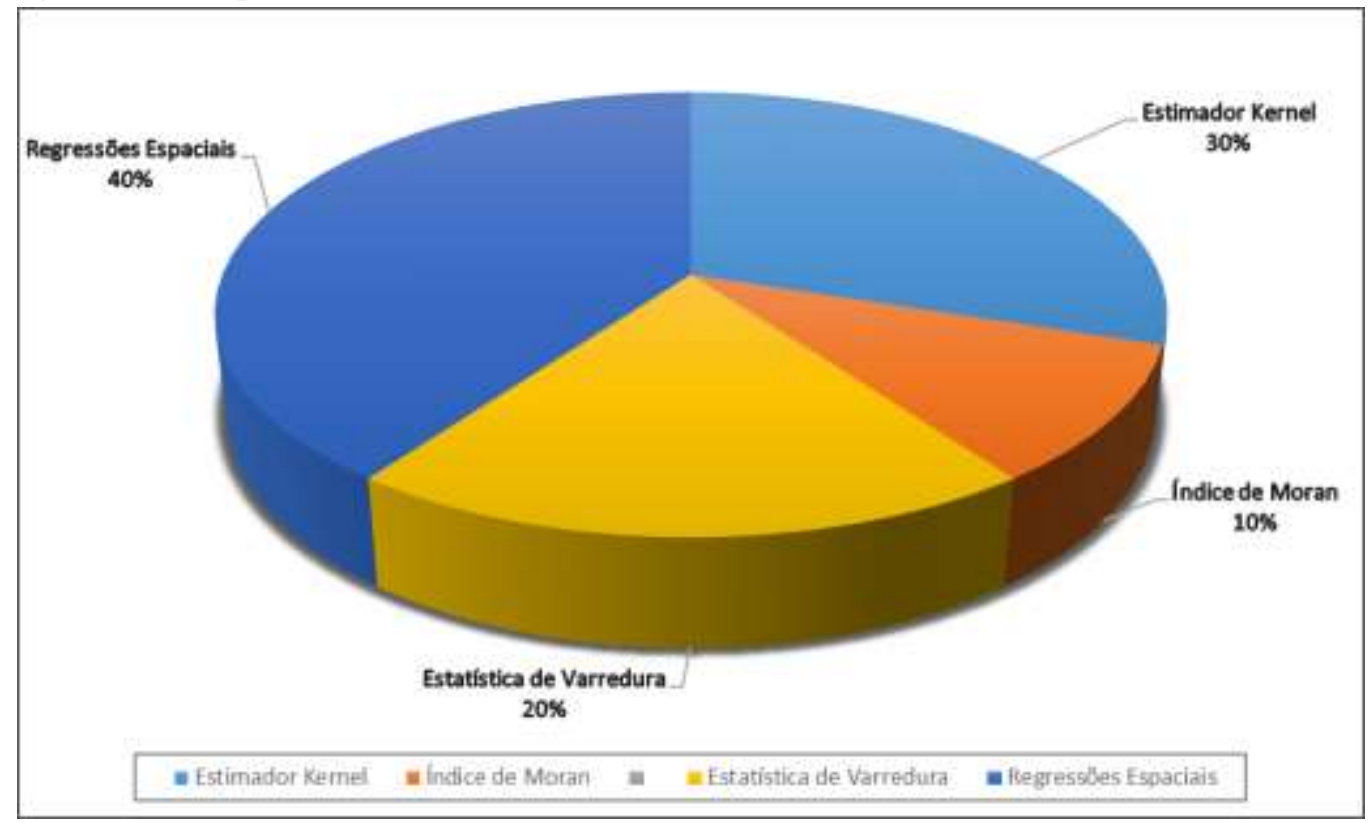


A Figura 4 demonstra os achados equivalentes à questão secundária "Qs3-Quais são as unidades de análise usadas com maior frequência para as análises espaciais sobre a mortalidade por TB", sendo evidenciado os Setores censitários como as unidades de análise mais frequentes $(42 \%)$.

Figura 4- Unidades de análise utilizadas em estudos sobre mortalidade por Tuberculose, segundo o Mapeamento Sistemático da Literatura (2007-2017)

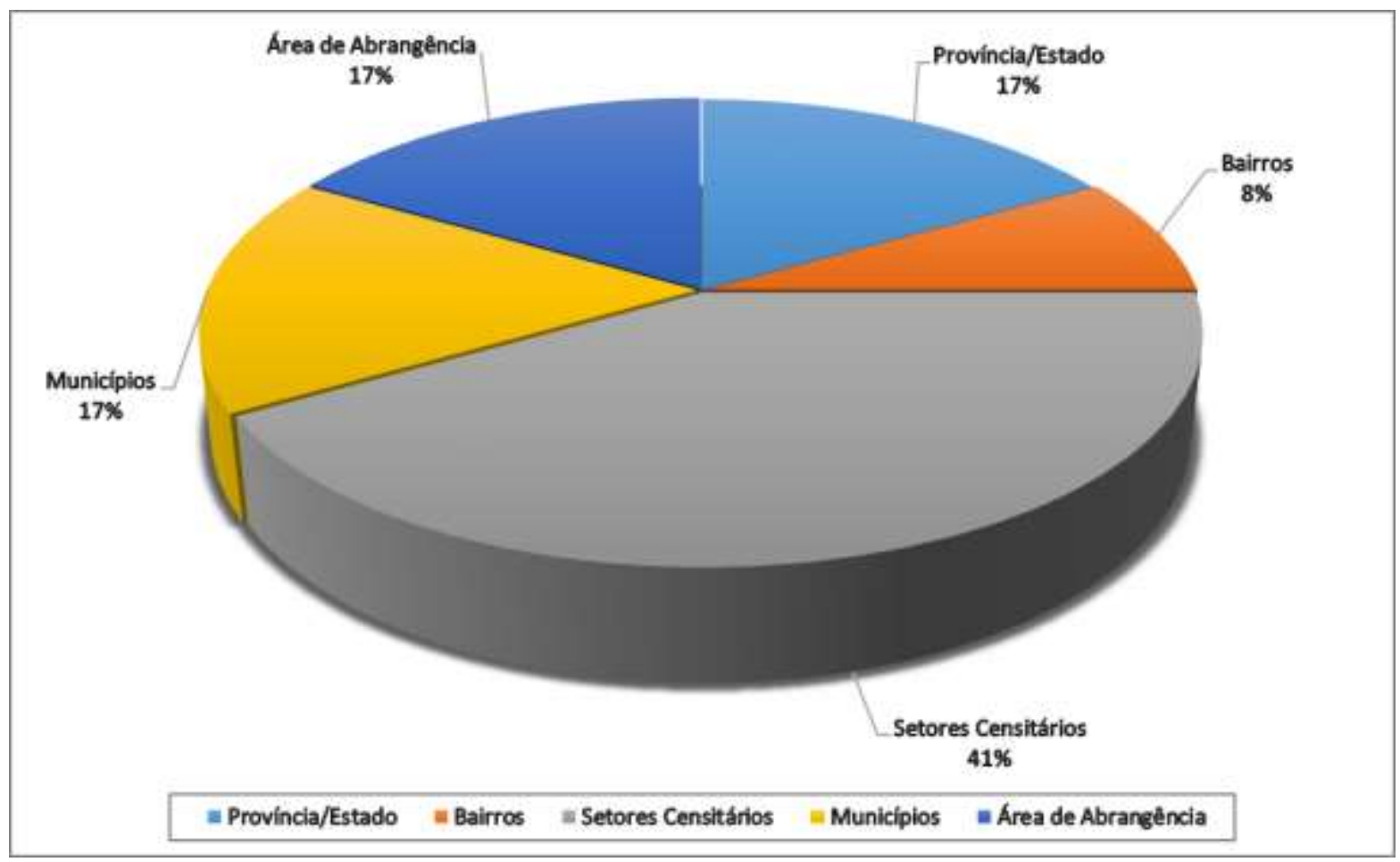

Fonte: próprio autor

No que se refere a "Qs4-Quais países tem empregado com maior frequência a abordagem espacial para a mortalidade por TB?", a Figura 5 evidenciou que mais da metade dos estudos foi realizada no Brasil (54\%). Um fator importante a destacar é que os países que usufruíram de tais análises fazem parte daqueles que concentram mais de $80 \%$ da carga mundial da doença e são classificados como prioritários para o controle da TB. 
Figura 5- Países que utilizaram técnicas de análise espacial para a mortalidade por Tuberculose, segundo o Mapeamento Sistemático da Literatura (2007-2017)

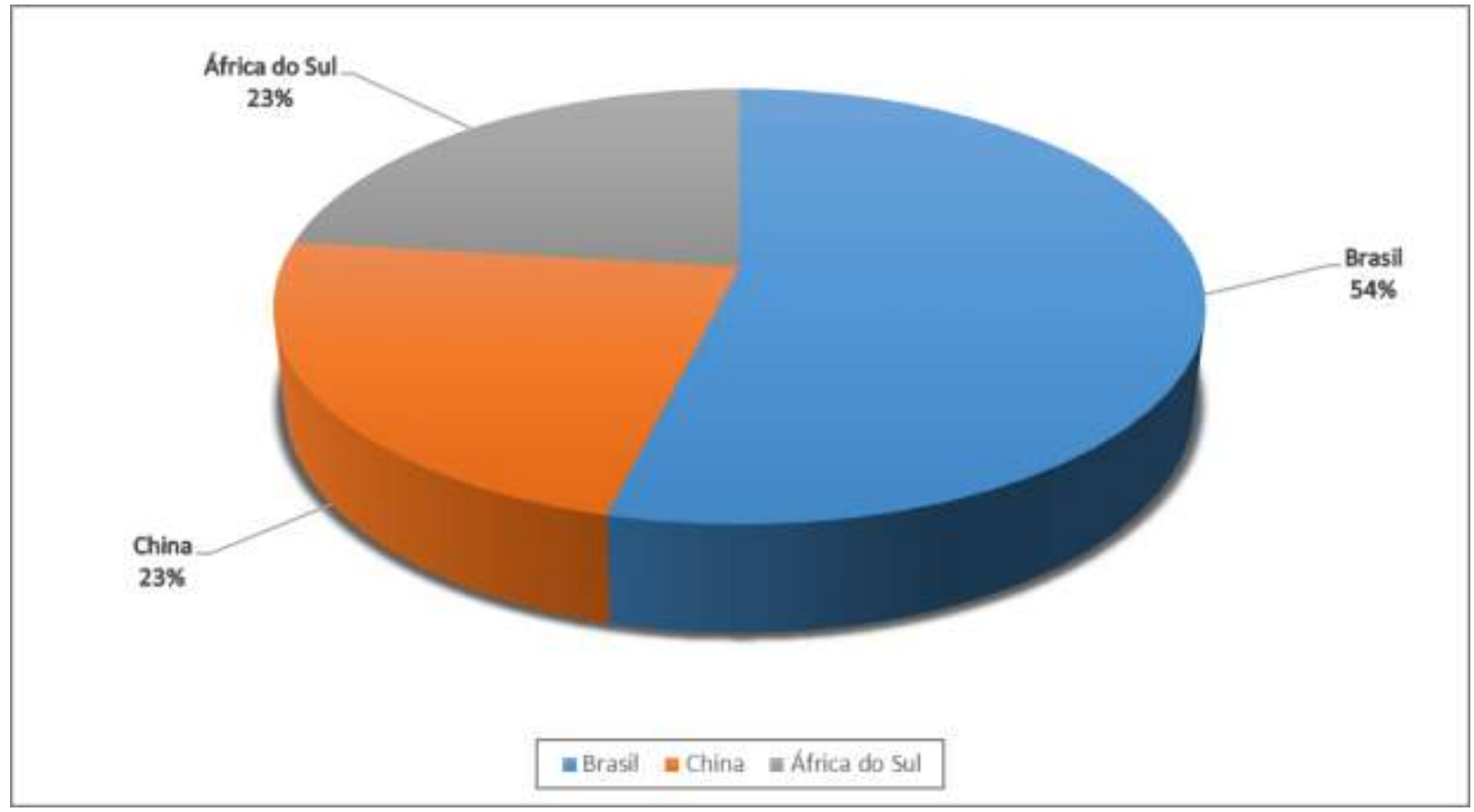

Fonte: próprio autor

A última questão secundária consistiu em: "Qs5-Quais as principais contribuições das técnicas de análise espacial para a vigilância da saúde?" Esta questão de pesquisa não foi incluída especificamente na estratégia de busca como um descritor, pois, já era esperado um número reduzido de estudos que abordassem a análise espacial sobre a mortalidade por TB, sendo assim, a inclusão do tema VS restringiria ainda mais a busca dos estudos.

Nesse sentido, no intuito de levantar dados sobre a VS e compreender o peso que os estudos de análise espacial sobre a mortalidade por TB têm dado a essa importante temática da saúde pública, optou-se por realizar a presente estratégia de busca e incluir uma questão secundária sobre a VS.

Para a obtenção da resposta a essa questão, foi realizado um levantamento, nos estudos incluídos nesse MSL, dos principais apontamentos sob a ótica da Vigilância da Saúde e em seguida, realizou-se uma categorização das informações encontradas, pautadas nos conceitos de VS, sendo elas: Identificação de áreas prioritárias para o controle da TB; Planejamento de ações intersetoriais, Orientar políticas públicas de saúde, Subsidiar escolhas de estratégias para as intervenções em saúde. Com base neste categorização, foi elaborado um diagrama (Figura 6) que evidencia- tais resultados. 
Figura 6- Categorização das principais contribuições dos estudos de análise espacial sobre a mortalidade por Tuberculose, segundo o Mapeamento Sistemático da Literatura (20072017)

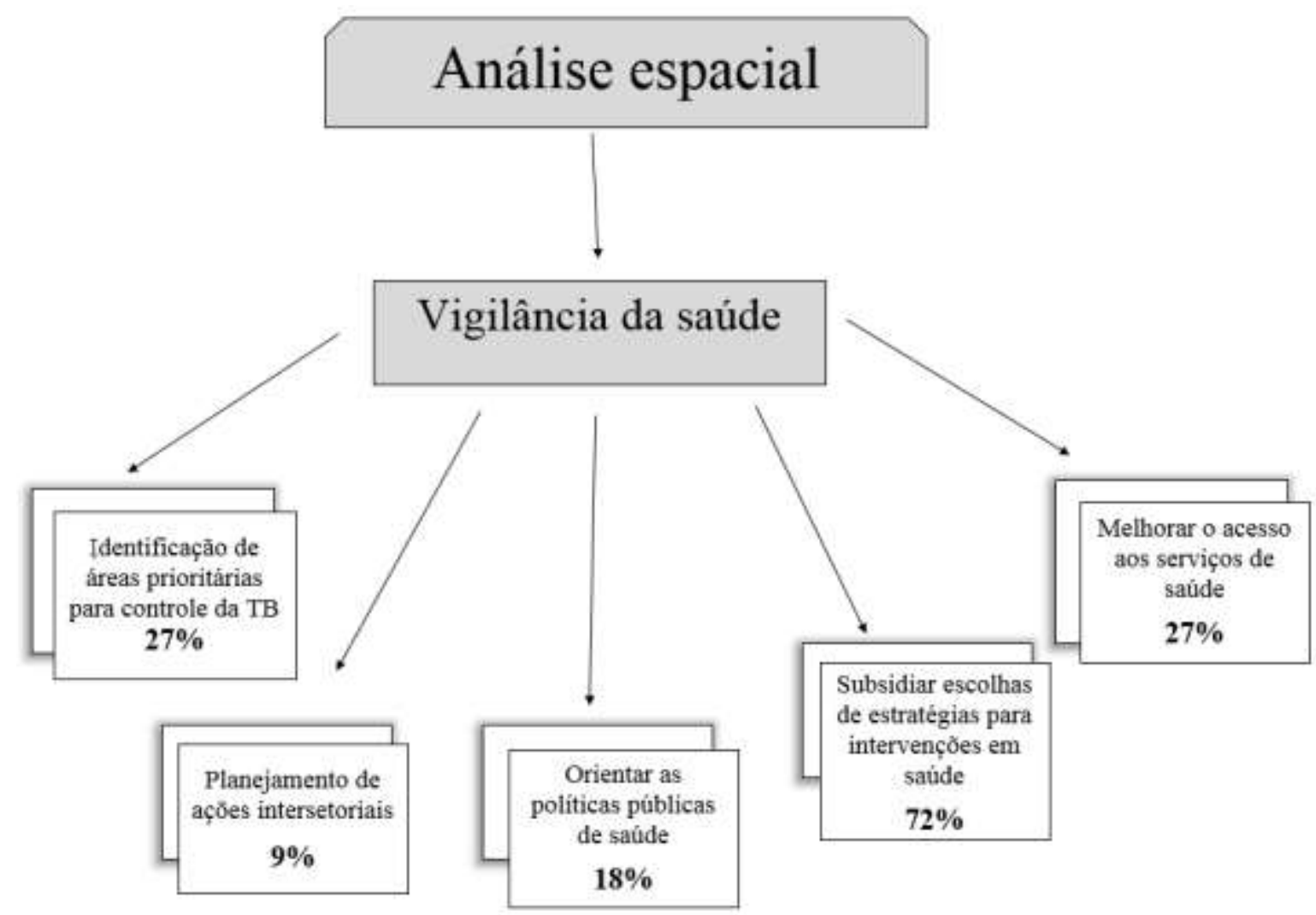

Fonte: próprio autor

\subsection{Análise dos resultados do MSL e Lacuna do conhecimento}

A realização deste MSL possibilitou identificar os estudos sobre a mortalidade por TB que utilizaram métodos de análise espacial. Observou-se que a quantidade de estudos sobre a mortalidade por TB é bem extensa, porém, após a realização da triagem dos resumos e leitura na íntegra dos papers, quanto aos estudos que também abordavam a análise espacial ficou evidente a grande redução do " $n$ " desses estudos, sendo que foram incluídos nesse MSL apenas 11 estudos.

Observou-se que os estudos estão sendo realizados principalmente nos países prioritários para o controle da TB, mais especificamente os países da BRICS, sendo que: segundo com o "Plano nacional pelo fim da tuberculose como problema de saúde pública", publicado recentemente, o cenário brasileiro, juntamente com a China, está entre os seis países que concentram 60\% dos casos novos de TB (BRASIL, 2017).

Por serem países cujo o enfrentamento da TB tem sido tratado de forma prioritária devido à alta carga que a doença apresenta, certamente há uma influência e 
motivação desses países em se dedicarem na intensificação de pesquisas científicas que contribuam para a identificação das áreas mais vulneráveis para a ocorrência da TB e igualmente para a mortalidade. E, nesse contexto, destaca-se a escolha das análises espaciais como ferramentas importantes para a VS no sentido de ações de promoção, prevenção e controle da doença.

Em relação aos métodos empregados nos estudos selecionados, pode-se observar que a abordagem mais frequente foram Regressões Espaciais, o que permite observar associação das mortes a distintos determinantes, conforme a pressuposição e ou hipótese do estudo. Pode-se observar que o estudo E1 investigou a relação de Indicadores de Equidade com a taxa bayesiana da mortalidade por TB, já o E8 mostrou os determinantes da mortalidade de TB em crianças portadoras do HIV.

Em seguida, têm-se a análise de densidade de pontos através do estimador de intensidade Kernel, que permitiu identificar as áreas mais vulneráveis para ocorrência do óbito (DAVIES; HAZELTON, 2010), sendo os estudos E5, E7, E10 exemplos de tal abordagem.

As técnicas de aglomerados espaciais são usadas para verificar a existência de áreas de risco por meio da constatação de um número acima do esperado de casos excessivamente próximos (KULLDORFF, 1995). Desta forma, o estudo E2 evidenciou os aglomerados de risco espacial para a mortalidade por $\mathrm{TB}$ ao Índice de vulnerabilidade Social do município, da mesma forma o E4 apresentou que as áreas com aglomerados espaciais de risco para o óbito por TB correspondem as regiões desassistidas em termos de condições sociais.

Ainda sobre o estudo E2, ele certificou a dependência espacial da mortalidade por TB e sua associação às áreas com maior vulnerabilidade social; uma técnica utilizada foi o Índice de Moran (I).

Quanto ao nível de agregação espacial dos estudos, pode-se observar que os mais frequentes foram os setores censitários, sendo importante reforçar que a escolha do nível de agregação de dados é relevante para o delineamento da pesquisa, haja vista a influência sobre a forma e estrutura que terão a base de dados e a base cartográfica (BARCELLOS; SANTOS, 1997).

Somado a isso, os setores censitários, por serem o menor nível de agregação espacial trazem como benefício identificar características singulares que não podem ser coletadas ou compreendidas em níveis de agregação com maior extensão. Além disso, outro fator relevante consiste nas pesquisas sociodemográficas realizadas no âmbito 
nacional, as quais são baseadas nos setores censitários, sendo assim, o uso desse nível de agregação como unidade de análise permite a construção de indicadores com maior facilidade (BARCELOS; SANTOS, 1997).

Através da realização do MSL, foi possível observar que o óbito por TB ainda está relacionado com a associação de diversas barreiras, como falhas no acesso por questões geográficas, culturais, econômicas, organizacionais e de gênero.

Por meio deste MSL, pôde-se constatar a escassez de estudos sobre mortalidade por TB com abordagem espacial, o que torna o estudo inédito e original. É sabida a relevância do ambiente no que tange ao adoecimento e morte por TB, havendo áreas de proteção e de risco, porém poucos estudos têm dado ênfase à essa dimensão.

Outra justificativa do estudo consiste na sua contribuição ao país, ao evidenciar diferenças no território no que tange às mortes por TB. Ele poderá orientar políticas públicas referentes a adoção de medidas interventivas para acabar com tais disparidades e reduzir as injustiças por meio da equidade.

Acresce-se ainda, como destaque ao estudo, o emprego da Estatística de Varredura, a qual consiste em um interessante recurso quando se tem fenômenos menos frequentes e ou raros como a mortalidade por tuberculose, haja vista que ela acomete percentuais menores da população e em situação de vulnerabilidade e iniquidade. 


\subsection{Objetivo geral}

Investigar áreas de risco de mortes por tuberculose em Londrina/Paraná.

\subsection{Objetivos específicos}

1) Descrever características sociodemográficas e clínico epidemiológicas dos óbitos por tuberculose em Londrina;

2) Descrever a distribuição espacial dos óbitos por tuberculose, segundo os setores censitários do Censo Demográfico 2010;

3) Investigar a dependência espacial das taxas de mortalidade por tuberculose;

4) Identificar padrão de concentração dos casos de óbitos por tuberculose;

5) Detectar aglomerados de risco de mortes por tuberculose por meio da Estatística de Varredura Espacial Tradicional e Isotônica;

6) Realizar uma análise comparativa dos resultados da aplicação da Estatística de Varredura Espacial Tradicional com a Estatística de Varredura Espacial Isotônica. 


\section{MODELO TEÓRICO}

"Foi o tempo que dedicaste à tua rosa que a fez tão importante"

(Antoine Saint Exupèry) 
Antes de adentrar os métodos utilizados para responder os objetivos da tese e estando ela inscrita em um programa de pós-graduação Enfermagem em Saúde Pública, foi necessário definir um quadro teórico para que se pudesse cotejar os resultados.

Desse modo, definiu-se a Vigilância em Saúde (VS) como eixo orientador do trabalho científico, haja vista que esta pode ser definida como um modelo tecnológico da organização do trabalho em saúde (não exercido somente pelo profissional de saúde, mas todo e qualquer ator interessado ou atuante na área da saúde) que tem como objeto de suas práticas o território, entendendo o território não como um processo estanque estático - território solo, dado e completo, mas como um processo social e constante mudança e transformação, resultante das relações sociais existentes nele, das suas forças políticas, econômicas, sociais, culturais e de valores ideológicos/ políticos (MENDES, 1993).

$\mathrm{Na}$ literatura se deparada com distintas definições de território, a saber: este pode ser visto como uma porção específica da Terra marcada com sua natureza, pela história de sua sociedade e também pela sua localização em diferentes escalas, como a global, continental, regional, estadual, município, bairro, até uma única casa (CORRÊA, 1999).

Segundo Santos (1988) o território apresenta-se indissociavelmente ligado a um conjunto de sistemas de objetos (fixos) criados pelo homem ou naturais, tais como prédios, estradas, árvores e montanhas, como também de ações (fluxos) que se referem à circulação de pessoas, mercadorias e ideias.

Nessa perspectiva, pode-se dizer que a inter-relação e a distribuição entre o sistema de objetos fixos e seus fluxos, além de sua forma de organização, disposição e construção, caracterizam a estrutura do território (MONKEN, 2003)

Para Santos (1998), a concepção de território considera todos os objetos existentes como sistemas combinados e utilizados pelos grupos humanos, e pode ser entendido como construção social, cujos elementos constitutivos são os homens, o meio ecológico, a materialização do trabalho em formas, as empresas responsáveis pela produção de bens, serviços, normas, etc.

Desta forma, a identificação e localização dos objetos, seus usos pela população e sua importância para os fluxos das pessoas são de grande relevância para o conhecimento da dinâmica social, hábitos e costumes e também para a determinação de vulnerabilidades de saúde, originadas nas interações de grupos humanos nos espaços geográficos (MONKEN, 2003).

No contexto da "Vulnerabilidade", Ayres et al. (2009, p. 127) conceitua como: 
"A Chance de exposição das pessoas ao adoecimento como resultante de um conjunto de aspectos não apenas individuais, mas também coletivos e contextuais que acarretam maior suscetibilidade a infecção e ao adoecimento, assim como maior ou menor disponibilidade de recursos de todas as ordens para se proteger de ambos."

Ainda de acordo com Ayres et al. (2009), a avaliação da vulnerabilidade deve estar articulada em três eixos: 1) Eixo individual: refere-se ao grau e qualidade da informação de que os indivíduos dispõem sobre o problema, além da capacidade de levantar informações e preocupações para colocar em prática ações preventivas e protetoras; 2) Eixo Social: diz respeito à obtenção de informações e à possibilidade de processá-las no intuito de promover mudanças, além disso, também está associado ao acesso aos meios de comunicação, escolarização, serviços de saúde e disponibilidade de recursos materiais; 3) Eixo Programático: refere-se aos programas nacionais, regionais e locais para prevenção e cuidado do paciente.

Pautado nesse referencial, Maciel e Reis-Santos (2015) definiram o modelo conceitual para os determinantes da TB, conforme demonstra a Figura 7.

Figura 7- Determinantes da Tuberculose no Brasil, segundo Maciel e Reis-Santos (2015)

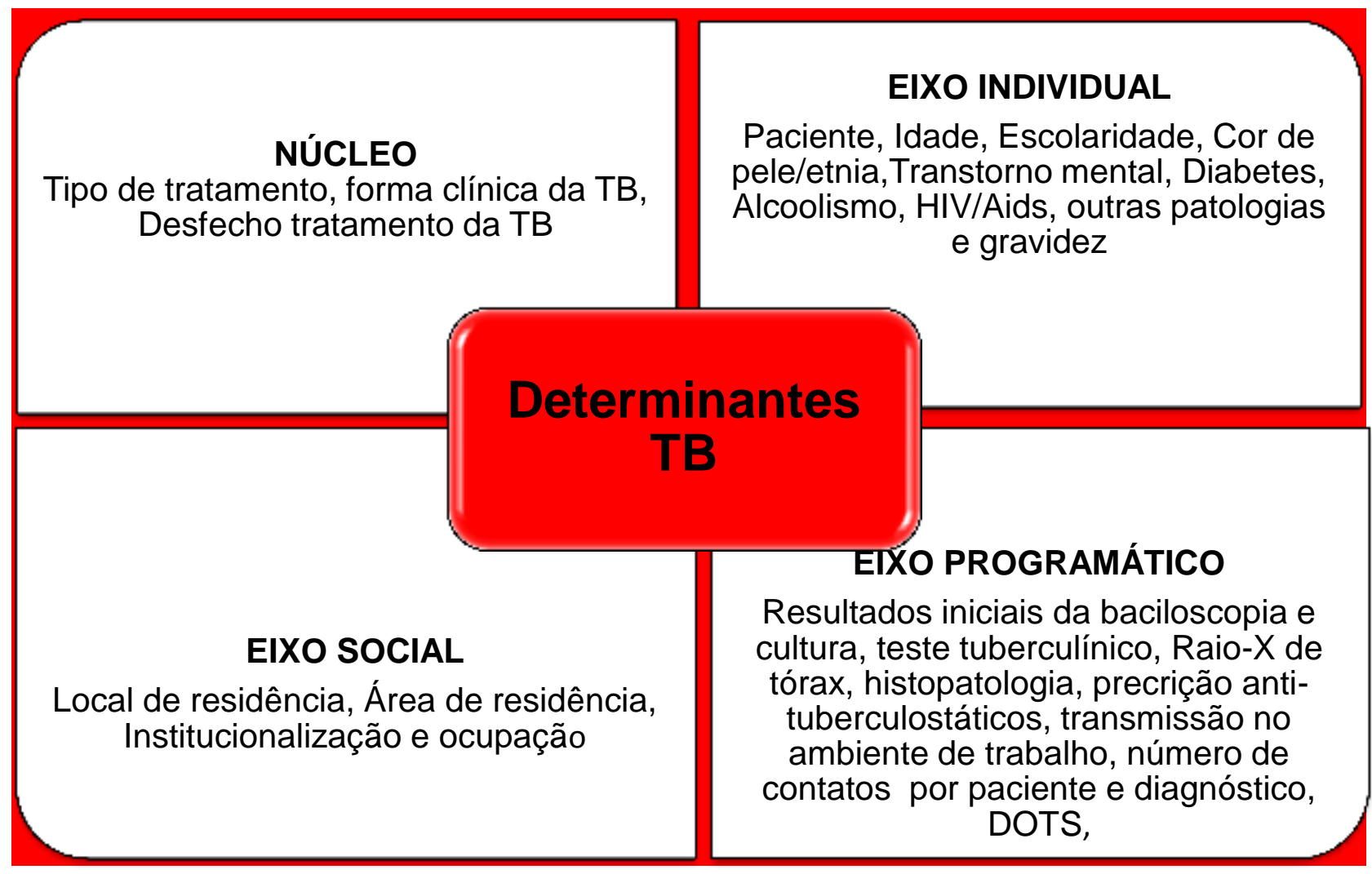

Fonte: Adaptado Maciel e Reis-Santos, 2015 
A partir do exposto, deve-se enfatizar que a promoção de ambientes saudáveis leva à a redução das vulnerabilidades e possíveis problemas de saúde, assim como a mortalidade por TB, e, para tal torna-se essencial um olhar que permita instrumentalizar o entendimento dos problemas de saúde, para que a partir deles seja possível promover as possíveis soluções através de estratégias singulares compatíveis com a situação de saúde de cada localidade (MONKEN et al., 2008).

Compreende-se promoção da saúde como um movimento social e de profissionais de saúde num enfoque político e técnico em torno do processo saúdedoença-cuidado. O conceito de promoção à saúde, de acordo com a Carta de Otawa de 1986, está associado a um conjunto de valores, dentre eles destacam-se a equidade, o desenvolvimento e a qualidade de vida, além da combinação de estratégias que podem ser realizadas desde o Estado e sistemas de saúde até os indivíduos, visando a resolução mútua para os problemas e soluções (BUSS; CARVALHO, 2009).

A Declaração de Sundsvall (1991) define ambiente sob uma concepção ampla, ou seja, perpassa a abordagem apenas geográfica, abrangendo também instâncias tanto físicas quanto sociais, econômicas, políticas e culturais. A construção destes ambientes saudáveis e favoráveis à saúde faz com que os espaços menos desenvolvidos, onde os problemas de saúde estão imbrincados, ganhem evidência e, desta forma, permite que estudos sejam desenvolvidos para a obtenção do diagnóstico situacional e entendimento dos problemas para desenvolver ações e soluções (BRASIL, 2002).

Ressalta-se, então, a importância das ações intersetoriais, as quais são caracterizadas mediante os processos de trabalho concretizados nos espaços sociais reais em que vive a população, no campo da saúde pública na dimensão da promoção da saúde (BUSS; CARVALHO, 2009).

Neste sentido, emerge a preocupação com a construção de um modelo assistencial que seja articulado com o conhecimento e técnicas oriundos da epidemiologia, do planejamento e das ciências sociais em saúde, e por isso neste contexto iniciaram-se discussões referentes ao termo "Vigilância da Saúde"

Teixeira, Paim e Vilasbôas (2000, p. 15) definem Vigilância da saúde como:

"Um conjunto de ações voltadas para o conhecimento, previsão, prevenção e enfrentamento continuado de problemas de saúde, selecionados e relativos aos fatores e condições de risco, atuais e potenciais, e aos acidentes, incapacidades, doenças- incluindo as 
zoonoses, e outros agravos à saúde de uma população num território determinado."

Sendo assim, a VS é motivada pela necessidade de ampliação das ações de vigilância epidemiológica, passando a contemplar os problemas de saúde e condições de vida da população (TEIXEIRA; PAIM; VILASBÔAS, 2000).

Ainda segundo os autores, a VS propõe a inserção de novos sujeitos, ultrapassando a equipe de profissionais de saúde e passa a envolver a população organizada, o que corresponde à ampliação do objeto além das determinações clínicoepidemiológicas no âmbito individual e coletivo.

O Quadro 5 sumariza as diferenças entre os modelos assistenciais hegemônicos (modelo medico-assistencial privatista e modelo sanitarista) a visão ampliada da VS.

Quadro 5- Modelos Assistenciais e Vigilância da Saúde (2000)

\begin{tabular}{|c|c|c|c|c|}
\hline Modelo & Sujeito & Objeto & Meios de Trabalho & Formas de organização \\
\hline $\begin{array}{c}\text { Médico } \\
\text { assistencial } \\
\text { privatista }\end{array}$ & $\begin{array}{c}\text { Médico } \\
\text { Espacialização } \\
\text { Complementariedade }\end{array}$ & $\begin{array}{c}\text { Doença } \\
\text { Doentes }\end{array}$ & $\begin{array}{c}\text { Tecnologia médica } \\
\text { (Indivíduo) }\end{array}$ & $\begin{array}{c}\text { Redes de serviços de saúde } \\
\text { Hospital }\end{array}$ \\
\hline Sanitarista & $\begin{array}{c}\text { Sanitarista } \\
\text { Auxiliares }\end{array}$ & $\begin{array}{c}\text { Modos de } \\
\text { transmissão } \\
\text { Fatores de } \\
\text { risco }\end{array}$ & Tecnologia sanitária & $\begin{array}{c}\text { Campanhas sanitaristas } \\
\text { Programas especiais } \\
\text { Sistemas de vigilância } \\
\text { epidemiológica e sanitária }\end{array}$ \\
\hline $\begin{array}{c}\text { Vigilância } \\
\text { da Saúde }\end{array}$ & $\begin{array}{c}\text { Equipe de saúde } \\
\text { População } \\
\text { (cidadãos) }\end{array}$ & $\begin{array}{c}\text { Danos, riscos, } \\
\text { necessidades } \\
\text { e } \\
\text { determinantes } \\
\text { dos modos de } \\
\text { vida e saúde }\end{array}$ & $\begin{array}{c}\text { Tecnologias de } \\
\text { comunicação social, } \\
\text { de planejamento e } \\
\text { programação local } \\
\text { situacional e } \\
\text { tecnologias médico- } \\
\text { sanitaristas }\end{array}$ & $\begin{array}{c}\text { Políticas públicas saudáveis } \\
\text { Ações intersetoriais } \\
\text { Intervenções específicas } \\
\text { (promoção, prevenção e } \\
\text { recuperação) }\end{array}$ \\
$\begin{array}{c}\text { Operações sobre problemas } \\
\text { e grupos populacionais }\end{array}$ \\
\hline
\end{tabular}

Fonte: Teixeira, Paim, Vilasbôas (2000; p. 56)

Dessa forma, pode-se perceber que a concepção de VS consiste num modelo assistencial que avança em relação aos modelos já existentes, redefinindo o objeto como as necessidades em saúde. Teixeira, Paim e Vilasbôas (2000) ressaltam ainda que:

"A Vigilância da Saúde supera a dicotomia entre as práticas coletivas (vigilância epidemiológica e sanitária) e as práticas individuais (assistência ambulatorial e hospitalar) através da incorporação das contribuições da nova geografia, do planejamento urbano, da epidemiologia, da administração estratégica e das ciências sociais em saúde, tendo como suporte político-institucional o processo 
de descentralização e de reorganização dos serviços e das práticas de saúde ao nível local. “

Segundo Teixeira, Paim e Vilasbôas (2000), para adotar a concepção ampliada da VS como um modelo de atenção à saúde ao nível municipal, são necessários avanços no processo de municipalização da gestão e gerência das unidades de saúde localizadas no território dos municípios, além disso, deve-se investir na reorganização da APS para que se tornem possíveis as ações intersetoriais partindo dos territórios da ESF.

Portanto, trata-se de desencadear um processo de construção das práticas de Vigilância da Saúde, tomando como eixo central o trinômio "informação-decisãoação", ou seja, uso de métodos/técnicas de planejamento que deem suporte ao processo de identificação e priorização de problemas de grupos populacionais de territórios (TEIXEIRA; PAIM; VILASBÔAS, 2000).

Portanto, tem-se como ponto de partida para o desencadeamento do processo de planejamento da VS a Territorialização do sistema municipal de saúde, isto é, o reconhecimento e o esquadrinhamento do território do município, o que implica no processo de coleta e sistematização de dados demográficos, socioeconômicos, políticoculturais, epidemiológicos e sanitários que, posteriormente, devem ser sistematizados de modo a se construírem os mapas básicos e temáticos do município (MONKEN et al., 2008).

Os mapas temáticos permitem a visualização ampla das redes sociais e de serviços de uma determinada população no seu território, deste modo, a realização da distribuição espacial dos principais problemas de saúde, identificados em função de informações epidemiológicas extraídas de bancos de dados oficiais, se torna uma ferramenta fundamental para subsidiar as ações de promoção à saúde decorrentes principalmente da ESF (SANTOS-NETO et al., 2014).

Ressalta-se que a ESF atua em sintonia com os princípios da VS, na medida em que elege como ponto central o estabelecimento de vínculos e a criação de laços de compromisso e corresponsabilidade entre os serviços de saúde e a população (GONZALES et al, 2015).

Somado a isso, de acordo com Hino et al. (2011), a ESF, no caso específico da TB, pode contribuir para o controle da doença, pois o trabalho é realizado de acordo com cada realidade local, e as equipes ainda desenvolvem atividades de educação em saúde, busca de sintomáticos respiratórios, realiza-se a supervisão medicamentosa, o monitoramento dos contactantes, a busca de faltosos, esclarecendo questões 
relacionadas à doença, tratamento e possíveis dúvidas que surjam no decorrer do tratamento, corroborando com as ações de promoção à saúde e construção dos ambientes mais saudáveis. Dessa forma, o enfoque através dos territórios concretos demonstra-se com grande utilidade para descrever estratégias e propor ações de promoção da saúde (BUSS; CARVALHO, 2009).

Partindo desse pressuposto, elaborou-se um quadro teórico explicativo sobre a importância da análise espacial como ferramenta norteadora para as ações da VS no controle da mortalidade por tuberculose, objeto de estudo da presente pesquisa. A Figura 8 apresenta a síntese do referencial teórico apresentado. 
Figura 8- Modelo teórico da importância da análise espacial para Vigilância da Saúde sob a ótica da mortalidade por

Tuberculose (2018)

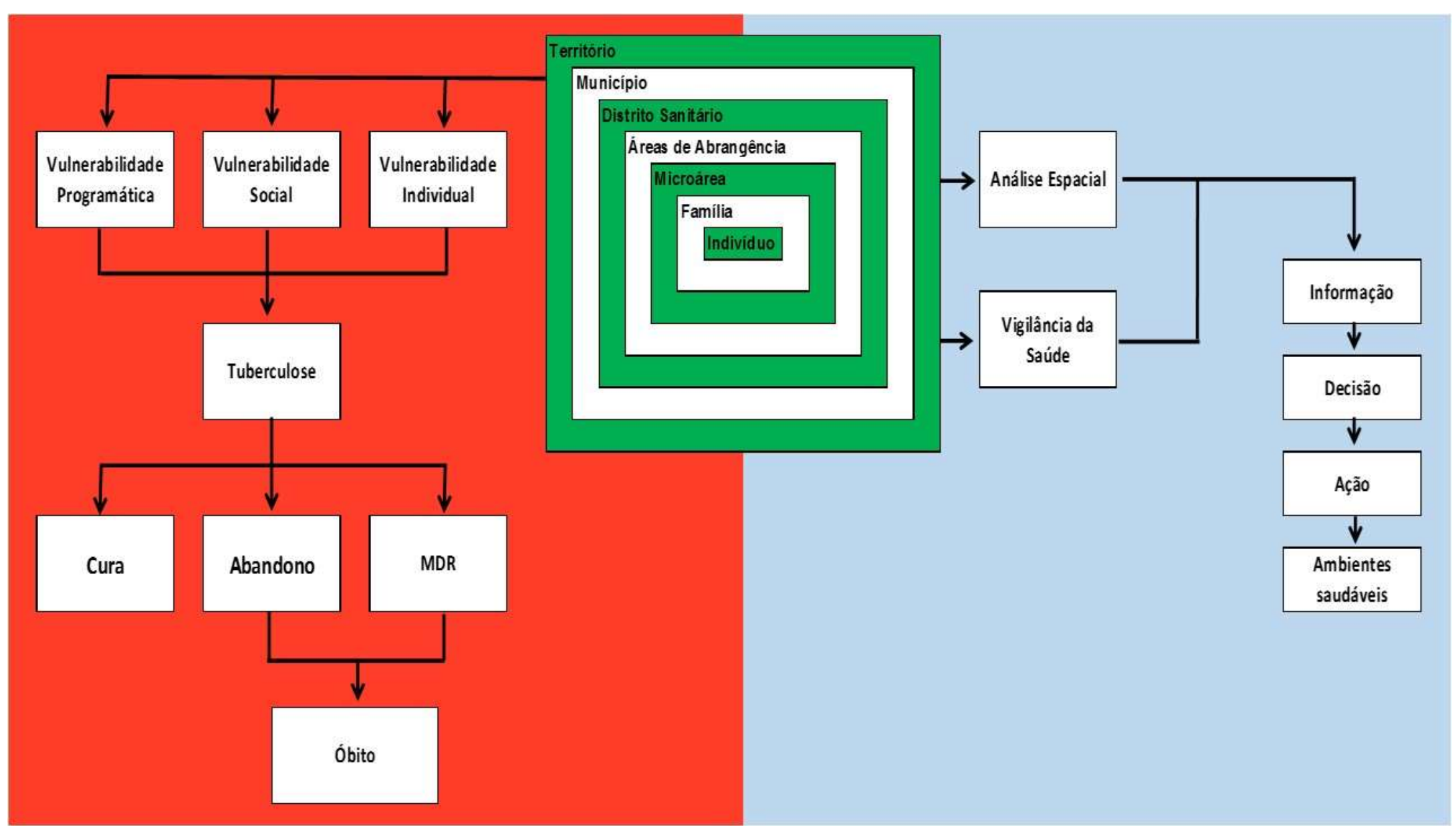

Fonte: Adaptado Maciel, Reis-Santos (2015); Teixeira, Paim, Vilasbôas (2000) 
Nesse sentido, o PNCT orienta que as ações para o controle da TB sejam descentralizadas e que haja a integração do controle da doença com a APS, incluindo o modelo de Programa dos Agentes Comunitários de Saúde (PACS) e do Programa Saúde da Família (PSF) para garantir a ampliação do acesso ao diagnóstico e ao tratamento (MARQUIEVIZ et al., 2013; BRASIL, 2011).

Destaca-se que o PSF está pautado no conceito de VS, tendo em vista a construção de vínculos e laços de compromisso e corresponsabilidade entre os serviços de saúde e a população, além de estabelecer o território como ferramenta fundamental para reorientação do processo de trabalho (HINO, 2011).

O conceito de VS surgiu como uma forma de ampliar a dicotomia Vigilância Epidemiológica e Sanitária, incorporando as contribuições da geografia, do planejamento urbano, da epidemiologia, da administração estratégica e das ciências sociais em saúde, pautando-se politicamente no processo de descentralização e reorganização dos serviços de saúde e da prática de saúde ao nível local (TEIXEIRA; PAIM; VILLASBÔAS, 2000).

As ferramentas propostas pela VS são utilizadas pelas equipes do PSF com a finalidade de garantir o acesso da população a diferentes atividades e ações de saúde e melhorando de maneira gradativa os principais indicadores de saúde e a qualidade de vida daquela comunidade (BRASIL, 2009).

Destaca-se, ainda, que o acesso aos serviços de saúde varia de região para região, o que faz com que os riscos de doença e, assim, seu prognóstico ou desfecho também sofram variações. O acesso dos usuários ao direito universal da saúde vai muito além da simples disponibilidade do estabelecimento em ofertar o atendimento, faz-se necessário uma nova consciência sanitária, construindo o sistema de saúde de acordo com as demandas determinadas pelas condições sociais (ASSIS; JESUS, 2012).

Portanto, embora existam esforços governamentais para melhorar os indicadores epidemiológicos da TB, vários são os fatores que influenciam no acesso aos serviços de saúde ofertados. Estes estão relacionados aos doentes (fatores demográficos, geográficos, socioeconômicos, culturais, religiosos e psíquicos), aos trabalhadores (tempo de formação, especialidade, características psíquicas, experiência profissional, tipo de prática), à organização dos Serviços de Saúde (recursos disponíveis e características da oferta) e à política utilizada (tipo de sistema de saúde, financiamento, distribuição dos recursos, quantidade, legislação e regulamentação profissional) (PALHA et al., 2012). 
Diante disso, emerge uma importante reflexão do impacto da APS no enfrentamento dos determinantes sociais, das condições de saúde e doença da população, tendo em vista a proximidade que as equipes de saúde da família estão dos sujeitos, da comunidade, do território e da realidade social enfrentada. Nesse sentido, faz-se necessário o desenvolvimento de ações em saúde prioritárias para aqueles grupos sociais mais afetados pela pobreza e pelas condições de vida sub-humanas, os quais experimentam mais severamente as doenças negligenciadas, como a TB (PLUG et al., 2012). 


\section{MATERIAIS E MÉTODOS}

"A persistência é o caminho do êxito"

(Charles Chaplin) 


\subsection{Desenho do estudo}

Trata-se de um estudo ecológico (ROTHMAN, GREENLAND; LASH, 2008).

\subsection{Cenário da pesquisa}

O estudo foi conduzido em Londrina, que está localizado na região norte do estado do Paraná (PR) e situa-se nas coordenadas geográficas $23^{\circ} 18^{\prime} \mathrm{S}$ latitude e $51^{\circ} 09^{\prime}$ W longitude (IPARDES, 2016). O município destaca-se como centro de desenvolvimento de negócios, tecnologia, pesquisa e saúde (PLANO MUNICIPAL 2014-2017). A Figura 9 ilustra a localização do município. 
Figura 9- Localização geográfica do município de Londrina/Paraná, Brasil (2018)
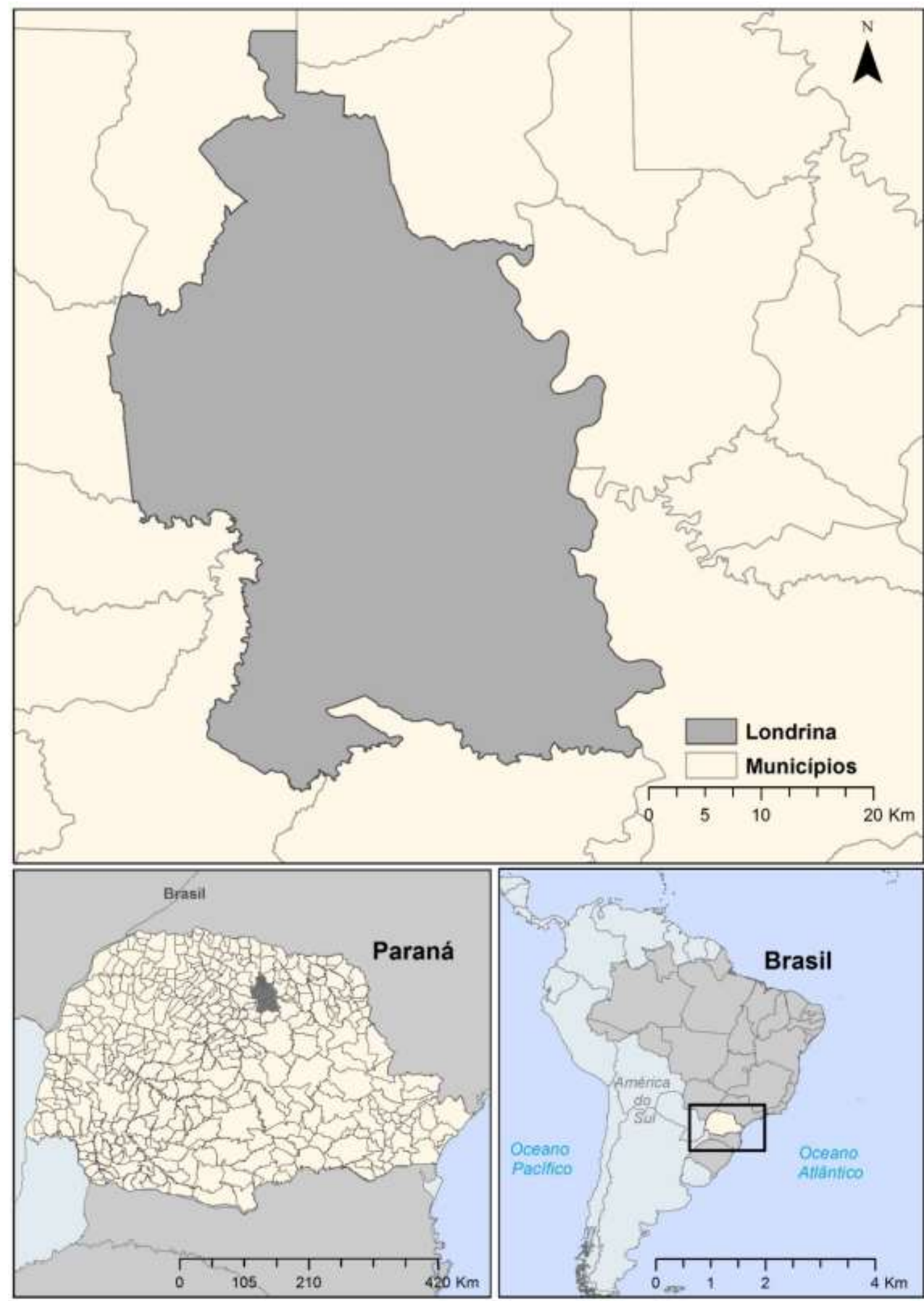

Fonte: próprio autor 
Londrina ocupa uma área de $1.656,606 \mathrm{Km}^{2}$, cerca de $1 \%$ da área total do Estado do Paraná. A zona urbana, uma área de $164.33 \mathrm{Km}^{2}$ e zona de expansão urbana $80,68 \mathrm{~km}^{2}$, totalizando $245,01 \mathrm{Km}^{2}$. A população municipal é de 548.249 habitantes, sendo a segunda cidade mais populosa do Paraná, destes, 493.520 concentram-se na área urbana. A densidade demográfica municipal é de 330.95 hab./Km² (IPARDES, 2016).

Quanto aos indicadores sociais, o município apresenta Índice de Desenvolvimento Humano Municipal (IDHM) de 0,78, classificado como Alto IDHM (0.700 a 0.799), segundo o Programa das Nações Unidades para o Desenvolvimento (PNUD). O atributo que mais contribui para o IDHM do município é a Longevidade, com índice de 0,837, seguida de Renda, com 0,789, e de Educação, com 0,712.

Referente à desigualdade social, o município apresenta Coeficiente de Gini 0,42 , contudo há desigualdade de distribuição de renda, pois a taxa de pobreza é de $36,5 \%$ (PNUD, 2014).

O município possui 56 Unidades Básicas de Saúde (UBS), 86 Equipes da Estratégia Saúde da Família (ESF) distribuídas em 54 UBS, o que possibilita a cobertura da ESF de 58.62\%. Ainda conta com 32 hospitais, e duas Unidades de Pronto Atendimento (UPA) (IPARDES, 2016; PREFEITURA MUNICIPAL DE LONDRINA, 2014).

Em 2015, Londrina apresentou taxa de incidência da TB de 32.95/100 mil habitantes, taxa de incidência de TB bacilífera foi de 17.16/100 mil habitantes e taxa de mortalidade, de 0.7/100 mil habitantes (BRASIL, 2014).

\subsection{Unidade de observação do estudo}

A unidade de análise do estudo foram os setores censitários, os quais podem ser definidos como a menor unidade territorial formada por área contínua, integralmente contida em área urbana ou rural no cenário brasileiro (IBGE, 2010). O município possui 713 setores censitários, sendo utilizados na pesquisa 678 setores considerados urbanos. A Figura 10 demonstra a localização dos setores censitários urbanos e rurais de Londrina. 
Figura 10- Setores censitários do município de Londrina/Paraná, Brasil (2018)

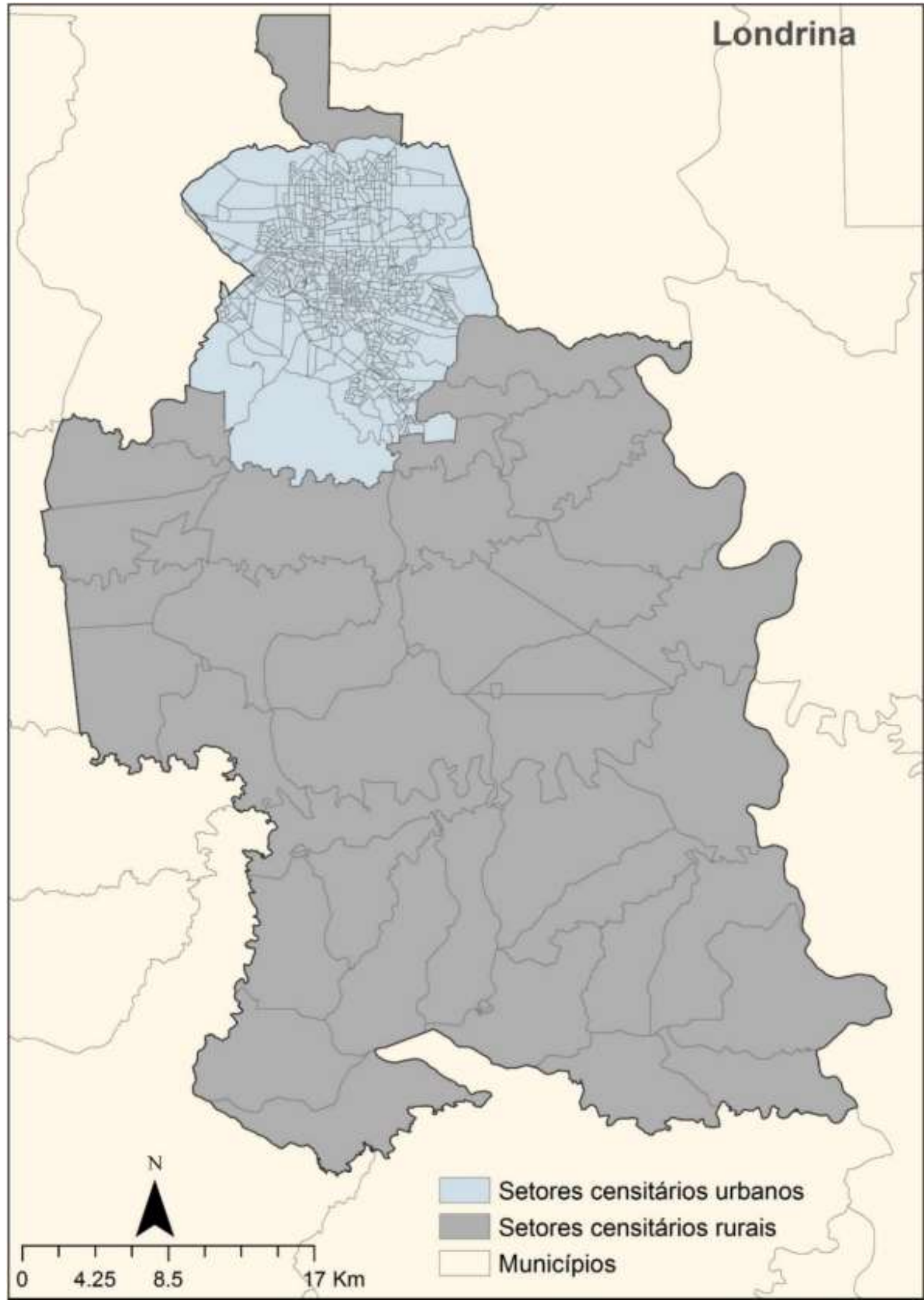




\subsection{População e período do estudo}

A população do estudo é composta dos casos de óbito que apresentaram como causa básica ou associada a TB, independente da forma clínica (Classificação Internacional de Doenças - CID versão 10 códigos A15.0 a A19.9) (OMS, 2008), registrada no Sistema de Informação sobre Mortalidade (SIM) da Secretaria Estadual de Saúde do Paraná, no período de 2008 a 2015 e residentes na zona urbana do município.

No Quadro 6 é possível verificar as definições dos códigos de acordo com a CID 10 (OMS, 2008).

Quadro 6- Formas clínicas consideradas no estudo, segundo a Classificação Internacional de Doenças, versão 10

\begin{tabular}{|c|c|c|}
\hline \multicolumn{2}{|c|}{ CID - 10} & Definição \\
\hline \multirow{4}{*}{$\begin{array}{l}\text { Tuberculose } \\
\text { Pulmonar }\end{array}$} & A 15.0 & $\begin{array}{l}\text { Tuberculose pulmonar, com confirmação por exame } \\
\text { microscópico de expectoração, com ou sem cultura }\end{array}$ \\
\hline & A 15.1 & $\begin{array}{l}\text { Tuberculose pulmonar, com confirmação somente por } \\
\text { cultura }\end{array}$ \\
\hline & A 15.2 & Tuberculose pulmonar, com confirmação histológica \\
\hline & A 15.3 & $\begin{array}{l}\text { Tuberculose pulmonar, com confirmação por meio não } \\
\text { especificado }\end{array}$ \\
\hline \multirow[t]{15}{*}{$\begin{array}{c}\text { Tuberculose } \\
\text { Extrapulmonar }\end{array}$} & A 16.0 & $\begin{array}{l}\text { Tuberculose pulmonar com exames bacteriológico e } \\
\text { histológico negativos }\end{array}$ \\
\hline & A 16.1 & $\begin{array}{l}\text { Tuberculose pulmonar, sem realização de exame } \\
\text { bacteriológico ou histológico }\end{array}$ \\
\hline & A 16.2 & $\begin{array}{l}\text { Tuberculose pulmonar, sem menção de confirmação } \\
\text { bacteriológica ou histológica }\end{array}$ \\
\hline & A 15.4 & $\begin{array}{l}\text { Tuberculose dos gânglios intratorácicos, com } \\
\text { confirmação bacteriológica e histológica }\end{array}$ \\
\hline & A 15.5 & $\begin{array}{l}\text { Tuberculose da laringe, da traqueia e dos brônquios, com } \\
\text { confirmação bacteriológica e histológica }\end{array}$ \\
\hline & A 15.6 & $\begin{array}{l}\text { Pleuris tuberculoso, com confirmação bacteriológica e } \\
\text { histológica }\end{array}$ \\
\hline & A 15.7 & $\begin{array}{l}\text { Tuberculose primária das vias respiratórias, com } \\
\text { confirmação bacteriológica e histológica }\end{array}$ \\
\hline & A 15.8 & $\begin{array}{l}\text { Outras formas de tuberculose das vias respiratórias, com } \\
\text { confirmação bacteriológica e histológica }\end{array}$ \\
\hline & A 15.9 & $\begin{array}{l}\text { Tuberculose não especificada das vias respiratórias, com } \\
\text { confirmação bacteriológica e histológica }\end{array}$ \\
\hline & A 16.3 & $\begin{array}{l}\text { Tuberculose dos gânglios intratorácicos, sem menção de } \\
\text { confirmação bacteriológica ou histológica }\end{array}$ \\
\hline & A 16.4 & $\begin{array}{l}\text { Tuberculose da laringe, da traqueia e dos brônquios, sem } \\
\text { menção de confirmação bacteriológica ou histológica }\end{array}$ \\
\hline & A 16.5 & $\begin{array}{l}\text { Pleurisia tuberculosa, sem menção de confirmação } \\
\text { bacteriológica ou histológica }\end{array}$ \\
\hline & A 16.7 & $\begin{array}{l}\text { Tuberculose respiratória primária sem menção de } \\
\text { confirmação bacteriológica ou histológica }\end{array}$ \\
\hline & A 16.8 & $\begin{array}{l}\text { Outras formas de tuberculose das vias respiratórias, sem } \\
\text { menção de confirmação bacteriológica ou histológica }\end{array}$ \\
\hline & & Continua \\
\hline
\end{tabular}




\begin{tabular}{|c|c|c|}
\hline \multicolumn{2}{|c|}{ CID - 10} & \multirow[t]{2}{*}{ Definição } \\
\hline \multirow{20}{*}{$\begin{array}{l}\text { Tuberculose } \\
\text { Extrapulmonar }\end{array}$} & & \\
\hline & & \\
\hline & A 16.9 & $\begin{array}{l}\text { Tuberculose respiratória, não especificada, sem menção } \\
\text { de confirmação bacteriológica ou histológica }\end{array}$ \\
\hline & A 17.1 & Tuberculoma meníngeo \\
\hline & A 17.8 & Outras tuberculoses do sistema nervoso \\
\hline & A 17.9 & Tuberculose não especificada do sistema nervoso \\
\hline & A18.0 & Tuberculose óssea e das articulações \\
\hline & A 18.1 & Tuberculose do aparelho geniturinário \\
\hline & A 18.2 & Linfadenopatia tuberculosa periférica \\
\hline & A 18.3 & $\begin{array}{l}\text { Tuberculose do intestino, do peritônio e dos gânglios } \\
\text { mesentéricos }\end{array}$ \\
\hline & A 18.4 & Tuberculose de pele e do tecido celular subcutâneo \\
\hline & A 18.5 & Tuberculose do olho \\
\hline & A 18.6 & Tuberculose do ouvido \\
\hline & A 18.7 & Tuberculose das supra-renais \\
\hline & A 18.8 & Tuberculose de outros órgãos especificados \\
\hline & A 19.0 & $\begin{array}{l}\begin{array}{l}\text { Tuberculose miliar aguda de localização única e } \\
\text { especificada }\end{array} \\
\end{array}$ \\
\hline & A 19.1 & Tuberculose miliar aguda de múltiplas localizações \\
\hline & A 19.2 & Tuberculose miliar aguda não especificada \\
\hline & A 19.8 & Outras tuberculoses miliares \\
\hline & A 19.9 & Tuberculose miliar não especificada \\
\hline
\end{tabular}

Fonte: Classificação Internacional de Doenças, versão 10 (CID - 10).

\subsection{Fonte de Informação e coleta de dados}

O estudo utilizou como fonte de dados secundários o Sistema de Informação sobre Mortalidade (SIM), que apresenta como documento oficial de entrada as Declarações de Óbito (DO) (Anexo A), o qual está sob responsabilidade da Secretaria Estadual de Saúde do Paraná.

O SIM foi desenvolvido pelo Ministério da Saúde, em 1975, é produto da unificação de mais de quarenta modelos de instrumentos utilizados, ao longo dos anos, para coletar dados sobre mortalidade no país (BRASIL, 2009).

Possui variáveis que permitem, a partir da causa mortis atestada pelo médico, construir indicadores e processar análises epidemiológicas que contribuam para a eficiência da gestão em saúde (BRASIL, 2009).

Com a finalidade de reunir dados quantitativos e qualitativos sobre óbitos ocorridos no Brasil, o SIM é considerado uma importante ferramenta de gestão na área da saúde. No nível federal, sua gestão está afeta à Secretaria de Vigilância à Saúde (ROCHA et al., 2015).

O Sistema de Informações sobre Mortalidade (SIM) revela-se como uma importante ferramenta para utilização dos dados de casos graves de TB, e permite 
proceder a diferentes métodos analíticos, uma vez que a doença é considerada como uma das dez principais causas de morte no mundo (ALAVI-NAINI et al., 2013; SELIG et al., 2010).

\subsection{Plano de análise}

Os passos metodológicos para análise dos dados da pesquisa estão esquematicamente representados na Figura 11, de forma a facilitar a compreensão das principais etapas do estudo. 
Figura 11- Síntese esquemática dos procedimentos metodológicos para análise dos dados da investigação

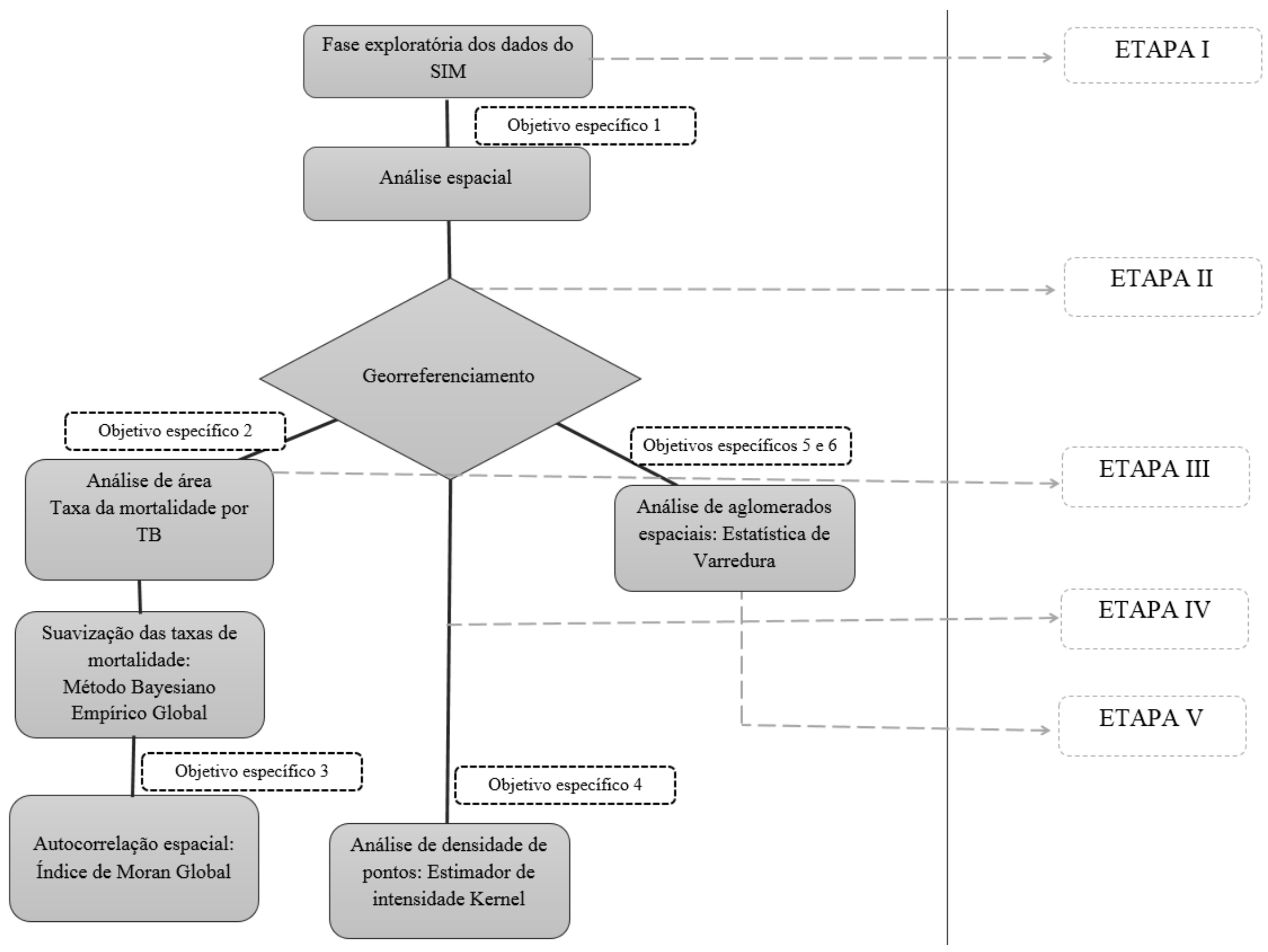




\subsubsection{Etapa I: Fase exploratória dos dados do SIM}

As variáveis de interesse para análise exploratória foram obtidas nos respectivos itens da DO utilizada no Brasil e compreenderam as características sociodemográficas e clínico-epidemiológicas representadas no Quadro 7.

Quadro 7- Variáveis selecionadas para a pesquisa conforme dados disponíveis na Declaração de Óbito (2018)

\begin{tabular}{|c|c|}
\hline \multicolumn{2}{|c|}{ Declaração de Óbito (DO) } \\
\hline $\begin{array}{c}\text { Características } \\
\text { Sociodemográficas }\end{array}$ & Características Clínico-Epidemiológicas \\
\hline $\begin{array}{ll}\checkmark & \text { Idade } \\
\checkmark & \text { Sexo } \\
\checkmark & \text { Cor da pele } \\
\checkmark & \text { Estado civil } \\
\checkmark & \text { Escolaridade } \\
\checkmark & \text { Ocupação }\end{array}$ & $\begin{array}{ll}\checkmark & \text { Local de ocorrência do óbito } \\
\checkmark & \text { Recebeu assistência médica } \\
\checkmark & \text { Diagnóstico confirmado por exame } \\
& \text { complementar } \\
\checkmark & \text { Diagnóstico confirmado por cirurgia } \\
\checkmark & \text { Diagnóstico confirmado por necropsia } \\
\checkmark & \text { Médico atestante } \\
\checkmark & \text { Causa básica } \\
\checkmark & \text { Forma clínica da TB segundo a CID } 10\end{array}$ \\
\hline
\end{tabular}

Fonte: Sistema de Informação sobre Mortalidade

As análises dessas informações foram realizadas através do software Statistica® versão 12.0, por meio de estatística descritiva dos parâmetros quantitativos, sendo calculadas e frequências absolutas e relativas para as variáveis. Referente a variável contínua Idade, calcularam-se as medidas de tendência central (média e mediana), valores máximos e mínimos, além disso, foi realizada uma categorização por faixas etárias: 0-19 anos; 20-39 anos; 40-59 anos e acima de 60 anos.

\subsubsection{Etapa II: Georreferenciamento dos endereços}

A técnica de georreferenciamento consiste no processo em que informações textuais dos endereços são convertidas em representações geográficas (SILVEIRA; OLIVEIRA, JUNGER, 2017). Sendo assim, primeiramente foi realizada a busca da coordenadas geográficas, latitude e longitude, pelo software de acesso livre Google Earth nas projeções World Geodetic System 1984(WGS/84) Universal Transversa de Mercator (UTM) zona 22 Sul.

Posteriormente, elaborou-se um único banco de dados com todas as coordenadas geográficas dos casos de óbitos por TB, o qual foi devidamente 
configurado para ser utilizado no software TerraView versão 4.2.2, no qual se procedeu o georreferenciamento propriamente dito, atribuindo-se uma representação geográfica para cada registro, compondo um shapefile de pontos.

$\mathrm{Na}$ sequência, foi realizada a junção do shapefile de pontos (casos) com o shapefile de polígonos (setores), utilizando-se a malha digital dos setores censitários na extensão Shapefile do município, disponibilizado gratuitamente pelo IBGE (IBGE, 2010).

$\mathrm{O}$ arquivo final dos endereços na extensão Shapefile seguiu a projeção UTM zona 22 sul e datum Sistema de Referência Geocêntrico para as Américas (SIRGAS) 2000.

\subsubsection{Etapa III: Análise de área}

5.6.3.1.Taxa bruta da mortalidade por TB segundo os setores censitários

Após o georreferenciamento foi realizado a análise espacial por área, considerando os setores censitários urbanos do município em estudo. As taxas brutas de mortalidade por TB (Tbi) foram calculadas dividindo-se o número de óbitos sob estudo $\left(Y_{i}\right)$ pela população urbana de Londrina/PR em 2010, perante cada setor censitário urbano, e finalmente multiplicando-se por 1/8, referente aos anos em estudo, de acordo a fórmula abaixo (GORDIS, 2009):

$$
\mathrm{T} b i=\frac{Y_{i}}{P_{i}} \times \frac{1}{T}(100.000)
$$

Utilizou-se o software ArcGis (versão 10.5) para o cálculo das taxas e ainda para a construção dos mapas coropléticos.

Cabe ressaltar que a distribuição espacial de taxas brutas, especialmente as de mortalidade por TB cuja frequência ocorre em menor escala, apresenta uma variabilidade considerável entre os setores censitários, denominada como flutuações aleatórias. As flutuações aleatórias estão associadas diretamente com o tamanho da população em risco e unidade de análise, sendo que, quanto menor a população ou a unidade de análise, o acréscimo ou decréscimo de um caso pode alterar significativamente a estimativa (CARVALHO et al., 2012, FORMIGA et al., 2008)

Por este motivo, no intuito de minimizar as flutuações aleatórias existentes no município, recorreu-se a técnica de suavização das taxas brutas, o método Bayesiano Empírico Global. 
5.6.3.2. Suavização das taxas de mortalidade: Método Bayesiano Empírico Global

O estimador Bayesiano Empírico Global proposto por Marshall (1991) parte da hipótese que a distribuição da taxa $\widetilde{\theta}_{l}$ é uma variável aleatória, que possui uma média $\mu_{i}$ e uma variância $\sigma^{2}$. Seu cálculo consiste da média ponderada entre as taxas brutas dos setores censitários e a taxa global do município, gerando uma nova taxa.

Segundo o autor, para o cálculo das taxas bayesianas empíricas globais considera-se:

$$
\tilde{\theta}=\tilde{m}+\tilde{C}_{i}\left(x_{i}-\tilde{m}\right)
$$

Em que $C i=\frac{s^{2}-\widetilde{m} / \tilde{n}}{s^{2}-\widetilde{m} / \tilde{n}+\widetilde{m} / n_{i}}, \widetilde{m}$ é a taxa global dos eventos, $\tilde{n}$ é o número médio de pessoas em risco, $\mathrm{n}_{\mathrm{i}}$ é o número de pessoas observadas na área $\mathrm{i}, s^{2}=$ $\sum i \frac{n i(r i-\dot{\mathrm{m}})^{2}}{n}$, n é o número de pessoas observadas em todas as áreas juntas, e $\mathrm{x}_{\mathrm{i}}$ é a taxa observada na área i.

Em seguida, foram calculadas as taxas bayesianas empíricas globais pelo período de tempo do estudo, dividindo-se o número de óbitos de cada intervalo de tempo pela população de cada setor censitário e multiplicando-se por 100.000.

Os cálculos das taxas bayesianas empíricas globais foram realizados no software TerraView versão 4.2.2 e os mapas coropléticos dos índices brutos e bayesianos foram construídos no software ArcGis 10.5.

\subsubsection{Autocorrelação espacial: Índice de Moran Global}

Posteriormente, para testar a dependência espacial das taxas de mortalidade por TB e como estão correlacionadas no espaço, isto é, para estimar quanto o valor observado da taxa num setor censitário é dependente dos valores das taxas nas localizações vizinhas, realizou-se o Índice de Moran Global (I), que expressa a autocorrelação considerando apenas o primeiro vizinho (BARBOSA, 2013, CÂMARA et al., 2004), a equação abaixo expressa como o cálculo é efetuado (MORAN, 1950):

$$
\frac{\sum_{i=l}^{n} \sum_{j=l}^{n} w i j(z i-z)(z j-z)}{\sum_{i=l}^{n}(z i-z)^{2}}
$$


Onde $n$ é o número de áreas, $z i$ é o valor do atributo considerado na área $i, z$ é o valor médio do atributo na região de estudo, e wij são os elementos da matriz normalizada de proximidade espacial. Neste caso, a correlação será computada apenas para os vizinhos de primeira ordem no espaço, conforme estabelecido pelos pesos wij.

Para a análise de autocorrelação espacial foi criada a matriz normalizada de proximidade espacial de distância através do software OpenGeoDa versão 1.8. Um fator importante a ser destacado é que o $I$ oferece um único valor como medida da autocorrelação espacial para todos os setores censitários em estudo, permitindo uma avaliação geral do município.

O I baseia-se no conceito de "correlação" e assemelha-se ao coeficiente de Pearson, o qual consiste em uma medida de dispersão relativa. A autocorrelação espacial mensura o quanto o valor do atributo observado é semelhante ou dessemelhante nas localidades avaliadas. Neste mesmo sentido norteiam-se os valores do I, que variam entre 1 a -1 , em que os valores positivos indicam áreas com valores semelhantes e valores negativos apontam dessemelhança (RAO et al, 2016).

Em outras palavras, valores mais próximos de 1 demonstram a semelhança dos vizinhos perante o evento em estudo e ainda indicam a formação de aglomerados. Já os valores negativos (-1) refletem na distribuição intercalada de valores altos e baixos no território, e, por fim, quando próximo de 0, não há nenhuma aglomeração, o que significa que os dados são distribuídos aleatoriamente (ZHAO et al., 2013).

Para verificar a validade estatística do índice, foi realizado o teste de pseudossignificância estatística. $O$ teste consiste na elaboração de diferentes permutações dos valores dos atributos associados às regiões, em que cada permutação gerou um novo arranjo espacial, haja vista que os valores são redistribuídos entre as áreas. Para análise desse teste, é construída uma situação empírica para os valores I. Caso o valor corresponda ao extremo da distribuição simulada, consiste num evento com significância (CÂMARA et al., 2004). Para todos os testes fixou-se erro tipo I em $5 \%$ como estatisticamente significativo $(\mathrm{p}<0.05)$.

\subsubsection{Análise de densidade de pontos: Estimador de Intensidade Kernel}

Segundo Câmara et al. (2004), a análise exploratória do comportamento espacial dos eventos começa pela estimativa da intensidade de ocorrência do processo pontual em toda a região de estudo. A forma mais simples e usual é feita pelo ajuste de 
uma função bidimensional aos eventos considerados, compondo uma superfície cujo valor será proporcional à intensidade de eventos por unidade de área.

A função de densidade Kernel permite estimar a quantidade de eventos por unidade de área, em cada célula de uma grade regular que recobre a região estudada, ponderando-os pela distância de cada um até o ponto que está sendo estimado.

Ainda de acordo com Câmara et al. (2004) com base nos conceitos apresentados, supõe-se que $u, \ldots, u n$ são localizações de $n$ eventos observados em uma região $A$ e que u represente uma localização genérica cujo valor se quer estimar. $\mathrm{O}$ estimador de intensidade é computado considerando-se os $m$ eventos $u_{i}, \ldots u_{i+m-1} i \mathrm{i}$ contidos num raio de tamanho $\tau$ em torno de $u$ e da distância d entre a posição e a iésima amostra, a partir de funções cuja forma geral é

$$
\lambda_{\tau}(u)=\frac{1}{\tau^{2}} \sum_{i=1}^{n} k\left(\frac{d\left(u_{i}, u\right)}{\tau}\right), d\left(u_{i}, u\right) \leq \tau
$$

O estimador Kernel contribui para uma visualização ampla da distribuição dos pontos amostrais, além de ser um indicativo da ocorrência de aglomerados espaciais (CÂMARA et al., 2004).

Sendo assim, o uso dessa técnica de densidade de pontos acima descrita, denominada como estimativa de Kernel, consiste na interpolação exploratória gerando uma superfície de densidade para a identificação e visualização de áreas quentes (hotspots) (OLIVEIRA; BRESCOVIT; SANTOS, 2015). No caso deste estudo, áreas com maiores densidades de óbitos por $\mathrm{TB}$ por $\mathrm{Km}^{2}$, ou seja, potencialmente mais vulneráveis a presença deste evento.

É importante destacar que o estimador Kernel tem como um dos parâmetros básicos o raio de influência $(\tau \geq 0)$, o qual define a vizinhança do ponto a ser interpolado e controla o grau de alisamento da superfície gerada. O raio de influência, também denominado como largura de banda, é responsável por definir a área centrada no ponto de estimação $u$ que indica quantos eventos $i u$ contribuem para a estimativa da função intensidade $\lambda$, portanto, um raio muito pequeno poderá gerar uma superfície muito descontínua e oscilante; se for grande demais, a superfície poderá ficar muito suavizada (CÂMARA et al., 2004)..

Nesse sentindo, para evitar o problema com o uso de raios muito grandes ou pequenos, recorreu-se à ferramenta disponibilizada pelo software Arcgis (versão 10.5) 
denominada como Incremental Spatial Autocorrelation (ISA). A ISA realiza a mensuração da autocorrelação espacial para uma série de distâncias, que varia de 0 a 30 testes, gerando um gráfico de linhas contendo essas distâncias e seus z-scores e pvalores correspondentes. Os z-scores equivalem a intensidade do agrupamento espacial, aqueles que apresentam picos estatisticamente significativos apontam as distâncias em que os processos espaciais que promovem agrupamento são mais pronunciados, ou seja, estabelece a distância para aglomerações dos casos de óbito por TB (STOPKA et al., 2017).

Os valores das distâncias de pico devem ser usados como parâmetro em análise espaciais baseadas nas faixas de distância ou Raios de distância, assim como o estimador de intenside Kernel (ZHENG, 2015).

As densidades dos óbitos por $\mathrm{Km}^{2}$ foram divididas em quintis e classificadas em cinco níveis: muito baixa, baixa, média, alta e muito alta, e a variação espacial dessas densidades foi exibida em tonalidade de cores, sendo as áreas de densidade de óbitos por $\mathrm{Km}^{2}$ iguais a zero (muito baixa) representadas pela cor branca e as áreas com densidades mais elevadas (muito alta) representadas pela cor preta.

O mapa coroplético e a mensuração da distância do raio na análise de densidade Kernel foram realizadas no software ArcGIS 10.5.

\subsubsection{Análise de detecção de glomerados espaciais: Estatística de Varredura}

5.6.5.1. Descrição da análise de formação de aglomerados através da Estatística de Varredura Espacial Tradicional

Para a detecção dos aglomerados espaciais, foi utlizada a técnica denominada Estatística de Varredura ou Estatística de Scan.

A Estatística de Varredura é uma técnica elaborada por Kulldorff e Nagarwalla (1995) que consiste na formação de círculos que se movem por toda a área em estudo ao redor dos centroides, os quais correspondem ao centro de cada unidade territorial em análise, isto é, realiza-se um processo de centralização, cujo raio pode variar de zero até o limite determinado pelo pesquisador (OLFATIFAR et al., 2016).

A formação dos aglomerados espaciais se dá a partir do cálculo do número dos eventos encontrados dentro de cada círculo. Se o valor observado for maior que o esperado na região z (região delimitada pelo círculo), denomina-se aglomerado, caso contrário, o raio do círculo é ampliando até um novo centroide, e assim ocorrerá 
sucessivamente até que todos os centroides sejam testados sobre as seguintes hipóteses (LUCENA; MORAES, 2012):

H0: não há aglomerado na região de estudo;

H1: a região z é um aglomerado.

As numerosas quantidades de círculos gerados são testadas usando simulações de Monte Carlo com base na hipótese nula.

No processo de centralização, o Log likelihood ratio (LLR) de cada potencial aglomerado é formulado com base no cálculo da prevalência observada e esperada dentro e fora da janela circular em que é atribuído o p-valor, segundo a fórmula a seguir (WALLER.; GOTWAY, 2004):

$$
\text { LLR }=\log \left(\frac{O_{\text {in }}}{E_{\text {in }}}\right)^{\text {Oin }}\left(\frac{O-O_{\text {in }}}{O-E_{\text {in }}}\right)^{O-O_{\text {in }}}
$$

$\mathrm{Na}$ qual O representa os casos observados e $\mathrm{E}$ os casos esperados, desta forma Oin e Ein denotam o número de casos observados e esperados dentro da janela circular, respectivamente. Ein é calculado multiplicando-se os óbitos por TB pela população dos setores censitários.

Quanto maior o LLR, menor a probabilidade de detecção de o aglomerado ocorrer devido ao acaso. Além disso, o Risco Relativo Espacial (RRE) (MELNICK, 2008; LAWSON et al., 2000) é calculado para cada aglomerado estatisticamente significativo, o que significa o risco dentro do aglomerado em comparação com o risco fora dele (GAO et al, 2014).

Após a formação do aglomerado, o software apresenta também o valor do RRE, o qual é obtido através do seguinte cálculo (PRATES; KULLDORFF, ASSUNÇÃO; 2014):

$$
R R E=\frac{N_{Z} / E_{Z}}{\left(N-N_{Z}\right) /\left(E_{A-} E_{Z}\right)}
$$

No qual $\mathrm{N}$ é o número total de casos, $\mathrm{N}_{\mathrm{Z}}$ é o número de casos no cluster $\mathrm{Z}$; $\mathrm{E}_{\mathrm{A}}$ é o número esperado de casos sobre a região sob a hipótese nula, e $\mathrm{E}_{Z}$ é o número esperado de casos na área $\mathrm{Z}$ sobre a hipótese nula. 
O valor do RRE é o que denomina o tipo de aglomerado em Aglomerado especial de Risco (RRE> 1) ou Proteção (RRE<1) (GORDIS, 2009; WAGNER; CALLEGARI-JACQUES,1998)

5.6.5.2. Descrição da análise de formação de aglomerados através da Estatística de Varredura Espacial Isotônica

Considera-se para um determinado centroide que o risco é modelado como mais alto dentro de alguma distância (d) desconhecida do centroide, em comparação com uma distância maior em relação ao mesmo centroide. A distância (d) corresponde ao raio (r) do círculo utilizado e, como mencionado anteriormente, este raio não é definido previamente. Isto significa que o risco é modelado como uma função r(d) da distância do centroide, e que usa uma Função por Etapas com uma única descontinuidade em d (XIAO-ZHOU et al., 2012).

A função de risco pode ser classificada como uma função decrescente, isto é, quanto maior a distância em relação ao centroide da unidade territorial de análise, menor o risco espacial para a ocorrência do óbito por TB.

Para Kulldorff (1999), se não houver suposição a priori sobre o número ou localização dessas etapas, a função de risco pode ser ajustada usando a máxima verossimilhança na chamada regressão isotônica. A Função de Regressão Isotônica é definida como aquela que entre todas as possíveis funções decrescentes, é a de maior probabilidade.

$\mathrm{Na}$ Estatística de Varredura Espacial Isotônica é importante mencionar que, ao invés de desenvolver apenas uma janela circular, utiliza um conjunto de círculos sobrepostos de diferentes tamanhos que são centrados no mesmo centroide, sendo que se parte da hipótese alternativa de que a taxa de mortalidade é mais alta dentro do círculo mais interno, um pouco mais baixa entre o primeiro e o segundo círculos, e assim por diante, até o último círculo. Esse processo é denominado como Steps in Risk Function, que, desta forma, permite a visualização gradativa da intensidade do RRE dentro do aglomerado, o que difere da versão Tradicional, a qual trata o RRE no interior do aglomerado como sendo equitativo para todo seu o território (KULLDORFF, 1999).

Não há um número pré-definido de círculos ou qualquer suposição prévia sobre seus respectivos tamanhos, exceto que o maior círculo deve ser menor do que o tamanho máximo do círculo especificado pelo usuário. O método busca a coleção de círculos que maximiza a estatística da razão de verossimilhança, tendo os casos de óbitos por TB dentro de cada círculo; vale ressaltar, que apesar de o método avaliar uma 
janela com múltiplos círculos, há apenas um único círculo que proporciona a mais alta verossimilhança e, por conseguinte, irá definir o aglomerado mais provável (KULLDORFF, 2015).

Após a identificação de todos os aglomerados risco, foi realizado o cálculo do Intervalo de Confiança em 95\% ( $\mathrm{IC}_{95 \%}$ ) no intuito de obter um parâmetro de confiabilidade para os valores do RRE (WAGNER; CALLEGARI-JACQUES,1998).

Cabe ressaltar que foi adotado o Modelo Discreto de Poisson. Além disso, consideraram-se as opções de "Altas taxas" e "Baixas taxas" e o tamanho máximo do aglomerado de $10 \%, 30 \%$ e $50 \%$ da população sob risco com janelas em formato circular e 999 replicações. Considerou-se p-valor <0,05 como estatisticamente significativo (AZAGE et al., 2015; SLUYDTS et al., 2014)

As análises de detecção de aglomerados foram realizadas no software SaTScan $^{\mathrm{TM}}$ versão 9.4. e todos os mapas temáticos foram construídos no software ArcGis 10.5.

\subsection{Aspectos éticos}

Atendendo os preceitos da Resolução n466/2012, para realização deste estudo, o projeto foi aprovado pelo Comitê de Ética em Pesquisa da Escola de Enfermagem de Ribeirão Preto da Universidade de São Paulo (EERP/USP), tendo o Certificado de Apresentação para Apreciação Ética (CAAE) e no 54479816.0.0000.5393 (ANEXO B) emitido em 06 de Abril de 2016 e no56305516.0.0000.5393. (ANEXO C) em 08 de Junho de 2016 (ANEXO B) para o cenário de pesquisa.

Por se tratar de estudo ecológico e utilizar dados secundários, o projeto enviado ao Comitê de Ética previa a dispensa do Termo de Consentimento Livre Esclarecido (TCLE). 


\subsection{Análise exploratória dos dados do SIM}

Foram identificados 61 óbitos por TB, destes, 40 (65,6\%) eram causa básica e $21(34,4 \%)$ eram causa associada. Os óbitos por TB ocorreram entre as idades de 14 a 90 anos, sendo que a média de idade foi de 56,9 anos, com DP= $+/-17,8$. Segundo a Tabela 1, observou-se que 27 casos (44,3\%) apresentavam idade entre 40 e 59 anos; 49 $(80,3 \%)$ eram homens; da cor branca 39 (63,9\%); 17 (27,9\%) eram casados; com ensino médio, 20, (32,8\%).

Tabela 1- Características Sociodemográficas das pessoas que morreram de tuberculose em Londrina/Paraná, Brasil (2008 a 2015)

\begin{tabular}{|c|c|c|}
\hline Variáveis & $n$ & $\%$ \\
\hline \multicolumn{3}{|l|}{ Idade(anos) } \\
\hline$<19$ anos & 1 & 1,6 \\
\hline $20-39$ & 8 & 13,1 \\
\hline $40-59$ & 2 & 44,3 \\
\hline$\geq 60$ & 25 & 41,0 \\
\hline Mediana & \multicolumn{2}{|c|}{56 anos } \\
\hline Média & \multicolumn{2}{|c|}{56,9 anos } \\
\hline \multicolumn{3}{|l|}{ Sexo } \\
\hline Masculino & 49 & 80,3 \\
\hline Feminino & 12 & 19,7 \\
\hline \multicolumn{3}{|l|}{ Cor } \\
\hline Branca & 39 & 63,9 \\
\hline Preta & 9 & 14,8 \\
\hline Amarela & 4 & $6 ; 6$ \\
\hline Parda & 9 & 14,8 \\
\hline \multicolumn{3}{|l|}{ Estado Civil } \\
\hline Solteiro & 17 & 27,9 \\
\hline Casado & 23 & 37,7 \\
\hline Viúvo & 6 & 9,8 \\
\hline Separado/divorciado & 6 & 9,8 \\
\hline União estável & 2 & 3,3 \\
\hline Ignorado & 7 & 11,5 \\
\hline \multicolumn{3}{|l|}{ Escolaridade } \\
\hline Sem escolaridade & 1 & 1,6 \\
\hline Ensino fundamental & 12 & 19,7 \\
\hline Ensino médio & 20 & 32,8 \\
\hline Ensino Superior Completo Incompleto & 15 & 24,6 \\
\hline Ignorado & 13 & 21,3 \\
\hline \multicolumn{3}{|l|}{ Ocupação } \\
\hline Aposentado/pensionista & 13 & 21,3 \\
\hline Dona de casa & 7 & 11,5 \\
\hline Outros & 28 & 45,9 \\
\hline Ignorado & 13 & 21,3 \\
\hline \multicolumn{3}{|l|}{ Local de ocorrência } \\
\hline Hospital & 54 & 88,5 \\
\hline Domicilio & 7 & 11,5 \\
\hline
\end{tabular}




\begin{tabular}{lll}
\hline Variáveis & $\boldsymbol{n}$ & $\mathbf{\%}$ \\
\hline Recebeu assistência médica & 32 & 52,5 \\
$\quad$ Sim & 2 & 3,3 \\
$\quad$ Não & 27 & 44,3 \\
$\quad$ Ignorado & & \\
Diagnóstico confirmado por exame & & \\
complementar & 14 & 23,0 \\
$\quad$ Sim & 2 & 3,3 \\
$\quad$ Não & 45 & 73,8 \\
$\quad$ Ignorado & & \\
Diagnóstico confirmado por cirurgia & 1 & 1,6 \\
$\quad$ Sim & 15 & 24,6 \\
$\quad$ Não & 45 & 73,8 \\
$\quad$ Ignorado & & \\
Diagnóstico confirmado por necropsia & 5 & 8,2 \\
$\quad$ Sim & 36 & 59,0 \\
$\quad$ Não & & \\
Atestante & 17 & 27,9 \\
$\quad$ Assistente & 19 & 31,1 \\
$\quad$ Substituto & 2 & 3,3 \\
$\quad$ Serviço de Vigilância de Óbito & & \\
Forma clínica da doença de acordo com a & & \\
CID-10 & 32 & 52,4 \\
$\quad$ Pulmonar & 29 & 47,5 \\
$\quad$ Extra-pulmonar & & \\
\hline
\end{tabular}

A Tabela 2. Mostra as características clínico-epidemiológicas dos casos de óbito por TB. Nota-se que grande parte dos óbitos $13(21,3 \%)$ acometeram os aposentados/pensionistas; 54 (88,5\%) ocorreram no hospital e 32 (52,5\%) após receber assistência médica; e $32(52,4 \%)$ obtiveram a forma clínica predominante foi a pulmonar.

Tabela 2- Características Clínico- Epidemiológicas das pessoas que morreram de tuberculose em Londrina/Paraná, Brasil (2008 a 2015)

\begin{tabular}{lll}
\hline Variáveis & $\boldsymbol{n}$ & $\mathbf{\%}$ \\
\hline Ocupação & & \\
$\quad$ Aposentado/pensionista & 13 & 21,3 \\
$\quad$ Dona de casa & 7 & 11,5 \\
$\quad$ Outros & 28 & 45,9 \\
$\quad$ Ignorado & 13 & 21,3 \\
Local de ocorrência & & \\
$\quad$ Hospital & 54 & 88,5 \\
$\quad$ Domicilio & 7 & 11,5 \\
Recebeu assistência médica & & \\
Sim & 32 & 52,5 \\
Não & 2 & 3,3 \\
Ignorado & 27 & 44,3 \\
& & Continua...
\end{tabular}




\begin{tabular}{lll}
\hline Variáveis & $\boldsymbol{n}$ & $\mathbf{\%}$ \\
\hline $\begin{array}{l}\text { Diagnóstico confirmado por exame } \\
\text { complementar }\end{array}$ & & \\
& 14 & 23,0 \\
$\quad$ Não & 2 & 3,3 \\
$\quad$ Ignorado & 45 & 73,8 \\
Diagnóstico confirmado por cirurgia & & \\
$\quad$ Sim & 1 & 1,6 \\
$\quad$ Não & 15 & 24,6 \\
$\quad$ Ignorado & 45 & 73,8 \\
Diagnóstico confirmado por necropsia & 5 & \\
$\quad$ Sim & 36 & 8,2 \\
$\quad$ Não & & 59,0 \\
Atestante & 17 & 27,9 \\
$\quad$ Assistente & 19 & 31,1 \\
$\quad$ Substituto & 2 & 3,3 \\
$\quad$ Serviço de Vigilância de Óbito & & \\
Forma clínica da doença de acordo com a & & \\
CID-10 & 32 & 52,4 \\
$\quad$ Pulmonar & 29 & 47,5 \\
$\quad$ Extra-pulmonar & & \\
&
\end{tabular}

A análise dos dados sociodemográficos identificou que houve subnotificação de alguns dados da ficha da D.O., como no caso do estado civil, escolaridade, ocupação, assistência médica, confirmação de diagnóstico por exame complementar ou cirurgia.

\subsection{Georreferenciamento dos endereços}

Foram georreferenciados $61(100 \%)$ casos de óbitos por TB no período do estudo. A Figura 12 demonstra a distribuição dos casos no município. Os óbitos ocorreram com maior frequência nas regiões Centro, Leste e Norte, respectivamente. 
Figura 12- Casos de óbito por tuberculose georreferenciados sobrepostos aos setores censitários. Londrina/Paraná, Brasil (2008 - 2015)

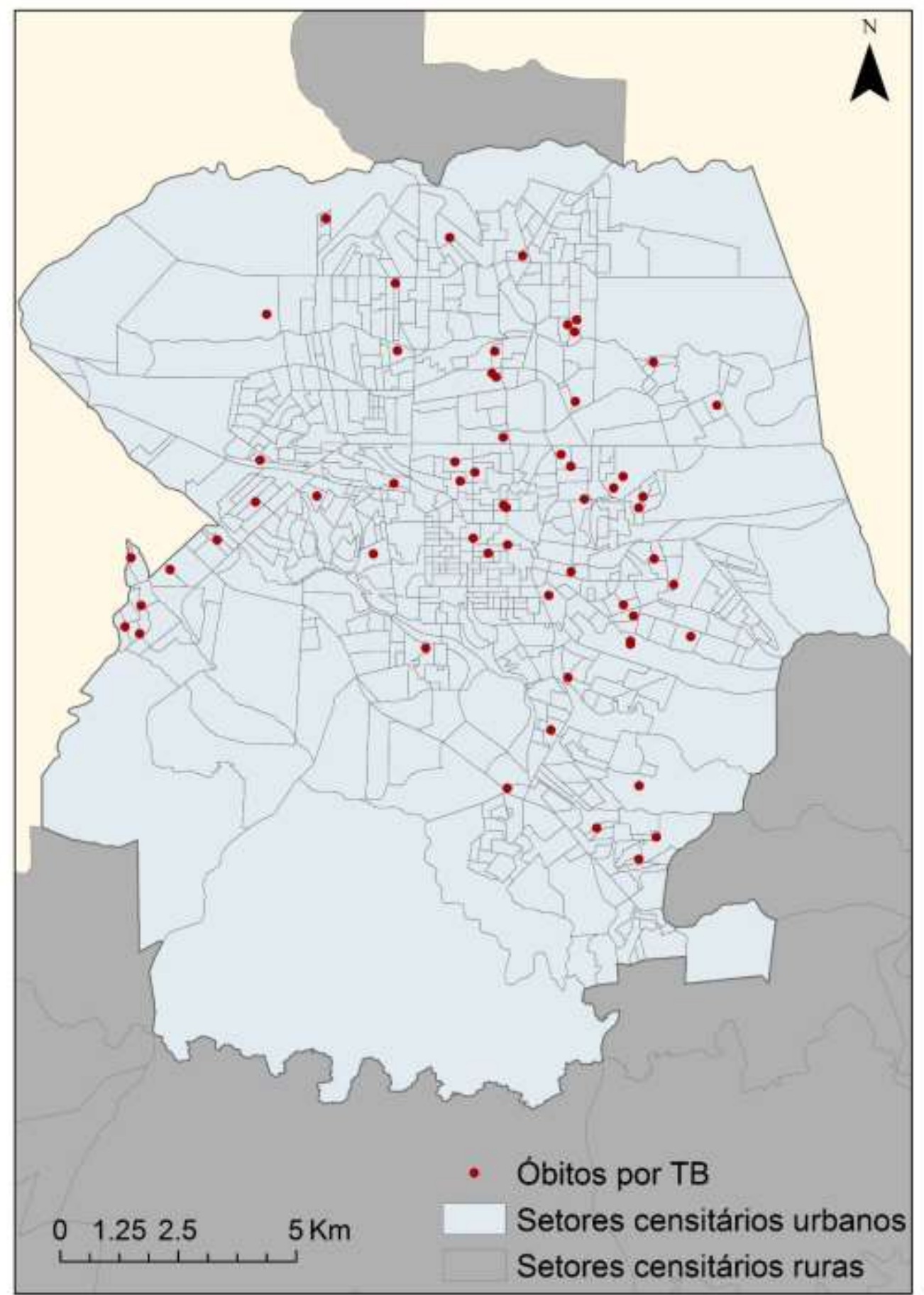

Fonte: próprio autor

\subsection{Análise de área}

O cálculo das taxas brutas anuais da mortalidade por TB de acordo com os 8 anos do estudo está representado na Figura 13A. Nota-se que há uma quantidade numerosa de setores censitários com valores nulos para as taxas brutas. As maiores 
taxas anuais foram identificadas na região Centro, nos bairros Vila Recreio $(74,7$ por 100.000 hab./ano) e na região Leste nos bairros Aeroporto (41,1 por 100.000 hab./ano), Ideal (36,2 por 100.000 hab./ano) e Interlagos (35,8 por 100.000 hab./ano).

Em seguida, aplicou-se o método Bayesiano Empírico Global, assim como demonstra a Figura 13B. Após a suavização das taxas de mortalidade anual pelo método Bayesiano Empírico Global, houve uma distribuição mais ampla das taxas brutas, e nenhum setor censitário permaneceu com valor nulo. As mais elevadas taxas bayesianas globais anuais foram identificadas na região Norte no bairro Alpes (2,5 por 100.000 hab./ano), região Centro manteve o bairro Vila Recreio (2,6 por 100.000 hab./ano) e região Leste com os bairros Aeroporto (2,7 por 100.000 hab./ano), Ideal (2,5 por 100.000 hab./ano) e Interlagos (2,6 por 100.000 hab./ano).

Figura 13- Mapa das taxas de mortalidade* por tuberculose, segundo os setores censitários Londrina/Paraná, Brasil (2008-2015)

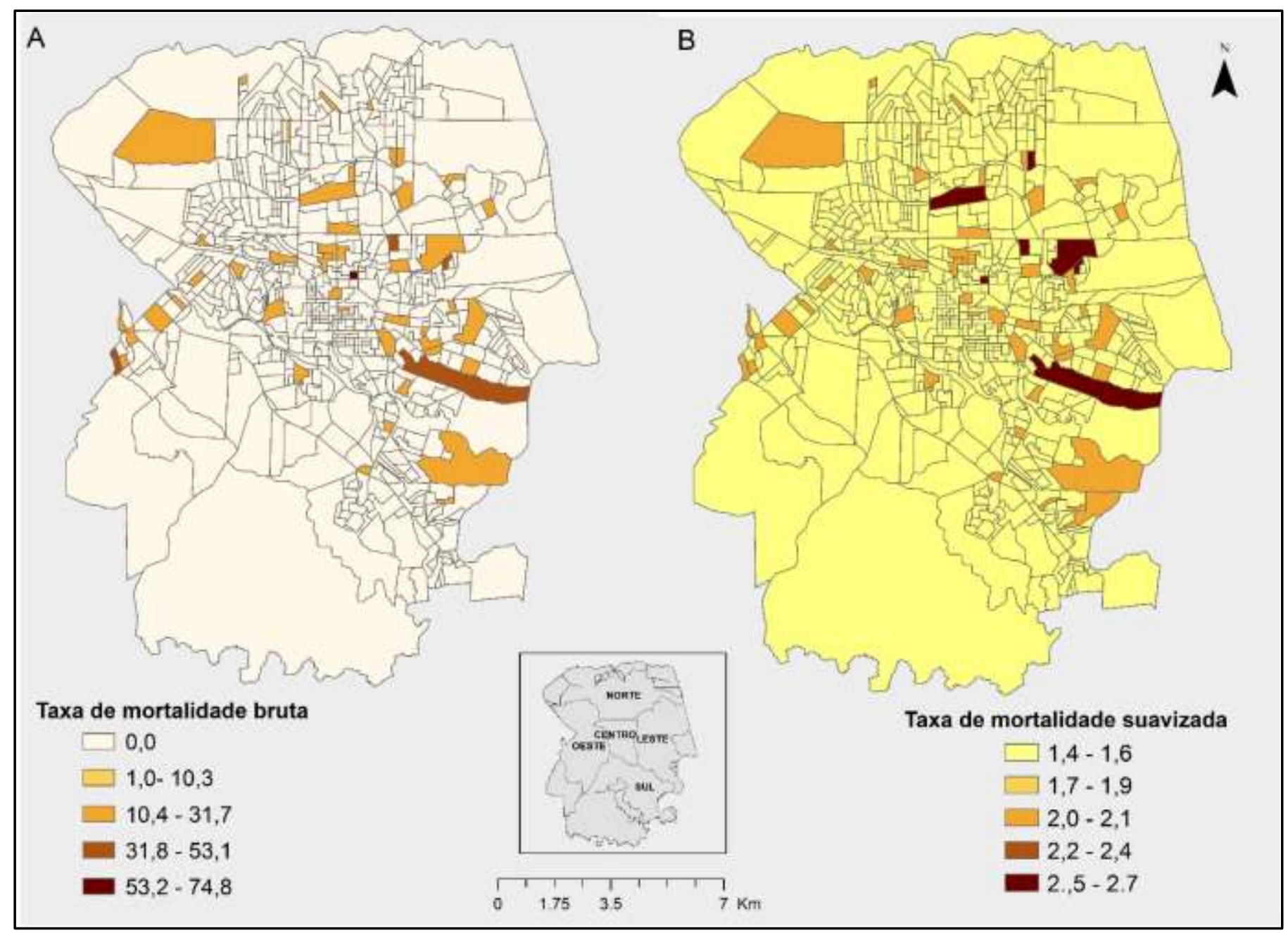

*(A) Taxas brutas anuais de mortalidade por TB; (B) Taxas suavizadas de mortalidade por TB por ano após aplicação do método Bayesiano Empírico Global. Fonte: próprio autor. 
No que tange à autocorrelação espacial, obteve-se valor $I=0,014$ e p $=0,004$ demonstrando uma dependência espacial baixa e positiva. $O$ teste de pseudossignificância estatística (Fig. 14) confirmou a validade estatística da análise. Além disso, demonstrou que apesar de o valor de $I$ tender à aleatoriedade, ou seja, o município em sua totalidade possui baixa dependência espacial, porém, o alto valor do z-score $(2,83)$, revelou que, nos poucos aglomerados existentes, há uma alta dependência espacial.

Figura 14- Teste da pseudo-significância estatística das taxas suavizadas de mortalidade por TB, Londrina/Paraná, Brasil (2008-2015)

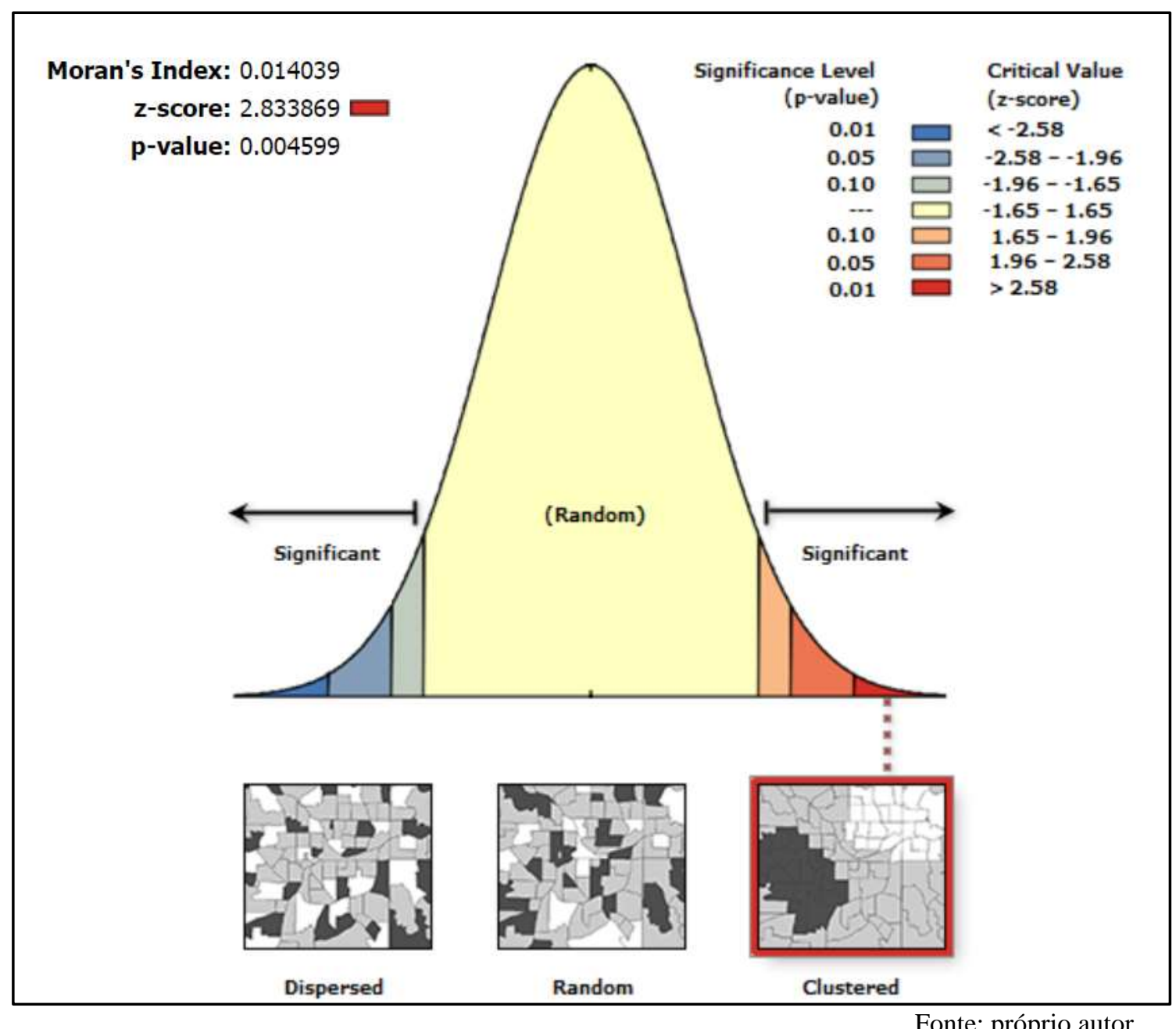

\subsection{Análise de densidade de pontos: Estimador de Intensidade Kernel}

A ferramenta ISA definiu como distância mais recorrente para os casos de óbito por TB o valor de 3198,6 metros, z-score > 1,96 e $\mathrm{p}=$ 0,008. O Gráfico 1 mostra o pico da distância e seu respectivo z-score. 
Gráfico 1- Autocorrelação Espacial por distância dos casos de óbito por TB, Londrina/Paraná,

Brasil (2008-2015)

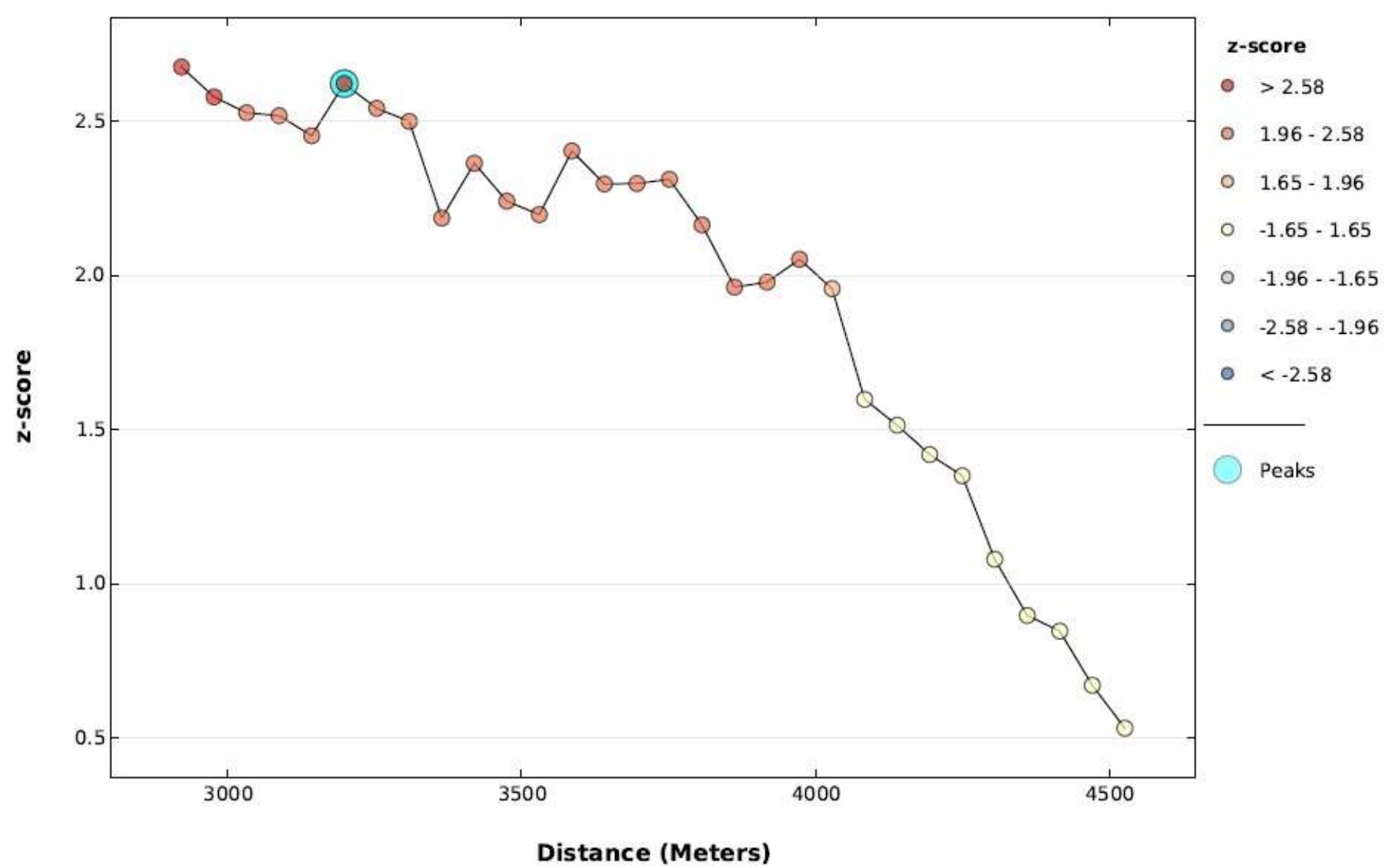

Fonte: próprio autor

Em seguida, realizou-se a densidade de pontos segundo o estimador de intensidade Kernel. Conforme a Figura 15 demonstra, foi elaborado o mapa temático referente a densidade dos óbitos por TB ocorridos na zona urbana de Londrina, no período de 2008 a 2015. Observa-se que as áreas com maiores densidades de óbitos relacionados à TB estão concentradas nos setores censitários regiões Norte, Centro e Leste, com uma variação de 0.5 a 1,2 óbitos por TB por $\mathrm{km}^{2}$. 
Figura 15- Mapa da distribuição da densidade dos óbitos por tuberculose. Londrina/Paraná, Brasil (2008-2015)

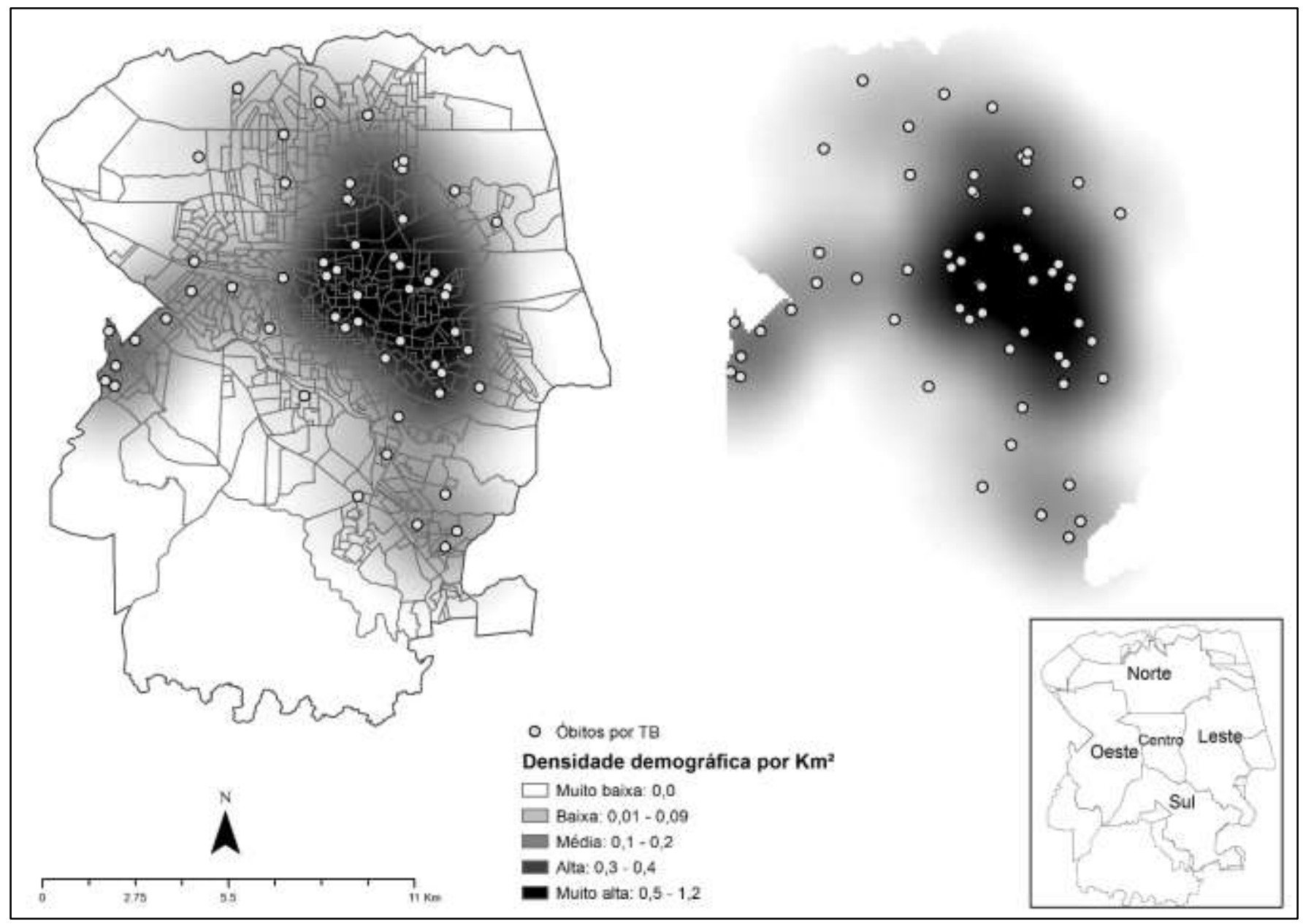

Fonte: próprio autor

\subsection{Análise de detecção de aglomerados espaciais: Estatística de}

\section{Varredura}

Quanto à aplicação da Estatística de Varredura Tradicional, para altas taxas identificou-se um aglomerado de risco para cada porcentagem da população exposta, ou seja, 10\%, 30\% e $50 \%$, os valores dos RRE e IC $95 \%$ estão expressos na Figura 16.

$\mathrm{Na}$ Figura 16, pode-se observar que os aglomerados de risco abrangem as regiões Norte e Leste do município; para aglomerado com $10 \%$ da população sob risco obtiveram-se 12 óbitos e para 30 e 50\% identificaram-se 29 óbitos.

Ainda sobre a varredura tradicional, para baixas taxas e população exposta de $10 \%$ identificou-se um aglomerado de proteção na região Noroeste do município, onde não houve óbitos por TB, já para 30 e 50\% da população sob risco o aglomerado de 
proteção envolveu toda a região Sul do município, com cinco óbitos para cada aglomerado.

Figura 16- Aglomerados espaciais de alto e baixo risco para a mortalidade por TB através da Estatística de Varredura Espacial Tradicional. Londrina/Paraná, Brasil (20082015)

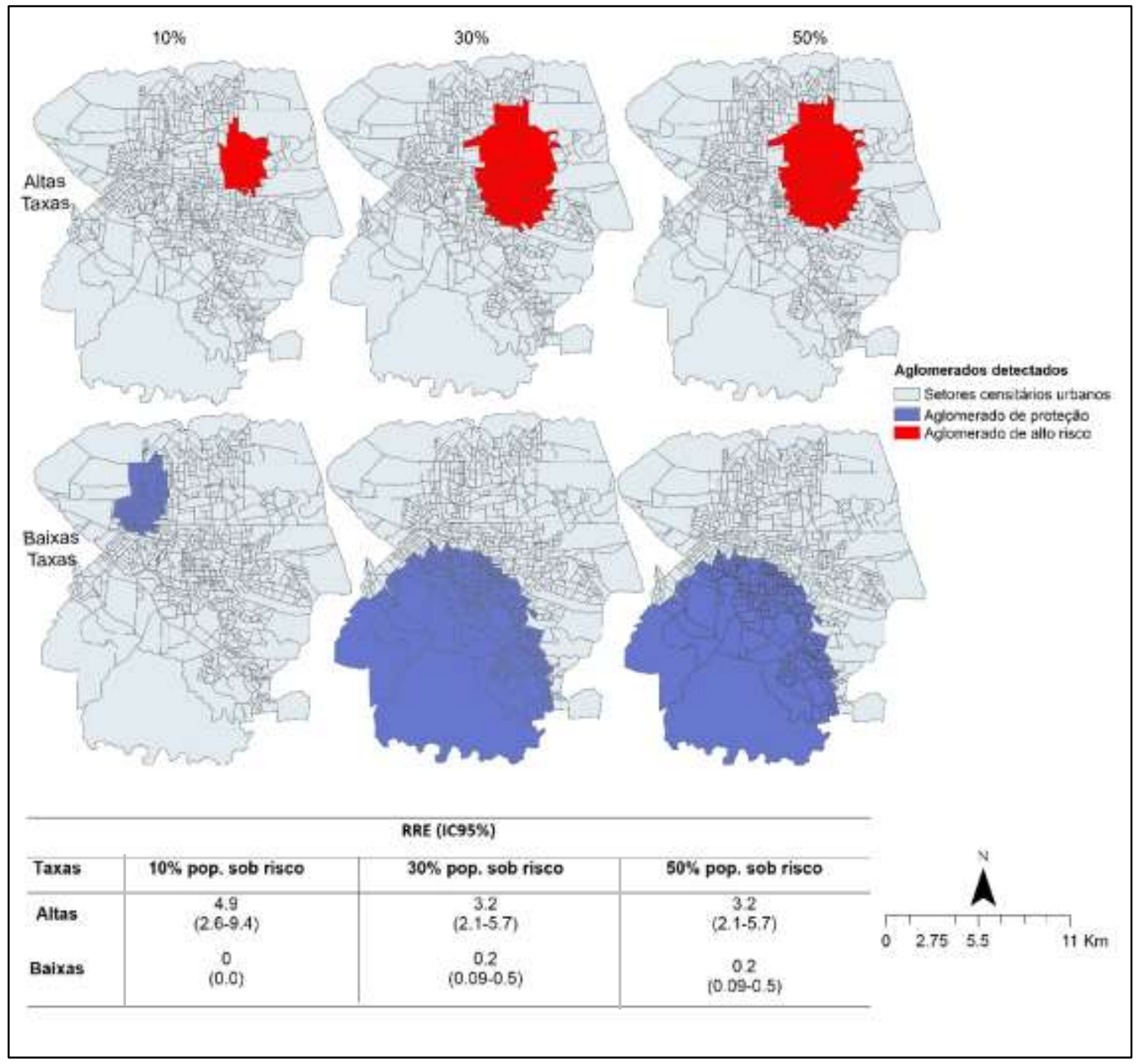

Fonte: próprio autor

Referente à Estatística de Varredura Espacial Isotônica, na Figura 17 pode-se observar que os aglomerados espaciais de risco também se encontram nas regiões Norte e Leste do município, demonstrando que não houve alteração na localização dos aglomerados de risco. Os aglomerados de proteção também mantiveram a mesma localização da varredura tradicional. Os valores dos RRE e $\mathrm{IC}_{95 \%}$ estão descritos na Figura 17. 
Evidencia-se que na versão isotônica estão presentes os Steps in risk function, os quais correspondem às múltiplas janelas circulares formadas durante o processo de centralização da varredura e que também maximizam o LLR.

Esses Steps permitiram averiguar a intensidade da mortalidade dentro dos aglomerados, pois para o aglomerado de risco com $10 \%$ da população pode-se observar que o Step 1 possui o menor raio com $0,3 \mathrm{Km}$ (Tabela 2.), e maior valor para o RRE, com 20,8 ( IC $_{95 \%}$ 7,5-57,1), com 4 óbitos e o Step 2 possui raio de 1,8 Km, RRE= 2,05 (IC $95 \% 1,1-3,0)$, totalizando 14 óbitos.

Para o aglomerado de risco para $50 \%$ da população sob risco obtiveram-se seis steps. O Step 1 possui raio, de $0.3 \mathrm{Km}, \mathrm{RRE}=24,4$ ( $\left.\mathrm{IC}_{95 \%} 8,9-67,3\right)$, com 4 óbitos, e o Step 6 apresentou raio de $3.9 \mathrm{Km}, \mathrm{RRE}=1,4$ ( $\left.\mathrm{IC}_{95 \%} 1,3-3,9\right)$, com 38 óbitos. Desse modo, nota-se que, para os aglomerados de risco, quanto menor o raio do aglomerado, maior o valor do RRE.

Referente aos aglomerados de proteção, destaca-se que o Step 1 possui o menor RRE, como ocorre no aglomerado para $30 \%$ da população sob risco, onde o Step 1 apresentou raio de 4,0 Km e RRE =0. Já o Step 2 obteve raio de 6,0, $\mathrm{RRE}=0,25\left(\mathrm{IC}_{95 \%}\right.$ 0,1-0,6), totalizando cinco óbitos, isto é, quanto menor o raio, menor o valor do RRE. 
Figura 17- Aglomerados espaciais dos óbitos por tuberculose através da Estatística de Varredura Espacial Isotônica segundo os "Steps in risk function", Londrina/Paraná, Brasil (2008-2015)

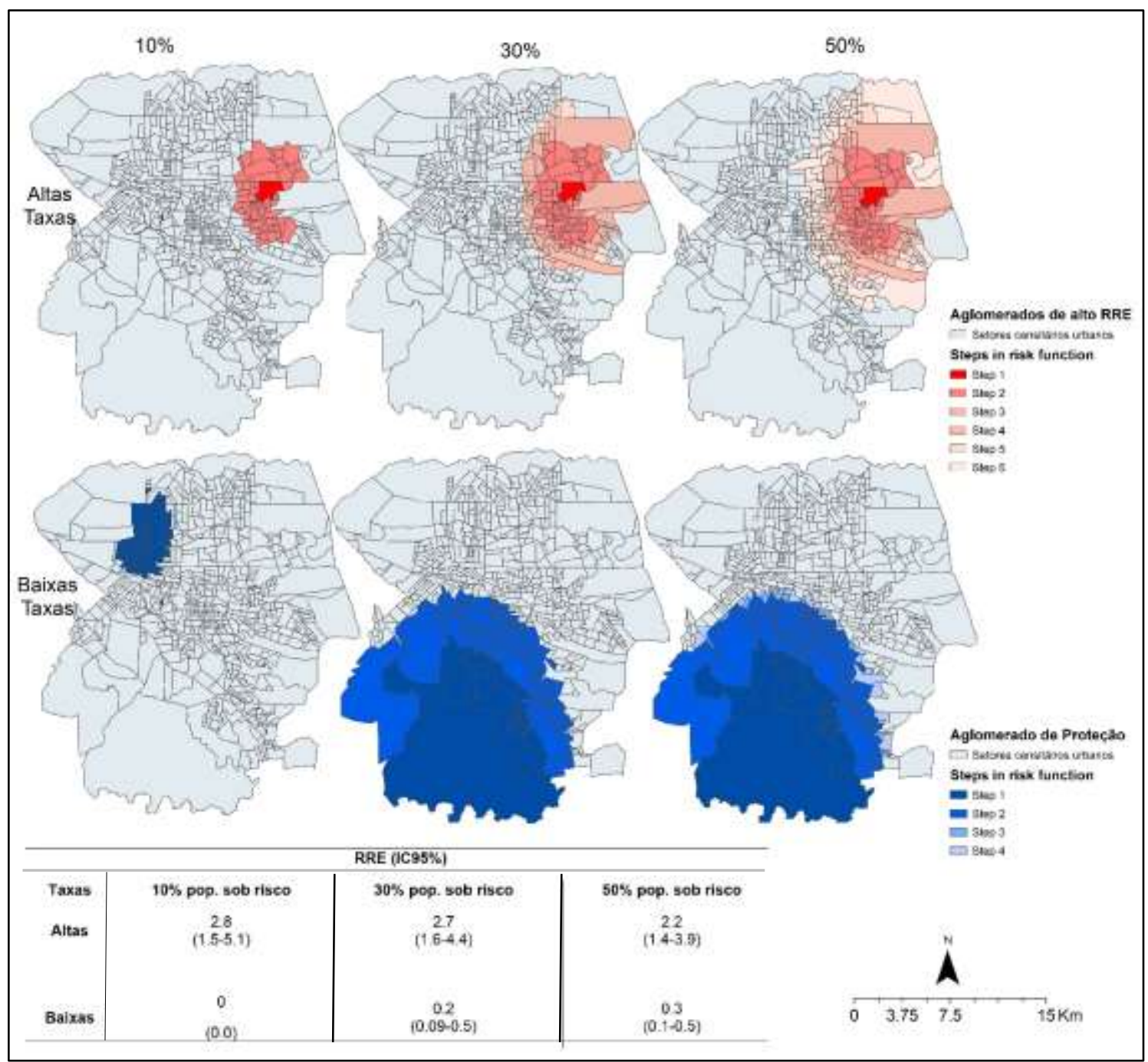

Fonte: próprio autor

A Tabela 2 mostra as características espaciais dos óbitos por TB dentro dos aglomerados identificados através da Estatística de Varredura Espacial Isotônica segundo os Steps in risk function. 
Tabela 3- Aglomerados espaciais de risco das mortes por TB segundo Steps in risk function. Londrina/Paraná, Brasil (2008-2015)

\begin{tabular}{|c|c|c|c|c|c|c|c|c|c|}
\hline Taxas & $\begin{array}{c}\text { Pop. } \\
\text { sob } \\
\text { risco } \\
(\%)\end{array}$ & $\begin{array}{c}\text { Steps in } \\
\text { risk } \\
\text { function }\end{array}$ & $\begin{array}{l}\text { No. Setores } \\
\text { censitários }\end{array}$ & $\begin{array}{c}\text { Pop. do } \\
\text { Aglomerado }\end{array}$ & $\begin{array}{c}\text { Casos } \\
\text { anuais/ } \\
100.000\end{array}$ & $\begin{array}{l}\text { No. } \\
\text { casos }\end{array}$ & $\begin{array}{c}\text { Casos } \\
\text { esperados }\end{array}$ & $\begin{array}{c}\text { RRE* }^{*} \\
\left(\text { IC }_{\mathbf{9 5 \%}}\right)\end{array}$ & $\begin{array}{l}\text { Raio } \\
(\mathbf{k m})\end{array}$ \\
\hline \multirow[t]{13}{*}{ Altas } & \multirow[t]{2}{*}{10} & 1 & 2 & 1846 & 27,0 & 4 & 0,2 & $\begin{array}{c}20,8 \\
(7,5-57,1)\end{array}$ & 0,3 \\
\hline & & 2 & 62 & 47193 & 3,7 & 14 & 5,7 & $\begin{array}{c}2,05 \\
(1,1-3,7)\end{array}$ & 1,8 \\
\hline & \multirow[t]{5}{*}{30} & 1 & 2 & 1846 & 27,0 & 4 & 0,2 & $\begin{array}{c}24,4 \\
(8,9-67,3)\end{array}$ & 0,3 \\
\hline & & 2 & 71 & 55843 & 3,5 & 16 & 6,8 & $\begin{array}{c}2,43 \\
(1,4-4,3)\end{array}$ & 1,9 \\
\hline & & 3 & 107 & 79956 & 3,2 & 21 & 2,9 & $\begin{array}{c}2,31 \\
(1,3-3,9)\end{array}$ & 2,5 \\
\hline & & 4 & 130 & 95969 & 3,1 & 24 & 3,6 & $\begin{array}{c}2,09 \\
(1,2-3,4)\end{array}$ & 2,8 \\
\hline & & 5 & 149 & 112273 & 3,0 & 27 & 2,0 & $\begin{array}{c}2,03 \\
(1,2-3,3)\end{array}$ & 2,9 \\
\hline & \multirow[t]{6}{*}{50} & 1 & 2 & 1846 & 27,0 & 4 & 0,2 & $\begin{array}{c}24,46 \\
(8,9-67,3)\end{array}$ & 0,3 \\
\hline & & 2 & 71 & 55843 & 3,5 & 16 & 6,8 & $\begin{array}{c}2,43 \\
(1,4-4,3)\end{array}$ & 1,9 \\
\hline & & 3 & 107 & 79956 & 3,2 & 21 & 2,9 & $\begin{array}{c}2,31 \\
(1,3-3,9)\end{array}$ & 2,5 \\
\hline & & 4 & 130 & 95969 & 3,1 & 24 & 1,9 & $\begin{array}{c}2,09 \\
(1,2-3,4)\end{array}$ & 2,8 \\
\hline & & 5 & 149 & 112273 & 3,0 & 27 & 2,0 & $\begin{array}{c}2,03 \\
(1,2-3,3)\end{array}$ & 2,9 \\
\hline & & 6 & 281 & 203846 & 2,3 & 38 & 11,7 & $\begin{array}{c}1,4 \\
(1,3-3,9)\end{array}$ & 3,9 \\
\hline \multirow[t]{7}{*}{ Baixas } & 10 & 1 & 63 & 53032 & 0 & 0 & 6,1 & $\begin{array}{c}0 \\
(0,0)\end{array}$ & 1,6 \\
\hline & \multirow[t]{2}{*}{30} & 1 & 31 & 23448 & 0 & 0 & 2,7 & $\begin{array}{c}0 \\
(0,0)\end{array}$ & 4,0 \\
\hline & & 2 & 216 & 35782 & 1,7 & 5 & 15,5 & $\begin{array}{c}0,2 \\
(0,1-0,6)\end{array}$ & 6,0 \\
\hline & \multirow[t]{4}{*}{50} & 1 & 31 & 23448 & 0 & 0 & 2,7 & $\begin{array}{c}0 \\
(0,0)\end{array}$ & 4,0 \\
\hline & & 2 & 217 & 144348 & 0,4 & 5 & 15,6 & $\begin{array}{c}0,2 \\
(0,09-0,6)\end{array}$ & 6,0 \\
\hline & & 3 & 230 & 154346 & 0,5 & 6 & 1,3 & $\begin{array}{c}0,6 \\
(0,1-0,5)\end{array}$ & 6,0 \\
\hline & & 4 & 261 & 156194 & 0,6 & 8 & 2,3 & $\begin{array}{c}0,6 \\
(0,1-0,6)\end{array}$ & 6,3 \\
\hline
\end{tabular}


A seguir, a Tabela 3 faz uma comparação dos dados obtidos através da varredura Tradicional e a Isotônica.

Tabela 4- Comparação entre a Estatística de Varredura Espacial Tradicional e a Isotônica. Londrina/Paraná, Brazil (2008-2015)

\begin{tabular}{|c|c|c|c|c|c|c|c|}
\hline \multirow{2}{*}{$\begin{array}{c}\text { Taxas } \\
\text { Pop. sob risco } \\
(\%)\end{array}$} & & \multicolumn{3}{|c|}{ Altas } & \multicolumn{3}{|c|}{ Baixas } \\
\hline & & 10 & 30 & 50 & 10 & 30 & 50 \\
\hline \multirow{2}{*}{$\begin{array}{l}\text { No. setores } \\
\text { censitários }\end{array}$} & Tradicional & 32 & 153 & 153 & 63 & 216 & 217 \\
\hline & Isotônica & 60 & 149 & 281 & 63 & 216 & 261 \\
\hline \multirow{2}{*}{$\begin{array}{c}\text { Pop. do } \\
\text { aglomerado }\end{array}$} & Tradicional & 22993 & 102433 & 102433 & 53032 & 143762 & 144328 \\
\hline & Isotônica & 47193 & 112265 & 203830 & 53032 & 143762 & 172652 \\
\hline \multirow{2}{*}{$\begin{array}{c}\text { Casos anuais/ } \\
100.000\end{array}$} & Tradicional & 6,4 & 3,4 & 3,4 & 0 & 0,4 & 0,4 \\
\hline & Isotônica & 3,7 & 3,0 & 2,3 & 0 & 0,4 & 0,6 \\
\hline \multirow{2}{*}{ No. casos } & Tradicional & 12 & 29 & 29 & 0 & 5 & 5 \\
\hline & Isotônica & 14 & 27 & 38 & 0 & 5 & 8 \\
\hline \multirow{2}{*}{ Casos esperados } & Tradicional & 2,9 & 13,3 & 13,3 & 6 & 18,3 & 18,4 \\
\hline & Isotônica & 5,9 & 14 & 25,8 & 6,1 & 18,3 & 22 \\
\hline \multirow{2}{*}{ Raio (Km) } & Tradicional & 1,4 & 2,4 & 2,4 & 1,6 & 5,9 & 6,0 \\
\hline & Isotônica & 1,8 & 2,9 & 3,9 & 1,6 & 5,9 & 6,3 \\
\hline \multirow{2}{*}{ LLR* } & Tradicional & 8,7 & 9,7 & 9,7 & 6,4 & 8,7 & 8,7 \\
\hline & Isotônica & 9,6 & 12,3 & 12,7 & 6,4 & 9,5 & 9,9 \\
\hline \multirow{2}{*}{$p$-valor } & Tradicional & 0,05 & $0,02 * *$ & $0,03 * *$ & 0,05 & $0,04 * *$ & $0,04 * *$ \\
\hline & Isotônica & $0,04 * *$ & $0,01 * *$ & $<0,01 * *$ & 0,05 & $0,02 * *$ & $0,02 * *$ \\
\hline
\end{tabular}

* Log Likelihood Ratio

Por meio da Tabela 3, foi possível observar que a versão isotônica abrangeu mais setores censitários devido a maior dimensão dos raios. Para $10 \%$ e $50 \%$ da população obteve-se, respectivamente, 60 e 281 setores na versão isotônica, contra 32 e 153 setores na versão tradicional.

Quanto aos casos de óbito por TB, a versão tradicional captou menos casos do 
que a isotônica, e para $50 \%$ da população a versão tradicional apresentou 29 óbitos contra 38 na isotônica.

O RRE na versão tradicional manteve-se maior do que na versão isotônica, variando de 3,2 a 4,9 e 2,2 a 2,8, porém ressalta-se que na versão isotônica os RRE assumiram padrões mais altos dentro dos steps, variando de 1,4 a 24,4. O mesmo ocorre com as taxas de mortalidade, na versão tradicional obtiveram-se 3,4 a 6,4 óbitos por 100 mil habitantes, enquanto que na versão isotônica, obtiveram-se 2,3 a 3,7 óbitos por 100 mil habitantes, porém as taxas dentro dos steps variaram de 3,0 a 27,0 óbitos por 100 mil habitantes.

Para os aglomerados de proteção, observa-se que considerando $10 \%$ e $30 \%$ da população sob risco os dados dos aglomerados são correspondentes, porém quando porcentagem da população sob risco é alterado para 50\%, nota-se que a versão isotônica agregou mais setores censitários com 261 setores e mais óbitos por TB, totalizando 8 .

Um aspecto importante a ser ressaltado consiste nos valores de LLR, visto que a Tabela 3 deixa explícito que, na versão isotônica os LLRs mantiveram-se aumentados tanto para os aglomerados de risco quanto os de proteção, destacando que a aleatoriedade dos aglomerados na versão isotônica é menor, se comparada à tradicional. 
7. DISCUSSÃO

"A injustiça num lugar qualquer é uma ameaça à justiça em todo o lugar"

(Martin Luther King) 
O estudo teve como objetivo identificar aglomerados espaciais de risco para ocorrência da mortalidade por tuberculose em Londrina. Ao analisar as características sociodemográficas dos óbitos por TB, identificou-se que a faixa etária mais acometida foi correspondente a população economicamente ativa, corroborando com os achados na literatura (AUGUSTO, 2013).

$\mathrm{O}$ fato de atingir as pessoas que se concentram na faixa economicamente ativa acaba por impactar negativamente na sua condição socioeconômica, já que se trata de uma doença que atinge as camadas menos favorecidas da população (CECILIO, 2013).

Além disso, ocorre uma sucessão de eventos relacionados à doença que passam a debilitar o indivíduo, tornando-o enfraquecido e contribuindo para uma consequente desnutrição, e este quadro progressivo pode levar à incapacidade de realizar suas próprias atividades, gerando desemprego e prejudicando ainda mais a situação financeira do indivíduo e de sua família. (PINTO et al, 2015).

É importante destacar neste momento a relação da condição socioeconômica do indivíduo doente com os gastos catastróficos relacionados à doença, que dizem respeito aos gastos com saúde devido a pagamentos realizados pelo próprio usuário com seus próprios recursos, dificultando ainda mais a continuidade do tratamento e o acesso aos serviços de saúde (BRASIL, 2017).

Apesar da predominância dos óbitos na meia-idade, destacam-se também os óbitos em idosos, pois nas regiões do país com alta expectativa de vida, assim como no município em estudo, torna-se importante atentar para o crescimento da incidência da TB na população idosa, tendo em vista que probabilidade de sobrevida pós TB é reduzida, se comparada aos mais jovens, devido ao declínio do sistema imunológico, podendo contribuir, desta forma, com o aumento da mortalidade nessas regiões (YEN, 2017; ZHENG, 2017; RAIMUNDO, 2016)

O sexo masculino foi o mais acometido pelos óbitos, assim como nos estudos de Dale (2016), Beyene (2016) e Ferrer (2013), os quais associam este evento ao fato de os homens estarem mais presentes no mercado de trabalho, menos presentes nos serviços de saúde e obterem maior prevalência de alcoolismo e de uso de drogas de abuso.

Além disso, os fatores culturais são tidos como os responsáveis por estes comportamentos que acabam por dificultar um acompanhamento mais integral da saúde do homem, incluindo ações de prevenção da população masculina (OLIVEIRA et al., 2009). 
Atualmente, a mulher vem se inserindo de forma significante no mercado de trabalho e conquistando o seu espaço, mas em algumas famílias são os homens os responsáveis pelo sustento da família, o que gera uma exposição maior ao Mycobacterium tuberculosis devido à rotina fora do domicílio (KNAUTH; COUTO; CALIARI; et al., 2012).

Outro fator que culmina com a maior prevalência da doença nos homens do que nas mulheres seria justamente o horário de funcionamento dos serviços de saúde, pois coincide com o horário do término de seus serviços (BELO et al, 2010).

Estudos revelam que a mortalidade por TB no Brasil ocorre predominantemente na população não branca (CECCON, 2017; CARDOSO, 2015; SANTOS-NETO, 2014), porém, no estudo a etnia branca foi a mais atingida, provavelmente devido ao fato de o município ter sido colonizado por europeus e $70 \%$ da população ser constituída pela etnia branca (IPARDES, 2016; DESSUNTI, 2013, FURLAN; OLIVEIRA; MARCON 2012).

No que se refere ao nível de escolaridade, estudos relatam que o baixo nível de escolaridade pode influenciar de forma negativa na aquisição de informações, já que o grau de instrução fornece um maior entendimento dos conhecimentos sobre a própria doença, aumentando, desta forma, a vulnerabilidade à TB ao refletir acesso individual e desigual à informação, aos bens de consumo e ao próprio serviço de saúde, funcionando como um marcador de precárias condições de vida (FURLAN; OLIVEIRA; MARCON, 2012; SAN PEDRO, 2013).

Além disso, a literatura também mostra o nível de escolaridade como uma ferramenta essencial para o entendimento do doente de TB quanto a sua situação clínica e ao acompanhamento do tratamento, reduzindo o índice de abandono e o risco para o óbito (SANCHEZ-BARRIGA, 2015; LIN, YEN, 2015; BLONDAL, 2013).

Em Londrina, a maioria dos casos apresentou ensino médio concluído, por esse motivo, no presente estudo, não é possível compreender como o nível de escolaridade desses indivíduos interferiu ou não no comprometimento do tratamento. Pelo fato de a literatura relacionar os óbitos de TB a situações de baixa escolaridade, é possível entender que, para o cenário de Londrina, outros fatores tiveram peso mais negativo que a escolaridade.

No que tange à ocupação, prevaleceram os aposentados/pensionistas, fato este que corrobora com o resultado do alto acometimento da população idosa ao óbito por TB no município em estudo. 
Segundo Cavalcante e Silva (2013) isto se dá devido ao fato dos aposentados apresentarem maior vulnerabilidade referente a condição econômica, dificuldade para deslocarem-se aos serviços de saúde, abandono dos familiares e à problemática da implementação de uma política pública que atenda as demandas à saúde do idoso.

Além disso, os idosos apresentam uma perda de reatividade imune celular para Mycobaterium tuberculosis, tornando-os mais vulneráveis tanto à infecção exógena quanto para a reativação de focos contendo bacilos em estado de latência (CHAVES et al., 2017).

A maioria dos óbitos ocorreu no nível hospitalar após receberem assistência médica; este achado pode sugerir a uma série de acontecimentos que podem ter contribuído para o óbito por TB, destaca-se, a dificuldade dos serviços de saúde na realização do diagnóstico da TB, seja pela APS quanto nos hospitais (SALINAS, 2012; SAIFOFINE, 2013).

No que se refere às formas clínicas, o estudou evidenciou a forma pulmonar como a mais frequente. Essa é a forma mais preocupante par o âmbito da saúde pública, tendo em vista que é a responsável pela transmissão da doença assim como em outros estudos de mortalidade (SANCHEZ-BARRIGA, 2015; DALE, 2016).

Todavia, além das características individuais e de organização dos serviços de saúde relacionados à mortalidade por $\mathrm{TB}$, é importante compreender os aspectos sociais e ambientais determinantes para a ocorrência desse evento, tendo em vista que o comportamento dessa enfermidade é fortemente influenciado pelo espaço (PINTO et al., 2015).

Dessa forma, torna-se fundamental estudá-los, também, sob a perspectiva da distribuição espacial, integrando dados de saúde disponíveis no SIM com dados ambientais e sociais, a partir do Sistema de Informação Geográfica (SIG), permitindo, assim, melhor caracterização e quantificação dos óbitos e seus possíveis determinantes (PEREIRA et al., 2015)

A análise espacial em saúde tem como principais aplicações o mapeamento de doenças (construção de mapas de indicadores epidemiológicos), a detecção de aglomerados (identificação de áreas de maior incidência) e processos de difusão e a avaliação da evolução da distribuição espacial de doenças (NARDI, et al., 2013)

No caso da TB, o emprego de um SIG possibilita a identificação de áreas onde se localizam eventos relevantes para o processo de transmissão da tuberculose (casos de retratamento e famílias com mais de um caso no período), ou simplesmente de áreas de 
maior incidência da doença, constituindo instrumento útil para a estruturação de um sistema de VS com base territorial, identificando grupos populacionais prioritários. Além disso, esse sistema permite refinar o foco de atenção para microáreas prioritárias e carentes de intervenções intensivas, como forma de enfrentar o problema da tuberculose com emprego racional de recursos (YAKAM et al., 2014).

Nesse contexto, o estudo demonstrou que a distribuição espacial dos casos de óbito por TB é heterogênea, isto é, não estavam distribuídos por todo o munícipio equitativamente, assim como achados no estudo realizado no Rio de Janeiro (MAGALHÃES; MEDRONHO, 2017). Este fato foi comprovado também pela correlação espacial, através do cálculo do Índice Global de Moran das taxas de mortalidade.

Dentre as diversas técnicas estatísticas existentes para mapear eventos e a forma de distribuição dos pontos, destaca-se a técnica Kernel, a qual pode facilitar e subsidiar a ações da VS para controle da TB, tendo em vista que fornece uma visão geral da distribuição dos pontos amostrais, bem como indicativo da ocorrência de aglomerados (CÂMARA et al., 2004).

Cabe ressaltar que as áreas com maior densidade de óbitos por $\mathrm{Km}^{2}$ apontadas pela densidade de pontos foram compatíveis com a técnica de detecção de aglomerados de risco, a Estatística de Varredura.

Quanto aos métodos de análise utilizados com vistas à identificação do risco de mortalidade nas áreas sob estudo, verificou-se que ambas as técnicas aplicadas, a Estatística de Varredura Espacial Tradicional e Isotônica, aplicadas evidenciaram aglomerados espaciais de risco e de proteção para ocorrência do óbito por TB (Figuras 16 e 17), em semelhantes regiões do município em estudo, porém com diferentes conformações. Observou-se que a análise Estatística de Varredura Espacial Isotônica obteve aglomerados espaciais de risco com maiores dimensões, agregando mais setores censitários e com maior número de óbitos, se comparada ao método Tradicional. Esse achado corrobora com estudo realizado por Kulldorff (1999) sobre câncer de mama nos Estados Unidos.

Assim como apontado nos resultados do estudo, a varredura espacial detecta a localização geral do aglomerado tratando o RRE como um valor constante, já a versão isotônica apresenta os "Steps in Risk Function", os quais estratificaram os tamanhos dos raios e os valores do RE dentro do aglomerado, permitindo um melhor diagnóstico da 
situação da mortalidade no município, evidenciando assim áreas com riscos reais para ou evento ou, mesmo, que consistem em regiões de proteção.

Ainda sobre a varredura, destaca-se que a versão isotônica apresentou valores de LLR maiores do que na tradicional, o que reflete em dois aspectos. $\mathrm{O}$ primeiro consiste na significância estatística dos achados, pois o aglomerado com maior LLR é o maior significante e isso consiste da sua não aleatoriedade. $O$ segundo aspecto consiste na maximização dos valores de LLR através da função de regressão isotônica para o RRE, assim como descrito por Kulldorff (1999).

Considerando a população e o cenário em estudo, a estatística de varredura espacial isotônica revelou ser mais sensível para a detecção dos aglomerados espaciais de risco e proteção, desvelando-se uma ferramenta útil a ser utilizada por epidemiologistas, investigadores e profissionais da saúde que também estejam trabalhando com eventos não frequentes, que no estudo foram os óbitos por TB.

Há ainda que se considerar as variações do RRE dentro do aglomerado como importante resultado que pode desvelar as persistentes iniquidades de acesso aos serviços de saúde, persistentes mesmo dentro de uma região detectada como risco, tendo em vista que o risco não é homogéneo e sofre variações intra-aglomerado.

Acresce-se a discussão sobre os aglomerados de proteção, os quais foram identificados por ambas as análises (tradicional e isotônica). Vale ressaltar que os resultados alcançados são decorrentes dos dados gerados pelos serviços de saúde; e, desta forma, sua existência pode ser também em decorrência da subnotificação da TB, embora se reconheça que o SIM é tido como padrão ouro em todo o território nacional.

Sendo a TB a líder das doenças infecciosas que mais matam no mundo, novas abordagens devem ser utilizadas com vistas à compreensão do problema e dar pistas aos caminhos para seu enfrentamento. As análises utilizadas no presente estudo podem servir como referência para outras doenças negligenciadas, como leishmaniose, Chagas, tracoma, incapacidades por hanseníase, entre outros (THERON et al.., 2015, BRASIL, 2017).

Em termos de avanço do conhecimento, técnicas mais robustas e exigentes em termos do "n" podem inferir o "não" risco a que uma população está exposta, quando na verdade ele está presente e pode ficar oculto aos olhos dos serviços de saúde e ao trabalho da vigilância em saúde. Se a ideia é o alcance da meta até 2035 de redução em 95\% dos casos, uma abordagem por localidade e com técnicas sensíveis a populações mais vulneráveis é absolutamente salutar. Stevens e Pfeiffer (2011) corroboram com 
esse pensamento ao destacarem que metodologias inovadoras para a abordagem espacial em saúde mais sensíveis possibilita a descoberta de resultados mais condizentes com a situação real e são um grande orientador para a tomada decisão em saúde.

Dentre as limitações desta investigação, sobressai a utilização de estudos ecológicos que têm restrições inerentes ao próprio método, não podendo inferir aos achados do município para o nível individual (CAMPOS; THEME-FILHA, 2012). Destaca-se então a falácia ecológica, associação observada entre variáveis em nível agregado que, necessariamente, não representa uma associação em nível individual (MORGENSTERN, 1995).

Tem-se ainda uma lacuna no que diz respeito ao sistema de informação utilizado, que, mesmo sendo o pioneiro a ser estruturado e ser o padrão ouro para utilização em pesquisas científicas, ele pode conter subnotificação de dados dos óbitos por TB. Além disso, a utilização de dados secundários que, pela incompletude ou pela presença de dados ignorados, podem ter trazido algum viés ao estudo.

Outra limitação consiste no uso apenas de áreas urbanas pelo fato de dificuldade no georreferenciamento dos endereços das regiões rurais.

No que se refere às potencialidades do estudo, podemos destacar a relevância de estudos com a abordagem ecológica para avaliar o impacto de mudanças sociais e intervenções na comunidade e, dessa maneira, auxiliar na alocação de recursos humanos e financeiros com o objetivo de alcançar a equidade no acesso aos serviços de saúde. (BITTENCOURT; CAMACHO; LEAL, 2006; SOARES; NASCIMENTO, 2010).

Somado a isso, esta investigação possui grande relevância na medida em que permite observar os agrupamentos dos óbitos por TB de forma a levantar hipóteses sobre os acontecimentos extrínsecos, tais como condições de vida, sociais e econômicos e até mesmo a organização dos serviços de saúde, fatores estes que podem determinar a mortalidade por TB.

Por fim, a identificação das áreas prioritárias para controle e combate da TB é fundamental para subsidiar o planejamento público das ações e o direcionamento da VS, para populações e áreas com maiores riscos para a ocorrência do óbito por TB. 


\section{CONCLUSÃO}

"Mestre não é quem sempre ensina, mas quem de repente aprende"

(Guimarães Rosa) 
Em conclusão, o estudo comprovou que a distribuição dos óbitos por TB no município de Londrina é heterogênea, além disso, comprovou que há correlação espacial das taxas de mortalidade, demonstrando que o padrão espacial dos óbitos não é aleatório.

A análise de densidade de pontos apontou as principais regiões vulneráveis à ocorrência do óbito por $\mathrm{TB}$, regiões estas que também foram detectadas com altos valores de risco para a ocorrência da mortalidade, perante análise de detecção de aglomerados espaciais.

A Estatística de Varredura Espacial Isotônica demonstrou-se mais sensível para detecção de aglomerados espaciais de risco para eventos mais específicos e menos frequente como no caso de taxas de mortalidade. Além disso, um importante diferencial dessa análise consiste nos Steps in risk function, pois permitem visualizar o gradiente do RRE dentro do aglomerado, dessa forma, evidenciou-se como uma ferramenta importante para análise local realizada pelos serviços de saúde da APS, principalmente às equipes da ESF.

A divulgação desses métodos de análise espacial pode contribuir para a compreensão mais aprofundada da problemática das mortes por tuberculose, notadamente em grupos mais vulneráveis. Esses tipos de abordagens serviria como uma espécie de lupa na busca por objetos menores, deixando os contornos dos óbitos mais evidentes, o que é profícuo na área da saúde.

Portanto, a identificação do gradiente do RRE nas populações expostas, certamente, servirá como um indutor de mudanças em termos da melhoria do acesso aos serviços de saúde no intuito de promover ambientes saudáveis, eliminando-se ou reduzindo os fatores predisponentes à ocorrência do óbito por TB. Espera-se que com isso, o país possa alcançar o nível certo de equidade, sem mortes injustas ou socialmente determinadas, e livre da TB. 
9. REFERÊTCIAS

* De acordo com a Associação Brasileira de Normas Técnicas. NBR 6023. 
ALAVI-NAINI R. et al. Factores associated with mortality in tuberculosis patients. Journal of Research in Medical Sciences, Índia, v. 18, n. 1, p.52-55, 2013. Disponível em: <https://www.ncbi.nlm.nih.gov/pmc/articles/PMC3719227/ >. Acesso em: 15 mai. 2017.

ALBUQUERQUE, M.F.P., et al. Risk factors associated with death in patients who initiate treatment for tuberculosis after two different follow-up periods. Revista Brasileira de Epidemiologia, São Paulo, v. 12, n.4, p.513-522, 2009. Disponível em:<http://www.scielo.br/pdf/rbepid/v12n4/01.pdf >. Acesso em: 17 jan. 2018.

ASSIS, M.M.A.; JESUS, W.L.A. Acesso aos serviços de saúde: abordagens, conceitos, políticas e modelo de análise. Ciência \& Saúde Coletiva, Rio de Janeiro, v. 17, p. 2865-2875, 2012. Disponível em: <http://www.scielo.br/pdf/csc/v17n11/v17n11a02.pdf>. Acesso em: 15 jan. 2018.

AUGUSTO, C. J. et al. Characteristics of tuberculosis in the state of Minas Gerais, Brazil: 2002-2009. Jornal Brasileiro de Pneumologia, São Paulo, v. 39, n. 3, p. 357364, 2013. Disponível em: <http://www.scielo.br/pdf/jbpneu/v39n3/1806-3713-jbpneu39-03-0357.pdf >. Acesso em: 10 set. 2017.

AYRES, J. R. C. M. et al. O conceito de vulnerabilidade e as práticas de saúde: novas perspectivas e desafios. Promoção da saúde: conceitos, reflexões, tendências, v. 2, p. 121-144, 2009.

AZAGE, M. et al. Childhood diarrhea exhibits spatiotemporal variation in northwest Ethiopia: a SaTScan spatial statistical analysis. PloS one, v. 10, n. 12, p. e0144690, $2015 . \quad$ Disponível em: $<$ http://journals.plos.org/plosone/article/file?id=10.1371/journal.pone.0144690\&type $=\mathrm{p}$ rintable >. Acesso em: 18 set. 2017.

BARBOSA, I. R. et al. Análise da distribuição espacial da tuberculose na região Nordeste do Brasil, 2005-2010. Epidemiologia e Serviços de Saúde, Brasília, v. 22, n. 4, 2013.2 Disponível em: <http://scielo.iec.pa.gov.br/scielo.php?script=sci_arttext\&pid=S1679497420130004000 15> Acesso em: 30 mai. 2017.

BARCELLOS, C.; SANTOS, S. M.. Colocando dados no mapa: a escolha da unidade espacial de agregação e integração de bases de dados em saúde e ambiente através do geoprocessamento. Informe Epidemiológico do Sus, Brasília , v. 6, n. 1, p. 2129, mar. 1997 . Disponível em < http://scielo.iec.gov.br/pdf/iesus/v6n1/v6n1a03.pdf >. acessos em : ago. 2017.

BELO, M.T.C.T. et al . Tuberculose e gênero em um município prioritário no estado do Rio de Janeiro. Jornal Brasileiro de Pneumologia, São Paulo , v. 36,n. 5, p. 621-625, 2010 
BEYENE, Y.; GERESU, B.; MULU, A. Mortality among tuberculosis patients under DOTS programme: a historical cohort study. BMC public health, v. 16, n. 1, p. 883, 2016. Disónível em: https://bmcpublichealth.biomedcentral.com/track/pdf/10.1186/s12889-016-35570 ? site=bmcpublichealth.biomedcentral.com >. Acesso em 30 ago. 2017.

BITTENCOURT, S. A.; CAMACHO, L. A. B.; LEAL , M. C. O Sistema de Informação Hospitalar e sua aplicação na saúde coletiva. Cadernos de Saúde Pública, Rio de Janeiro, v. 22, n. 1, p. 19-30, 2006. Disponível em: <http://www.scielo.br/pdf/csp/v22n1/03.pdf>. Acesso em: 10 dez. 2017.

BLÖNDAL, K. et al. Overall and cause-specific mortality among patients with tuberculosis and multidrug-resistant tuberculosis. The International Journal of Tuberculosis and Lung Disease, v. 17, n. 7, p. 961-968, 2013. Disponível em:< http://docserver.ingentaconnect.com/deliver/connect/iuatld/10273719/v17n7/s18.pdf?ex pires $=1518519602 \&$ id $=0000 \&$ titleid $=3764 \&$ checksum $=$ A2F238B8A89466A73265E 82 3D6E1E446>. Acesso em: 25 set. 2017.

BRASIL. Programa Nacional de Controle a Tuberculose. Ministério da Saúde, 2012 Disponível em: $<$ portal.saude.gov.br/portal/arquivos/pdf/2ap_padrao_tb_20_10_11.pdf>. Acesso em: 20 set. 2017.

L

BRASIL. Ministério da Saúde. Secretaria de Vigilância em Saúde. Departamento de Vigilância das Doenças Transmissíveis. Plano nacional pelo fim da tuberculose / Ministério da Saúde, Secretaria de Vigilância em Saúde, Departamento de Vigilância das Doenças Transmissíveis. - Brasília : Ministério da Saúde, 2017. Disponível em: $<$ http://portalarquivos.saude.gov.br/images/pdf/2017/fevereiro/24/Plano-NacionalTuberculose.pdf >. Acesso em: 28 jun. 2017.

BRASIL. Ministério da Saúde. Secretaria de Vigilância em Saúde. Departamento de Vigilância das Doenças Transmissíveis. Panorama da tuberculose no Brasil: indicadores epidemiológicos e operacionais / Ministério da Saúde, Secretaria de Vigilância em Saúde, Departamento de Vigilância das Doenças Transmissíveis. Brasília, 2014. Disponível em: <http://bvsms.saude.gov.br/bvs/publicacoes/panorama\%20tuberculose\%20brasil_2014. pdf >. Acesso em: 20 ago. 2016.

BRASIL. Ministério da Saúde. Secretaria de Vigilância em Saúde. Departamento de Vigilância Epidemiológica. Manual de recomendações para o controle da tuberculose no Brasil / Ministério da Saúde, Secretaria de Vigilância em Saúde, Departamento de Vigilância Epidemiológica. - Brasília : Ministério da Saúde, 2011. Disponível em: <http://bvsms.saude.gov.br/bvs/publicacoes/manual_recomendacoes_controle_tubercul ose_brasil.pdf >. Acesso em: 20 jun. 2017.

BRASIL. Ministério da Saúde. Secretaria de Vigilância em Saúde. Departamento de Vigilância Epidemiológica. Guia de vigilância epidemiológica / Ministério da Saúde, 
Secretaria de Vigilância em Saúde, Departamento de Vigilância Epidemiológica. - 7. ed. - Brasília : Ministério da Saúde, 2009. 816 p. - (Série A. Normas e Manuais Técnicos).

Disponível

em: <http://bvsms.saude.gov.br/bvs/publicacoes/guia_vigilancia_epidemiologica_7ed.pdf $>$. Acesso em: 24 ago. 2017.

Brasil. Ministério da Saúde. Secretaria de Políticas de Saúde. Projeto Promoção da Saúde. As Cartas da Promoção da Saúde / Ministério da Saúde, Secretaria de Políticas de Saúde, Projeto Promoção da Saúde. - Brasília: Ministério da Saúde, 2002. Disponível em: <http://bvsms.saude.gov.br/bvs/publicacoes/cartas_promocao.pdf>. Acesso em: 05 fev. 2018.

BUSS, P. M; CARVALHO, A. I. Desenvolvimento da promoção da saúde no Brasil nos últimos vinte anos (1988-2008). Ciência \& Saúde Coletiva, Rio de Janeiro, v. 14, n. 6, 2009. Disponível em: < http://www.scielo.br/pdf/csc/v14n6/39.pdf>. Acesso em: 12 jan. 2018.

CÂMARA, G et al. Análise espacial de áreas. In: DRUCK, S. et al. (org.). Análise espacial de dados geográficos. Brasília: Embrapa; 2004. p. 107-151.

CAMPOS, A. Z.; THEME-FILHA, M. M. Internações por condições sensíveis à atenção primária em Campo Grande, Mato Grosso do Sul, Brasil, 2000 a 2009. Cadernos de Saúde Pública, Rio de Janeiro, v. 28, n. 5, p. 845-855, 2012. Disponível em: <http://www.scielo.br/pdf/csp/v28n5/04.pdf>. Acesso em: 09 nov. 2017.

CARDOSO, J. N. Perfil epidemiológico e fatores associados ao óbito por tuberculose em Teresina (2011-2014). Rio de Janeiro, 85p., 2015. (Tese) Escola Nacional de Saúde Pública Sergio Arouca. Disponível em: <http://pesquisa.bvsalud.org/bvsvs/resource/pt/ens-33396>. Acesso em: 19 set. 2017.

CARVALHO, A. X. Y. et al. Taxas bayesianas para o mapeamento de homicídios nos municípios brasileiros. Cadernos de Saúde Pública, Rio de Janeiro, v. 28, p. 12491262, 2012. Disponível em: < http://www.scielo.br/pdf/csp/v28n7/04.pdf>. Acesso em: 05 ago. 2017.

CAVALCANTE, E.F.O.; SILVA, D.M.G.V. Perfil de pessoas acometidas por tuberculose. Revista da Rede de Enfermagem do Nordeste, Fortaleza, v. 14, n. 4, 2013. Disponível em: < file://C:/Users/user/Downloads/1152-7744-1-PB.pdf>. Acesso em: 20 set. 2017.

CECCON, Roger Flores et al. Tuberculosis mortality in Brazilian capitals, 20082010. Epidemiologia e Serviços de Saúde, Brasília, v. 26, n. 2, p. 349-358, 2017. Disponível em: <http://www.scielo.br/pdf/ress/v26n2/en_2237-9622-ress-26-0200349.pdf>. Acesso em: 19 set. 2019.

CECILIO, H.P.M. et al. Profile of hospital admissions and deaths from tuberculosis. Acta Paulista de Enfermagem, São Pailo, v. 26, n. 3, p. 250-255, 2013. Disponível em: <http://www.scielo.br/pdf/ape/v26n3/en_08.pdf >. Acesso em: 13 set. 2017. 
CHAVES, E.C. et al . Aspectos epidemiológicos, clínicos e evolutivos da tuberculose em idosos de um hospital universitário em Belém, Pará. Revista Brasileira de Geriatria e Gerontologia, Rio de Janeiro, v. 20, n. 1, p. 45-55, 2017. Disponível em: $<$ http://www.scielo.br/pdf/rbgg/v20n1/pt_1809-9823-rbgg-20-01-00045.pdf >. Acesso em: 11 fev. 2018.

CORRÊA, R. L. Redes geográficas: reflexões sobre um tema persistente. Cidades, Rio de Janeiro, v. 9, n. 16, p. 200-218, 2012. Disponível em: $<$ http://revista.fct.unesp.br/index.php/revistacidades/article/view/2378/2122>. Acesso em: 12 dez. 2017.

CRUZ-BENITO, J. Systematic Literature Review \& Mapping. 2016. Disponível: <https://repositorio.grial.eu/bitstream/grial/685/3/201611_PhD_EKS_SLR-1.pdf>.

Acesso em: maio de 2017.

DALE, K. et al. Mortality among tuberculosis cases in Victoria, 2002-2013: case fatality and factors associated with death. The International Journal of Tuberculosis and Lung Disease, v. 20, n. 4, p. 515-523, 2016. Disponível em: <http://docserver.ingentaconnect.com/deliver/connect/iuatld/10273719/v20n4/s17.pdf?e xpires $=1518612982 \& i d=0000 \&$ titleid $=3764 \&$ checksum $=$ A9A4995779DDA76F51BA8 4519323AB9B >. Acesso em: 08 set. 2017.

DAVIES, T.M.; HAZELTON, M.L. Adaptive kernel estimation of spatial relative risk. Statistics in Medicine, v. 29, p.2423-2437 2010. Disponível em: http://onlinelibrary.wiley.com/doi/10.1002/sim.3995/pdf>. Acesso em: 10 dez. 2017.

DESSUNTI, E.M. et al. Infecção latente de tuberculose: adesão ao tratamento e evolução dos casos. Revista Enfermagem UERJ, Rio de Janeiro, v. 21, n. 6, p. 711717, 2014. Disponível em: < http://www.facenf.uerj.br/v21esp2/v21e2a03.pdf>. Acesso em 12 set. 2017.

FERRER, G.C. N. et al. The burden of disease due to tuberculosis in the state of Santa Catarina, Brazil. Jornal Brasileiro de Pneumologia, São Paulo, v. 40, n. 1, p. 61-68, 2014. Disponível em: < http://www.scielo.br/pdf/jbpneu/v40n1/1806-3713-jbpneu-4001-00061.pdf >. Acesso em: 05 set. 2017.

FIGUEIREDO, T.M.R.M. et al . Desempenho da atenção básica no controle da tuberculose. Revista de Saúde Pública, São Paulo, v. 43, n. 5, p. 825-831, 2009

Disponível em: <http://www.scielo.br/scielo.php?script=sci_arttext\&pid=S003489102009000500011\&lng=en\&nrm=iso>. Acesso em: 08 dez. 2017.

FORMIGA, M. C. C. et al. Mortalidade Infantil no Estado do Rio Grande do Norte. In: Simpósio Nacional de Probabilidade e Estatística,18. 2008, Estância de São Pedro SP. Anais. Estância de São Pedro, 2008. Disponível em: < http://www.redeabe.org.br/sinape/submissao_ok.php?page=39> Acesso em: 24 ago. 2016.

FURLAN, M.C.R.; OLIVEIRA, S.P.; MARCON, S.S. Factors associated with nonadherence of tuberculosis treatment in the state of Paraná. Acta Paulista de Enfermagem, São Paulo, v. 25, n. SPE1, p. 108-114, 2012. Disponível em: 
http://www.scielo.br/pdf/ape/v25nspe1/pt_17.pdf >. Acesso em: 13 set. 2017.

GALVÃO, T.F.; PEREIRA, M.G. Revisões sistemáticas da literatura: passos para sua elaboração. Epidemiologia e Serviços de Saúde, Brasília, v. 23, p. 183-184, 2014. Disponível em:< http://scielo.iec.gov.br/pdf/ess/v23n1/v23n1a18.pdf >. Acesso em: 30 mai. 2017.

GAO, F. et al. Fine scale Spatial-temporal cluster analysis for the infection risk of Schistosomiasis japonica using space-time scan statistics. Parasites \& vectors, v. 7, n. 1, p. 578, 2014. Disponível em: <https://www.ncbi.nlm.nih.gov/pmc/articles/PMC4273478/pdf/13071_2014_Article_57 8.pdf>. Acesso em 12 set. 2017.

GONZÁLES, R.I.C. et al. A descoberta da tuberculose no território: análise qualitativa do trabalho do agente comunitário de saúde. Ciencia y Enfermeria. Concepción. v. 21, n. 2, p. 87-97, 2015. Disponível em: <http://www.lume.ufrgs.br/bitstream/handle/10183/130185/000977630.pdf?sequence=1 >. Acesso em: 10 jan. 2018.

GORDIS, L. Colocar Medidas de ocorrência das doenças Epidemiology. p. 31-62, Saunders. 2009.

HEAD, M. G. et al. Research Investments in Global Health: A Systematic Analysis of UK Infectious Disease Research Funding and Global Health Metrics, 1997-2013. EBioMedicine 3,. London, v. 3, p. 180-190, 2016. Disponível em: <https://www.ncbi.nlm.nih.gov/pmc/articles/PMC4739409/pdf/main.pdf>. Aceso em: 17 mai. 2016.

HERNANDES, E. et al . Using GQM and TAM to evaluate StArt - a tool that supports Systematic Review. CLEI Eletronic Journal, Montevideo , v. 15, n. 1, p. 32012. Disponível em: < http://www.scielo.edu.uy/pdf/cleiej/v15n1/v15n1a03.pdf>. Acesso em: 20 set 2017.

HINO, P. et al. A ocorrência da tuberculose em um distrito administrativo do município de São Paulo. Escola Anna Nery Revista de Enfermagem, Rio de Janeiro, v. 17, n. 1, p. 153-159, 2013. Disponível em: < http://www.scielo.br/pdf/ean/v17n1/21.pdf>. Acesso em: 20 jan. 2017.

HINO, P. et al. Padrões espaciais da tuberculose e sua associação à condição de vida no município de Ribeirão Preto. Ciência \& Saúde Coletiva, Rio de Janeiro, v.16, n.12, p. 4795-4802, 2011. Disponível em: <http://www.scielo.br/scielo.php?script=sci_arttext\&pid=S1413-81232011001300028>. Acesso em: 20 abr. 2016.

$\begin{array}{lccc}\text { INSTITUTO BRASILEIRO DE GEOGRAFIA } & \text { E ESTATÍSTICA } & \text { (IBGE). Censo } \\ \text { Demográfico } & 2010 . & \text { Disponível } & \text { em: }\end{array}$ <http://www.brasileirosnomundo.itamaraty.gov.br/a-comunidade/estimativaspopulacionais-das-comunidades/estimativas-do-ibge/censo-demografico-ibge2010.pdf>. Acesso em: 20 fev. 2016. 
INSTITUTO PARANAENSE DE DESENVOLVIMENTO ECONÔMICO E SOCIAL.Paraná em números: Caderno Estatístico Município de Londrina, 2016. Disponível em: <http://www.ipardes.gov.br/cadernos/MontaCadPdf1.php?Municipio=86000\&btOk=ok $>$ Acesso em: 20 ago. 2017.

KITCHENHAM, B. Guidelines for Performing Systematic Literature Reviews inSoftware Engineering. EBSE Technical Report, EBSE-2007-001, 2007. Disponível em: < https://userpages.uni-koblenz.de/ laemmel/esecourse/slides/slr.pdf >. Acesso em: 02 dez. 2017.

KNAUTH, D. R.; COUTO, M. T.; FIGUEIREDO, W. S.A visão dos profissionais sobre a presença e as demandas dos homens nos serviços de saúde: perspectivas para a análise da implantação da Política Nacional de Atenção Integral à Saúde do Homem. Ciência \& Saúde Coletiva, Rio de Janeiro, v.17, n.10, p. 2617-2626, 2012. Disponível em: < http://www.scielo.br/pdf/csc/v17n10/11.pdf >. Acesso em: 27 set. 2017.

KULLDORFF, M, Information Management Services, Inc. SaTScanTM User Guide. SaTScanTM v. 9.4: Software for the spatial and space-time scan statistics. Boston (MA): Harvard University; 2015. Disponível em: <https://www.satscan.org/cgibin/satscan/register.pl/SaTScan_Users_Guide.pdf?todo=process_userguide_download>. Acesso em: 20 fev. 2017.

KULLDORFF, M. An isotonic spatial scan statistic for geographical disease surveillance. Journal of the National Institute of Public Health, v. 48, n. 2, p. 94-101, 1999. Disponível em: < https://www.satscan.org/papers/ku-JNIPH1999.pdf>. Acesso em: 02 mar. 2017.

KULLDORFF, M.; NAGARWALLA, N. Spatial disease clusters: Detection and inference. Statistics in Medicine, v. 14, n. 8, p.799-810, 1995. Disponível em: $<$ http://www.ncbi.nlm.nih.gov/pubmed/7644860>. Acesso em: 15 fev. 2016.

LAWSON A.B. et al. Disease mapping models na empirical evaluation. Disease Mapping Collaborative Group. Stat Med, v. 19, p.2217-1141, 2000. Disponível em: <http://www.personal.soton.ac.uk/dab1f10/lawsonetal.pdf>. Acesso em 25 jan. 2018.

LIN, Y; YEN, Y. Determinants of mortality before start of and during tuberculosis treatment among elderly patients: a population-based retrospective cohort study. Age and ageing, v. 44, n. 3, p. 490-496, 2015. Disponível em:< https://academic.oup.com/ageing/article/44/3/490/49749>. Acesso em: 15 set. 2017.

LONNROTH, K.; RAVIGLIONE, M. The WHO's new End TB Strategy in the post2015 era of the Sustainable Development Goals. Transactions of the Royal Society Tropical Medicine and Hygiene, v. 110, p. 148-150, 2016. Disponível em: <http://www.ncbi.nlm.nih.gov/pmc/articles/PMC4755423/pdf/trv108.pdf>. Acesso em: 05 abr. 2016.

LOPES, L. M. G.; VIEIRA, N. F.; LANA, F.C. F. Análise dos atributos da atenção primária à saúde na atenção à tuberculose no Brasil: uma revisão integrativa. Revista 
de Enfermagem do Centro Oeste Mineiro, Divinópolis, v. 5, n. 2, p. 1684- 1703, $2015 . \quad$ Disponível em: <http://www.seer.ufsj.edu.br/index.php/recom/article/view/678/870>. Acesso em: 05 ago. 2016.

LUCENA, S. E. F.; MORAES, R. M. Detecção de agrupamentos espaço-temporais para identificação de áreas de risco de homicídios por arma branca em João Pessoa, PB. Boletim de Ciências Geodésicas, Curitiba, v. 18, n. 4, p. 605-623, 2012. Disponível em: <http://www.scielo.br/pdf/bcg/v18n4/a06v18n4.pdf>. Acesso em: 15 mai. 2017.

MACIEL, E. L.; REIS-SANTOS, B. Determinants of tuberculosis in Brazil: from conceptual framework to practical application. Revista Panamericana de Salud Pública, v. 38, n. 1, p. 28-34, 2015. Disponível em: https://www.scielosp.org/pdf/rpsp/2015.v38n1/28-34>. Acesso em: 07 dez. 2017.

MAGALHÃES, M.A.F.M.; MEDRONHO, R.A. Análise espacial da Tuberculose no Rio de Janeiro no período de 2005 a 2008 e fatores socioeconômicos associados utilizando microdados e modelos de regressão espaciais globais. Ciência \& Saúde Coletiva, Rio de Janeiro, v. 22, n.3, p.831-39, 2017. Disponível em: http://www.scielo.br/pdf/csc/v22n3/1413-8123-csc-22-03-0831.pdf >. Acesso em: 15 dez. 2017.

MARQUIEVIZ, J. et al. A Estratégia de Saúde da Família no controle da tuberculose em Curitiba (PR) .Ciência \& Saúde Coletiva, Rio de Janeiro, v. 18, n. 1,p. 265-271, 2013. Disponível em: <http://www.scielo.br/scielo.php?script=sci_arttext\&pid=S1413$81232013000100027 \& \operatorname{lng}=$ pt\&nrm=iso $>$. Acesso em: 10 abr. 2016.

MARSHALL, R.J. Mapping disease and mortality rates using empirical Bayes estimators. Applied Statistics, p. 283-294, 1991. Disponivel em: < http://www.jstor.org/stable/2347593 >. Acesso em: 18 nov. 2017.

MELNICK, E. L. Spatial Risk Assessment. Encyclopedia of quantitative risk analysis and assessment. p. 428-432, John Wiley \& Sons, 2008.

MENDES, E.V. et al. Território: Conceitos Chave. In: Distrito Sanitário: o processo social de mudança das práticas sanitárias do Sistema Único de Saúde. São Paulo, HUCITEC; Rio de Janeiro, ABRASCO, 1993,p.166-169.

MIGLIORIA, G. B.; SOTGIU, GIOVANNI . Assessing tuberculosis management: what really happens to patients? The Lancet Infectious Diseases, v. 15, n. 11, p. 1249 - 1251, 2015. Disponível em: <http://www.thelancet.com/pdfs/journals/laninf/PIIS14733099(15)00095-X.pdf>. Acesso em: 10 mar. 2016.

MOHER, D. et al. Preferred reporting items for systematic reviews and meta-analyses: the PRISMA statement. PLoS medicine, v. 6, n. 7, p. e1000097, 2009. Disponível em: https://www.ncbi.nlm.nih.gov/pmc/articles/PMC2707599/pdf/pmed.1000097.pdf>.

Acesso em: 10 out. 2017.

MONKEN, M. Desenvolvimento de tecnologia educacional a partir de uma abordagem geográfica para a aprendizagem da territorialização em vigilância da 
saúde. Rio de Janeiro, 170p. v. 164, 2003 (Dissertação). Escola Nacional de Saúde Pública. Disponível em: < https://thesis.icict.fiocruz.br/pdf/monkenmd.pdf >. Acesso em: 05 jan. 2018.

MONKEN, M. et al. O território na saúde: construindo referências para análises em saúde e ambiente. Território, ambiente e saúde. Rio de Janeiro, Fiocruz, p. 23-42, 2008. Disponível em: < http://www.scielo.br/pdf/csp/v25n6/27.pdf >. Acesso em: 10 dez. 2017.

MORAN, P.AP. A test for the serial independence of residuals. Biometrika, v. 37, n. 1/2, p. 178-181, 1950. Disponível em:< http://www.jstor.org/stable/2332162 >. Acesso em: 10 ag. 2017.

MORGENSTERN, H. Annu. Ecologic studies in epidemiology: Concepts, Principles, and Methods. Annual Reviews Public Health, v. 16, p.61-81, 1995. Disponível em: http://www.annualreviews.org/doi/pdf/10.1146/annurev.pu.16.050195.000425>. Acesso em 10 ago. 2017.

MUSENGE, E.; VOUNATSOU, P.; KAHN, K. Space-time confounding adjusted determinants of child HIV/TB mortality for large zero-inflated data in rural South Africa. Spatial and spatio-temporal epidemiology, v. 2, n. 4, p. 205-217, 2011. Disponível em:<https://www.ncbi.nlm.nih.gov/pmc/articles/PMC4250009/>. Acesso em: 02 dez. 2017.

NARDI, S.M.T. et al. Geoprocessamento em Saúde Pública: fundamentos e aplicações. Revista Instituto Adolfo Lutz, São Paulo, v. 72, n. 3, p. 185-91, 2013. Disponível em: file:///C:/Users/user/Downloads/22284-33176-1-PB.pdf>. Acesso em: 07 jan. 2018.

NUNES, C. Tuberculosis incidence in Portugal: spatiotemporal clustering. International Journal of Health Geographics, v. 6, n. 30, p. 1-10, 2007. Disponível em:<https://www.ncbi.nlm.nih.gov/pmc/articles/PMC1965471/pdf/1476-072X-630.pdf >. Acesso em: 20 ago. 2017.

OLFATIFAR, M.et al. Clustering of pulmonary tuberculosis in Hamadan province, western Iran: A population based cross sectional study (2005-2013). Journal of research in health sciences, v. 16, n. 3, p. 166-169, 2016. Disponível em: <http://jrhs.umsha.ac.ir/index.php/JRHS/article/view/2824/pdf>. Acesso em: jul. 2017.

OLIVEIRA, H.M..M.G. et al . Perfil epidemiológico de pacientes portadores de TB internados em um hospital de referência na cidade do Rio de Janeiro.Jornal Brasileiro de Pneumologia, São Paulo, v. 35, n. 8, p. 780-787, 2009. Disponível em: http://www.scielo.br/pdf/jbpneu/v35n8/v35n8a10.pdf>. Acesso em: 10 out. 2017.

OLIVEIRA, U., BRESCOVIT, A.D., SANTOS, A.J. Delimiting Areas of Endemism through Kernel Interpolation. PLoS ONE, v.10, n. 1, p. e0116673, 2015. Disponível em: http://journals.plos.org/plosone/article/file?id=10.1371/journal.pone.0116673\&type=pri ntable >. Acesso em: 12 set. 2017. 
ORGANIZAÇÃO MUNDIAL DE SAÚDE. Classificação Estatística Internacional de Doenças e Problemas Relacionados à Saúde - Índice Alfabético. São Paulo: EDUSP, v.3, 2008, 1046p.

PALHA, P. F. et al . Acesso aos serviços de atenção à tuberculose: análise da satisfação dos doentes. Revista da Escola de Enfermafem da USP, São Paulo, v. 46, n. 2, p. 342-348, 2012. Disponível em: <http://www.scielo.br/scielo.php?script=sci_arttext\&pid=S0080-62342012000200011>. Acesso em: 15 ago. 2016.

PEREIRA, A. G. L. et al . Spatial distribution and socioeconomic context of tuberculosis in Rio de Janeiro, Brazil. Revista de Saúde Pública, São Paulo, v. 49, n. 48, $2015 . \quad$ Disponível em: <http://www.scielo.br/scielo.php?script=sci_arttext\&pid=S0034-89102015000100234>. Aceso em: 18 ago 2016.

PESSOA, E. A. A Constituição Federal e os Direitos Sociais Básicos ao Cidadão Brasileiro. In: Âmbito Jurídico, Rio Grande, XIV, n. 89, 2011. Disponível em: $<$ http://www.ambitojuridico.com.br/site/index.php?n_link=revista_artigos_leitura\&artig o_id=9623>. Acesso em: 02 fev. 2018.

PETERSEN, K.; FELDT, R.; MUJTABA, S.; MATTSSON, M. Systematic Mapping Studies in Software Engineering. In:12th International Conference on Evaluation and Assessment in Software Engineering, 2008. Disponível em: < https://dl.acm.org/citation.cfm?id=2227123>. Acesso em 05 dez. 2017.

PILLER, R.V.B. Epidemiologia da Tuberculose. Pulmao RJ, Rio de Janeiro, v. 21, n. 1, p.4-9, 2012. Disponível em: <http://sopterj.com.br/profissionais/_revista/2012/n_01/02.pdf<. Acesso em: 02 mar. 2016 .

PINTO, M. L. et al. Occurrence of tuberculosis cases in Crato, Ceará, from 2002 to 2011: a spatial analisys of specific standards. Revista Brasileira de Epidemiologia, São Paulo, v. 18, n. 2, p. 313-325, jun. 2015. Disponível em: <http://www.scielo.br/pdf/rbepid/v18n2/pt_1415-790X-rbepid-18-02-00313.pdf>.

Acesso em: 12 out. 2017.

PLUG, I. et al. Socieconomic inequalities in mortality from conditions amenable to medical interventions: do they reflect inequalities in access or quality of health care? BMC Public Health, Londres, v. 12, n. 346, p. 1-13, 2012. Disponível em: $<$ https://bmcpublichealth.biomedcentral.com/track/pdf/10.1186/1471245812346? site=b mcpublichealth.biomedcentral.com >. Acesso em 10 mar. 2016.

PRATES, M.O.; KULLDORFF, M.; ASSUNÇÃO, R.M. Relative risk estimates from spatial and space-time scan statistics: are they biased?. Statistics in medicine, v. 33, n. 15, p. 2634-2644, 2014. Disponível em: < https://www.ncbi.nlm.nih.gov/pmc/articles/PMC4047196/pdf/nihms572329.pdf>. Acesso em: 03 abr. 2017. 
PREFEITURA MUNICIPAL DE LONDRINA. Plano Municipal de saúde 2014-2017. Disponível em: <http://www1.londrina.pr.gov.br/dados/images/stories/Storage/sec_saude/Plano\%20Mu nicial/plano_municipal_de_saude_2014_2017.pdf>. Acesso em: 19 ago. 2016.

PROENCA JUNIOR, D.; SILVA, É. R. Contexto e processo do Mapeamento Sistemático da Literatura no trajeto da Pós-Graduação no Brasil. Transinformação, Campinas, $\quad$ v. 28, n. 2, p. 233-240, 2016. Disponível em: <http://www.scielo.br/pdf/tinf/v28n2/0103-3786-tinf-28-02-00233.pdf>. Acesso em 11 fev. 2018.

PROGRAMA DAS NAÇÕES UNIDAS PARA O DESENVOLVIMENTO (PNUD): Atlas do Desenvolvimento Humano no Brasil. PNUD, 2013. Disponível em: < http://www.atlasbrasil.org.br/2013/data/rawData/idhm-do-brasil.pdf >. Acesso em: 20 ago. 2016.

RAIMUNDO, A.G. et al. Tuberculosis: the profile in the new millennium. Journal of Nursing UFPE, Recife, v. 10, n. 3, p. 1387-1396, 2015. Disponível em: < https://periodicos.ufpe.br/revistas/revistaenfermagem/article/view/11079/12518 >. Acesso em: 10 set. 2017.

RAO, H. et al. Spatial transmission and meteorological determinants of tuberculosis incidence in Qinghai Province, China: a spatial clustering panel analysis. Infectious Diseases of Poverty, v. 5, n. 1, p. 45, 2 dez. 2016. Disponível em: < https://www.ncbi.nlm.nih.gov/pmc/articles/PMC4890510/pdf/40249_2016_Article_139 .pdf >. Acesso em: 12 ago. 2017.

RIBEIRO, C.D. Justiça social e equidade em saúde: uma abordagem centrada nos funcionamentos. Saude \& Sociedade, São Paulo , v. 24, n. 4, p. 1109-1118, 2015

Disponível em:<http://www.scielo.br/pdf/sausoc/v24n4/1984-0470-sausoc-24-0401109.pdf >. Acesso em 09 fev. 2018.

ROCHA, M. S. Do que morrem os pacientes com tuberculose: causas múltiplas de morte de uma coorte de casos notificados e uma proposta de investigação de causas presumíveis. Cadernos de Saúde Pública, Rio de Janeiro, v. 3, n. 14, p. 709 - 721, 2015. Disponível em: <http://www.scielosp.org/pdf/csp/v31n4/0102-311X-csp-31-0400709.pdf>. Acesso em: 24 ago. 2017.

RUFFINO-NETTO, A. Tuberculose: a calamidade negligenciada. Revista da Sociedade Brasileira de Medicina Tropical, Uberaba v.35, n.1, p.51-58, 2002. Disponível em: <http://www.scielo.br/pdf/rsbmt/v35n1/7636.pdf> Acesso em: 10 fev. 2017.

SAIFODINE, A. et al. Patient and health system delay among patients with pulmonary tuberculosis in Beira city, Mozambique. BMC public health, v. 13, n. 1, p. 559, 2013. Disponível em< https://bmcpublichealth.biomedcentral.com/track/pdf/10.1186/14712458-13-559? site=bmcpublichealth.biomedcentral.com>. Acesso em: 07 out. 2017.

SALES, C. M. M. et al . Análise espacial da tuberculose infantil no estado do Espírito Santo, 2000 a 2007. Revista da Sociedade Brasileira de Medicina Tropical, Uberaba. v. $43, \mathrm{n} . \quad 4, \mathrm{p}$ 435-439, 2010. Disponível em: 
<http://www.scielo.br/scielo.php?script=sci_arttext\&pid=S0037-86822010000400020> Acesso em: 22 ago. 2017.

SALINAS, J. et al. Delays in the diagnosis of pulmonary tuberculosis in Coahuila, Mexico. The International Journal of Tuberculosis and Lung Disease, v. 16, n. 9, p. 1193-1198, 2012. Disponível em: < http://docserver.ingentaconnect.com/deliver/connect/iuatld/10273719/v16n9/s12.pdf?ex pires $=1518518930 \& i d=0000 \&$ titleid $=3764 \&$ checksum $=$ FD06E589B3632869DFE610 1 0D9DA3C4B>. Acesso em: 10 out. 2017.

SAN PEDRO, A.; OLIVEIRA, R. M. Tuberculose e indicadores socioeconômicos: revisão sistemática da literatura. 294 Rev Panam Salud Publica, v. 33, n. 4, p. 294301, 2013. Disponível em: <https://www.scielosp.org/pdf/rpsp/2013.v33n4/294-301>. Acesso em: 05 set. 2017.

SÁNCHEZ-BARRIGA, J.J. Mortality trends and risk of dying from pulmonary tuberculosis in the 7 socioeconomic regions and the 32 States of Mexico, 2000-2009. Archivos de Bronconeumología (English Edition), v. 51, n. 1, p. 16-23, 2015. Disponível em: < file:///C:/Users/user/Downloads/S0300289614001823_S300_es.pdf>. Acesso em 10 set. 2017.

SANTOS, M. Metamorfoses do Espaço Habitado. São Paulo: Hucitec, v. 4, p. 136, 1988.

SANTOS, A.L.; RIGOTTO, R.M. Território e territorialização: incorporando as relações produção, trabalho, ambiente e saúde na atenção básica à saúde. Revista Trabalho, Educação e Saúde, Rio de Janeiro , v. 8, n. 3, p. 387-406, Nov. 2010 Disponível em: <http://www.scielo.br/pdf/tes/v8n3/03.pdf >. Acesso em: 08 jan. 2018.

SANTOS, C.B. et al. Utilização de um Sistema de Informação Geográfica para descrição dos casos de tuberculose. Boletim de Pneumologia Sanitária, Rio de Janeiro, v.12, n.1, p.07-12, 2004. Disponível em: < http://scielo.iec.gov.br/pdf/bps/v12n1/v12n1a02.pdf>. Acesso em 20 ago. 2017.

SANTOS NETO, M. et al. Pulmonary tuberculosis in São Luis, State of Maranhão, Brazil: space and space-time risk clusters for death (2008-2012). Revista da Sociedade Brasileira de Medicina Tropical, Uberaba, v. 48, n.1, p. 69-76, 2015. Disponível em: <http://www.scielo.br/pdf/rsbmt/v48n1/0037-8682-rsbmt-48-01-00069.pdf>. Acesso em 15 ago. 2017.

SANTOS-NETO, M. et al. Análise espacial dos óbitos por tuberculose pulmonar em São Luís, Maranhão. Jornal Brasileiro de Pneumologia, São Paulo, v. 40, n. 5, p. 543551, 2014. Disponível em:<http://www.scielo.br/pdf/jbpneu/v40n5/pt_1806-3713jbpneu-40-05-00543.pdf>. Acesso em: 30 mar. 2016.

SARTORIUS, B et al. Dying in their prime: determinants and space-time risk of adult mortality in rural South Africa. Geospatial health, v. 7, n. 2, p. 237, 2013. Disponível em: < https://www.ncbi.nlm.nih.gov/pmc/articles/PMC3725424/pdf/emss-53912.pdf>. Acesso em: 05 dez. 2017. 
SELIG, L. et al. Proposta de vigilância de óbitos por tuberculose em sistemas de informação. Revista de Saúde Pública, São Paulo, v.44, n.6, p.1072-1078, 2010. Disponível em: <http://www.scielo.br/pdf/rsp/v44n6/1837.pdf>. Acesso em 20 jan. 2017.

SILVEIRA, I.H.; OLIVEIRA, B.F.A.; JUNGER, W.L. Utilização do Google Maps para o georreferenciamento de dados do Sistema de Informações sobre Mortalidade no município do Rio de Janeiro, 2010-2012. Epidemiologia e Serviços de Saúde, v. 26, p. 881-886, 2017. Disponível em: <http://www.scielo.br/pdf/ress/v26n4/2237-9622-ress26-04-00881.pdf>. Acesso em: 05 dez. 2017.

SLUYDTS, V. et al. Spatial clustering and risk factors of malaria infections in Ratanakiri Province, Cambodia. Malaria journal, v. 13, n. 1, p. 387, 2014. Disponível em: $\quad<$ https://malariajournal.biomedcentral.com/track/pdf/10.1186/1475-2875-13387? site=malariajournal.biomedcentral.com > . Acesso em: 16 set. 2017.

SOARES, P. A.; NASCIMENTO, L. F. C. Análise espacial das internações por doenças do coração no Vale do Paraíba. Arquivos Brasileiros de Cardiologia, São Paulo, v. 94, n.6, p. 747-753, 2010. Disponível em: < http://www.scielo.br/pdf/abc/v94n6/aop03810.pdf>. Acesso em: 20 dez. 2017.

STEVENS, K.B.; PFEIFFER, D.U. Spatial modelling of disease using data-and knowledge-driven approaches. Spatial and spatio-temporal epidemiology, v. 2, n. 3, p. 125-133, 2011. Disponível em: https://ac.els-cdn.com/S187758451100030X/1-s2.0S187758451100030X-main.pdf?_tid=a8ffb36a-10a3-11e8-bbbb-

00000aab0f02\&acdnat $=1518515754 \_10 f f 647 \mathrm{bbd6fd4a1b704c0884b16bc4c>}$. Acesso em: 05 out. 2017.

Stop TB Partnership and World Health Organization. Global Plan to Stop TB 20062015. Geneva, World Health Organization, 2006. Disponível em: < http://www.stoptb.org/assets/documents/global/plan/GlobalPlanFinal.pdf> Acesso em: 10 set. 2017.

STOPKA, T.J. et al. Identifying and characterizing hepatitis C virus hotspots in Massachusetts: a spatial epidemiological approach. BMC infectious diseases, v. 17, $\mathrm{n}$. 1, p. 294, 2017. Disponível em: < https://www.ncbi.nlm.nih.gov/pmc/articles/PMC5399408/pdf/12879_2017_Article_240 0.pdf >. Acesso em 25 ago. 2017.

TEIXEIRA, C.F.; PAIM, J.S.; VILASBÔAS, A.L.. SUS, modelos assistenciais e vigilância da saúde. Fundamentos da vigilância sanitária, . Rio de Janeiro: Fiocruz., p. 49-60, 2000. Disponível em:< http://scielo.iec.gov.br/pdf/iesus/v7n2/v7n2a02.pdf>. Acesso em: 20 dez. 2017.

THE WORLD BANK. World bank estimate. Disponível em:<https://data.worldbank.org/indicator/SI.POV.GINI>. Acesso em: 04 fev. 2018.

THERON, G. et al. Data for action: collection and use of local data to end tuberculosis. The Lancet, v. 386, n. 10010, p. 2324-2333, 2015. Disponível em: 
http://www.thelancet.com/pdfs/journals/lancet/PIIS0140-6736(15)00321-9.pdf>.

Acesso em: 10 out. 2017.

WAGNER, M.B; CALLEGARI-JACQUES, S.M. Medidas de associação em estudos epidemiológicos: risco relativo e odds ratio. Jornal de pediatria, Rio de Janeiro. v. 74, no. 3 (1998), p. 247-251., 1998. Disponível em: < http://www.lume.ufrgs.br/bitstream/handle/10183/54354/000246332.pdf?sequence=1>. Acesso em: 11 set. 2-17.

WALLER, L. A.; GOTWAY, C.A. Spatial Clusters of Health Events: Point Data for Cases and Controls. Applied spatial statistics for public health data, p. 155- 199, John Wiley \& Sons, 2004.

WORLD HEALTH ORGANIZATION (WHO).Global tuberculosis report 2016. Geneva; 2016. Disponível em: < http://www.who.int/tb/publications/global_report/gtbr2016_executive_summary.pdf >. Acesso em: 20 dez. 2017.

WORLD HEALTH ORGANIZATION (WHO).Global tuberculosis report 2017. Geneva; $2017 . \quad$ Disponível em: <http://apps.who.int/iris/bitstream/10665/259366/1/9789241565516eng.pdf?ua=1>.Ace sso em: 05 jan. 2018

XIAO-ZHOU, L. et al. A spatial scan statistic for nonisotropic two-level risk cluster. Statistics in medicine, v. 31, n. 2, p. 177-187, 2012. Disponível em: <http://onlinelibrary.wiley.com/doi/10.1002/sim.4341/pdf〉. Acesso em: 02 mar. 2017.

YAKAM, A.N. Spatial analysis of tuberculosis in Douala, Cameroon: clustering and links with socio-economic status. International Journal of Tuberculosis and Lung Disease, v. 18, n. 3, p.292-297, 2014. Disponível em: < http://docserver.ingentaconnect.com/deliver/connect/iuatld/10273719/v18n3/s9.pdf?exp ires $=1518517721 \& \mathrm{id}=0000 \&$ titleid $=3764 \&$ checksum $=853$ EE6260EBA9A374F507234 82B8B405>. Acesso em: 05 jan. 2018.

YAMAMURA, M. et al. Areas with evidence of equity and their progress on mortality from tuberculosis in an endemic municipality of southeast Brazil. Infectious diseases of poverty, v. 6 , n. 1, p. 134, 2017. Disponível em: <https://www.ncbi.nlm.nih.gov/pmc/articles/PMC5637336/pdf/40249_2017_Article_34 8.pdf>. Acesso em: $10 \mathrm{dez} .2017$.

YAMAMURA, M. et al. Características epidemiológicas dos casos de óbito por tuberculose e territórios vulneráveis. Revista Latino-Americana de Enfermagem, v. 23, n. 5, 2015. Disponível em: < http://www.scielo.br/pdf/rlae/v23n5/pt_0104-1169rlae-23-05-00910.pdf>. Acesso em: 15 out. 2017.

YEN, Y. et al. Determinants of mortality in elderly patients with tuberculosis: a population-based follow-up study. Epidemiology \& Infection, v. 145, n. 7, p. 13741381, 2017. Disponível em <https://www.cambridge.org/core/services/aop-cambridgecore/content/view/FD94D7A6CB7156AB17B213BE21FADC53/S0950268817000152a .pdf/determinants_of_mortality_in_elderly_patients_with_tuberculosis_a_populationbas ed_followup_study.pdf >. Acesso em: 20 set. 2017. 
ZHAO, F et al. Space-Time Clustering Characteristics of Tuberculosis in China, 20052011. PLoS ONE, v. 8, n. 12, p. e83605, 2013. Disponível em: <https://www.ncbi.nlm.nih.gov/pmc/articles/PMC3868653/pdf/pone.0083605.pdf>. Acesso em: 20 ago. 2017.

ZHENG, Q et al. Epidemiological analysis of pulmonary tuberculosis in Heilongjiang province China from 2008 to 2015. The International Journal of Mycobacteriology, v. 6, n. 3, p. 264-267, 2017. Disponível em: <http://www.ijmyco.org/temp/IntJMycobacteriol63264-2802106_074701.pdf>. Acesso em: 09 set. 2017. 
Apêndice A- Strings de busca nas bases de dados

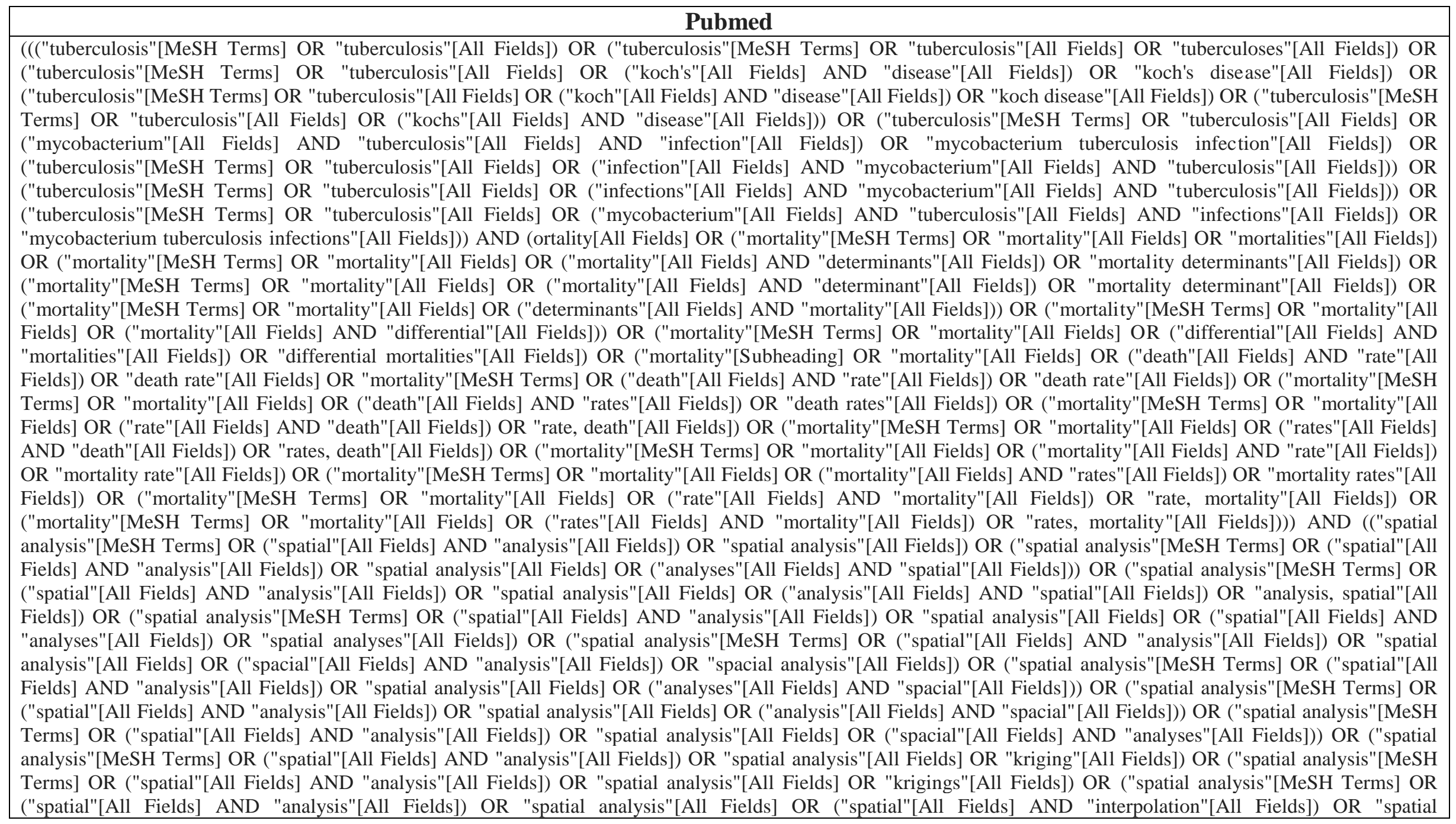


interpolation"[All Fields]) OR ("spatial analysis"[MeSH Terms] OR ("spatial"[All Fields] AND "analysis"[All Fields]) OR "spatial analysis"[All Fields] OR ("interpolation"[All Fields] AND "spatial"[All Fields])) OR ("spatial analysis"[MeSH Terms] OR ("spatial"[All Fields] AND "analysis"[All Fields]) OR "spatial analysis"[All Fields] OR ("interpolations"[All Fields] AND "spatial"[All Fields])) OR ("spatial analysis"[MeSH Terms] OR ("spatial"[All Fields] AND "analysis"[All Fields]) OR "spatial analysis"[All Fields] OR ("spatial"[All Fields] AND "interpolations"[All Fields]) OR "spatial interpolations"[All Fields]) OR ("spatial analysis"[MeSH Terms] OR ("spatial"[All Fields] AND "analysis"[All Fields]) OR "spatial analysis"[All Fields] OR ("spatial"[All Fields] AND "autocorrelation"[All Fields]) OR "spatial autocorrelation"[All Fields]) OR ("spatial analysis"[MeSH Terms] OR ("spatial"[All Fields] AND "analysis"[All Fields]) OR "spatial analysis"[All Fields] OR ("autocorrelation"[All Fields] AND "spatial"[All Fields])) OR ("spatial analysis"[MeSH Terms] OR ("spatial"[All Fields] AND "analysis"[All Fields]) OR "spatial analysis"[All Fields] OR ("autocorrelations"[All Fields] AND "spatial"[All Fields])) OR ("spatial analysis"[MeSH Terms] OR ("spatial"[All Fields] AND "analysis"[All Fields]) OR "spatial analysis"[All Fields] OR ("spatial"[All Fields] AND "autocorrelations"[All Fields]) OR "spatial autocorrelations"[All Fields]) OR ("spatial analysis"[MeSH Terms] OR ("spatial"[All Fields] AND "analysis"[All Fields]) OR "spatial analysis"[All Fields] OR ("spatial"[All Fields] AND "dependency"[All Fields]) OR "spatial dependency"[All Fields]) OR ("spatial analysis"[MeSH Terms] OR ("spatial"[All Fields] AND "analysis"[All Fields]) OR "spatial analysis"[All Fields] OR ("dependencies"[All Fields] AND "spatial"[All Fields])) OR ("spatial analysis"[MeSH Terms] OR ("spatial"[All Fields] AND "analysis"[All Fields]) OR "spatial analysis"[All Fields] OR ("dependency"[All Fields] AND "spatial"[All Fields])) OR ("spatial analysis"[MeSH Terms] OR ("spatial"[All Fields] AND "analysis"[All Fields]) OR "spatial analysis"[All Fields] OR ("spatial"[All Fields] AND "dependencies"[All Fields]) OR "spatial dependencies"[All Fields]) OR ("spatial analysis"[MeSH Terms] OR ("spatial"[All Fields] AND "analysis"[All Fields]) OR "spatial analysis"[All Fields] OR ("kernel"[All Fields] AND "density"[All Fields] AND "estimation"[All Fields]) OR "kernel density estimation"[All Fields]) OR ("spatial analysis"[MeSH Terms] OR ("spatial"[All Fields] AND "analysis"[All Fields]) OR "spatial analysis"[All Fields] OR ("density"[All Fields] AND "estimation"[All Fields] AND "kernel"[All Fields]) OR "density estimation, kernel"[All Fields]) OR ("spatial analysis"[MeSH Terms] OR ("spatial"[All Fields] AND "analysis"[All Fields]) OR "spatial analysis"[All Fields] OR ("density"[All Fields] AND "estimations"[All Fields] AND "kernel"[All Fields])) OR ("spatial analysis"[MeSH Terms] OR ("spatial"[All Fields] AND "analysis"[All Fields]) OR "spatial analysis"[All Fields] OR ("estimation"[All Fields] AND "kernel"[All Fields] AND "density"[All Fields])) OR ("spatial analysis"[MeSH Terms] OR ("spatial"[All Fields] AND "analysis"[All Fields]) OR "spatial analysis"[All Fields] OR ("estimations"[All Fields] AND "kernel"[All Fields] AND "density"[All Fields])) OR ("spatial analysis"[MeSH Terms] OR ("spatial"[All Fields] AND "analysis"[All Fields]) OR "spatial analysis"[All Fields] OR ("kernel"[All Fields] AND "density"[All Fields] AND "estimations"[All Fields]) OR "kernel density estimations"[All Fields]))

\section{Scopus}

TITLE-ABS-KEY ( tuberculosis OR tuberculoses OR "Koch's Disease" OR "Koch Disease" OR "koch disease" OR "Mycobacterium tuberculosis Infection" OR "Infection, Mycobacterium tuberculosis" OR "Infections, Mycobacterium tuberculosis" OR "Mycobacterium tuberculosis Infections" ) AND TITLE-ABS-KEY ( mortality OR mortalities OR "Case Fatality Rate" OR "Case Fatality Rates" OR "Rate, Case Fatality" OR "Rates, Case Fatality" OR "Mortality, Excess" OR "Excess Mortalities" OR "Mortalities, Excess" OR "Excess Mortality" OR "Decline, Mortality" OR "Declines, Mortality" OR "Mortality Declines" OR "Mortality Decline" OR "Mortality Determinants" OR "Determinant, Mortality" OR "Mortality Determinant" OR "Determinants, Mortality" OR "Mortality, Differential" OR "Differential Mortalities" OR "Mortalities, Differential" OR "Differential Mortality" OR "aspecific death rate" OR "aspecific death rates" OR "death rate, aspecific" OR "death rates, aspecific" OR "rate, aspecific death" OR "rates, aspecific death" OR "Age Specific Death Rate" OR "Death Rate" OR "Death Rates" OR "Rate, Death" OR "Rates, Death" OR "Mortality Rate" OR "Mortality Rates" OR "Rate, Mortality" OR "Rates, Mortality" OR death OR "determination off death" ) AND TITLE-ABS-KEY ( "Spatial analysis" OR "Analyses, Spatial" OR "Analysis, Spatial" OR "Spatial Analyses" OR "Spacial Analysis" OR "Analyses, Spacial" OR "Analysis, Spacial" OR "Spacial Analyses" OR bridging OR origins OR "Spatial Interpolation" OR "Interpolation, Spatial" OR "Interpolations, Spatial" OR "Spatial Interpolations" OR "spatial correlation" OR "correlation, spatial" OR "correlations, spatial" OR "spatial correlations" OR "Spatial Dependency" OR "Dependencies, Spatial" OR "Dependency, Spatial" OR "Spatial Dependencies" OR "Kernel Density Estimation" OR "Density Estimation, Kernel" OR "Density 


\begin{tabular}{|c|}
\hline Estimations, Kernel" OR "Estimation, Kernel Density" OR "Estimations, Kernel \\
\hline BVS \\
\hline 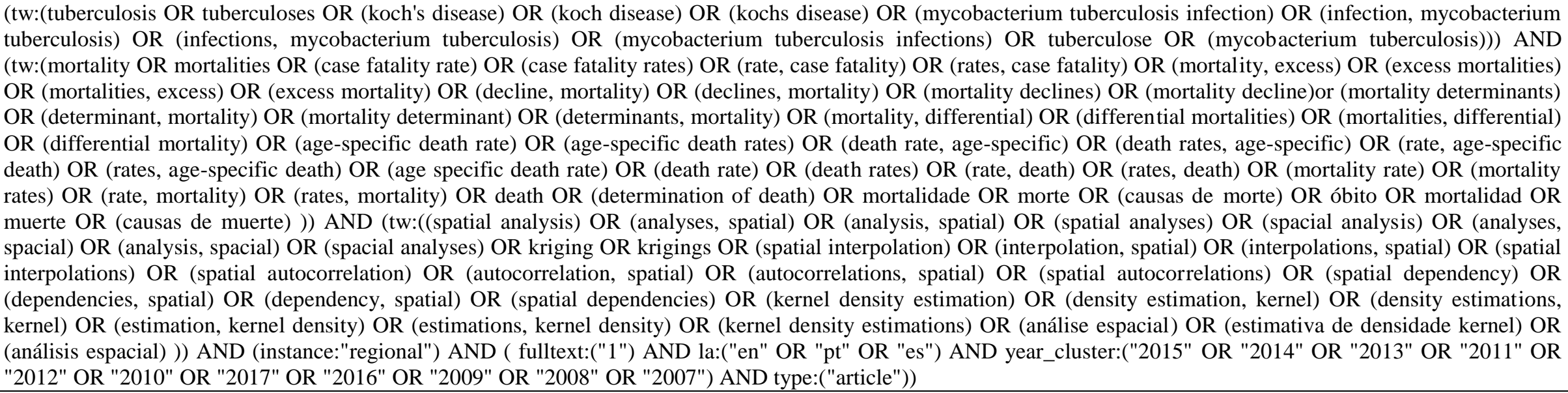 \\
\hline EMBASE \\
\hline $\begin{array}{l}\text { (tuberculosis OR tuberculoses OR (mycobacterium AND tuberculosis AND infection)) AND (n } \\
\text { autocorrelation) OR (autocorrelation, AND spatial) OR (spatial AND dependency) OR (kernel AND }\end{array}$ \\
\hline CINAHL: \\
\hline 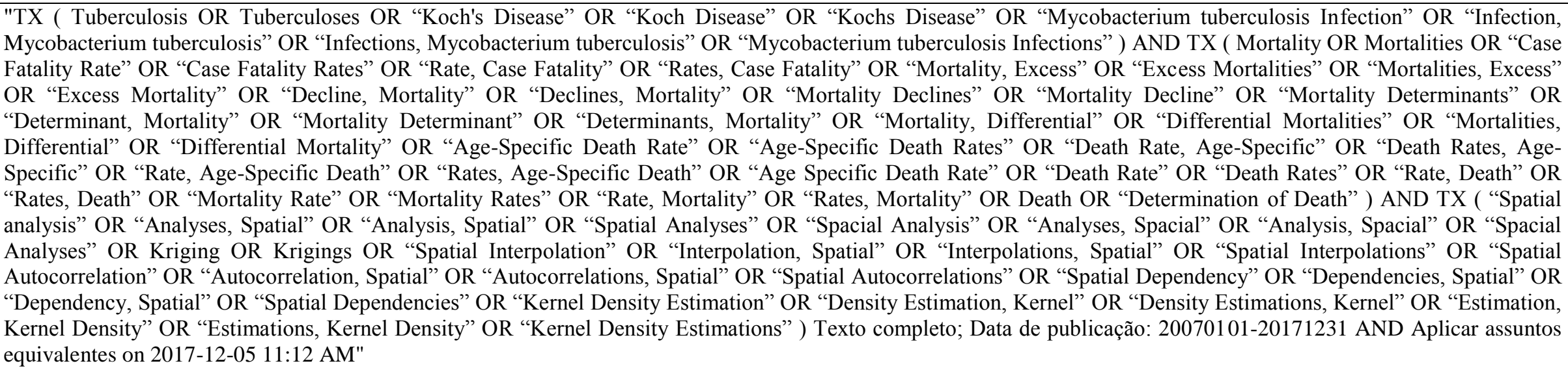 \\
\hline
\end{tabular}


Anexo A- Declaração de óbito

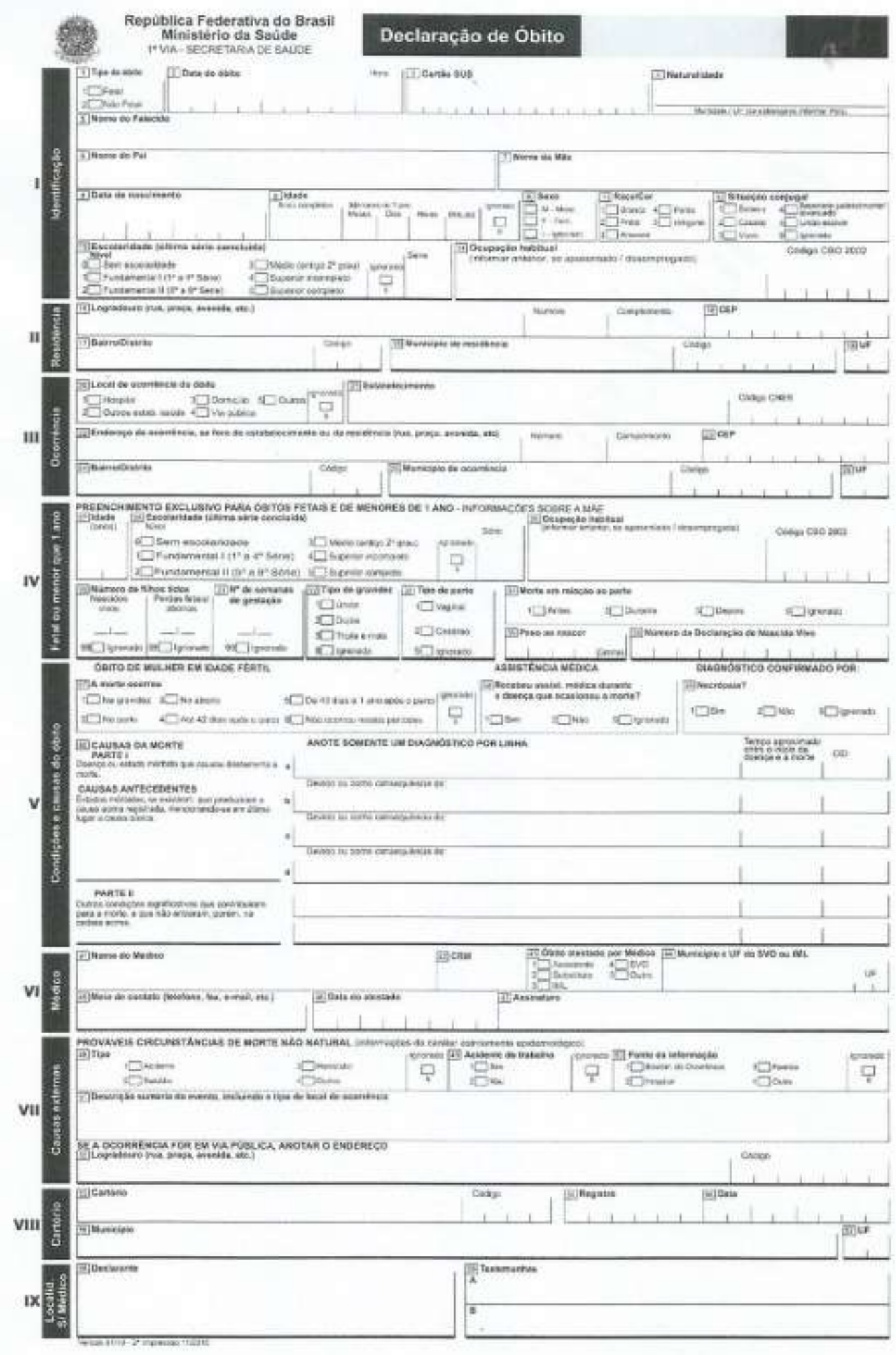


Anexo B- Aprovação do Comitê de Ética em Pesquisa

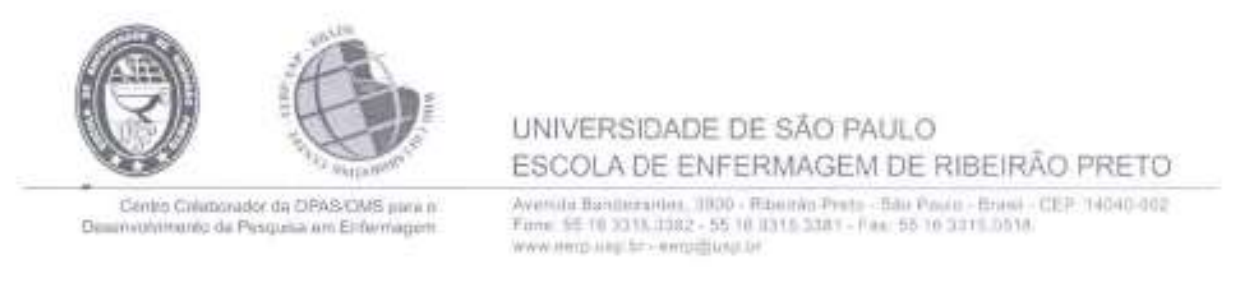

Oficio CEP-EERP/USP $n^{\circ}$ 109/2016, de 11.04.2016

Prezado Senhor,

Comunicamos que o projeto de pesquisa, abaixo especificado, foi analisado e considerado aprovado pelo Comitề de Ética em Pesquisa com Seres Humanos da Escola de Enfermagem de Ribeirăo Preto da Universidade de Săo Paulo (CEP-EERP/USP), em sua $24^{a}$ Reuniâo Extraordinária, realizada em 06 de abril de 2016

Protocolo CAAE: 54479816.0 .0000 .5393

Projeto: Análise espacial e espaço-temporal dos óbitos por tuberculose nos municipios prioritários do Paraná, Brasil (2008 a 2014)

Pesquisadores: Luana Seles Alves

Ricardo Alexandre Arcéncio (orientador)

Em atendimento à Resoluçăo 466/12, deverá ser encaminhado ao CEP o relatório final da pesquisa e a publicaçấo de seus resultados, para acompanhamento, bem como comunicada qualquer intercorrẻncia ou a sua interrupçáo.

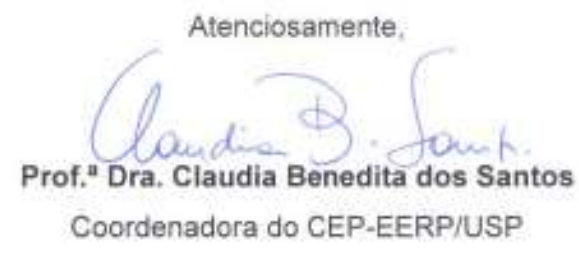

IImo. Si

Prof. Dr. Ricardo Alexandre Arcêncio

Departamento de Enfermagem Materno-Infantil e Saúde Pública

Escola de Enfermagem de Ribeirăo Preto - USP 
Anexo C- Aprovação do Comitê de Ética em Pesquisa-

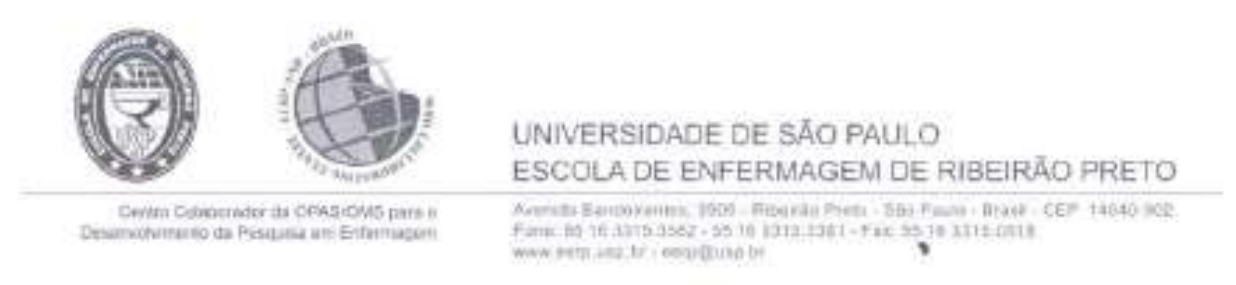

Oficio CEP-EERPIUSP no 186/2016, de 09.06.2016

Prezado Senhor,

Comunicamos que o projeto de pesquisa abaixo especificado foi analisado e considerado aprovado pelo Comitê de Ética em Pesquisa da Escola de Enfermagem de Ribeirăo Preto da Universidade de São Paulo (CEP-EERPJUSP) em súa $27^{*}$ Reunião Extraordinária, realizada em 08 de junho de 2016.

Protocolo CAAE: 56305516.0 .0000 .5393

Projeto: A MORTALIDADE POR TUBERCULOSE E SUA RELAÇĀO COM AS INIQUIDADES SOCIAIS: UM ESTUDO MULTICENTRICO

Pesquisadores: Ricardo Alexandre Arcêncio

Em atendimento à Resoluçāo 466/12, deverá ser encaminhado ao CEP o relatório final da pesquisa e a publiççâo de seus resultados, para acompanhamento, bem como comunicada qualquer intercorrência ou a sua interrupçāo.

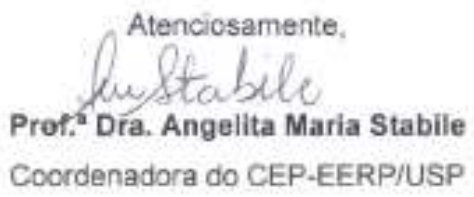

Ilmo. St.

Prof, Dr, Ricardo Alexandre Arcéncio

Departamento de Enfermagem Materno-Iniantil e Saúde Pública Escola de Enfermagem de Ribeirăo Preto-USP 